\title{
New Concepts about DOL-DFL Nexus: The Relationships with Market Sensitivities, Firm-Specific Risk and Other Issues
}

\author{
Marco A. Paganini ${ }^{1}$ \\ ${ }^{1}$ Managing Director, TRU Consulting, Milan, Italy \\ Correspondence: Marco A. Paganini, TRU Consulting, Via Ippolito Rosellini, 8, 20124, Milan, Italy. Tel: \\ 39-02-36518-169.
}

Received: October 21, 2021

Accepted: November 17, 2021

Online Published: November 28, 2021

doi:10.5539/ijef.v14n1p16

URL: https://doi.org/10.5539/ijef.v14n1p16

\begin{abstract}
This paper investigates several issues related to the Degree of Operating Leverage (DOL) and the Degree of Financial Leverage (DFL) in the light of advanced concepts on the matter proposed by recent studies. In particular, the paper treats mainly the relationships between DOL and market sensitivities and the impact of the uncertainty on DOL and DFL volatility together with minor issues.

We used the DOL function already developed to analyse what market conditions facilitate or hinder, with or without economies of scale, Revenue development or a profit-maximising policy. DOL records the reaction coming from the factor and product markets together with the management decision process. DOL highlights whether the current economic strategy is, or not, successful and why, so that management can perceive clues to evaluate both the policy and its implementation.

The uncertainty related to six fundamental economic variables determining EBIT and Net Profit growth volatility eventually contaminates DOL and DFL. Not all such variables impact DOL and DFL volatility, but when it happens, the firm's risk is representable through the asymptotes of the DOL and DFL curves generated by each specific variable. Such a risk rate is independent of the chosen uncertainty range and is firm unique in any financial period. In normal economic conditions, DOL undervalues firm-specific risk while DFL carries out a containment function. The higher risk rate comes from the unit price change, that coupled with a sturdy quantity/mix growth, could induce negative economic and financial results.
\end{abstract}

Keywords: Debt Ratio, DFL, DOL, firm-specific risk, sensitivity, uncertainty, volatility

\section{Introduction}

The economic literature has been dealing with the Degree of Operating Leverage (from now on DOL) and the Degree of Financial Leverage (from now on DFL) for a long time with only didactical purposes, without reaching an analytical and operational level suitable to explain firm results and plan future actions. In recent articles by Sarkar (2020), Chen et al. (2019), Dudycz (2020) and Paganini (2021), to name a few, leaps forward have been made both to create more precise analytical DOL and DFL functions fitting the economic reality and able to use them profitably in planning and managerial control internally to the firm.

Nonetheless, several issues related to DOL and DFL remain unresolved. The most essential is the risk level associated with the DOL-DFL nexus and the possibility of using the DOL function in the sensitivity analysis replacing the concept of elasticity. In addition, there are several minor issues related to DOL or DFL, which are either new or deserving further studies. Firstly, we find the DOL oversimplifications that prevented its operational development, confining it to the margin of didactics. Secondly, the similarity that unites operating leverage with mechanical lever, generating an inversion of the role played by margins improperly replaced by costs; thirdly, the concept of Potential DOL is noticeable as a time series that unites the Income Statements in an uninterrupted string of ex-ante relationships. Finally, we would like to clarify whether investment and financial decisions impact both DOL and DFL or only one of them.

Many of these topics are not new; some are even pivotal, such as the impact that the DOL-DFL nexus induces on a firm's risk. The economic literature is rich about systematic risk, not null concerning the relationship between such a kind of risk and the DOL-DFL nexus, but it dries up when such a nexus relates to the firm's risk owing to diversification options. Of course, the issue of systematic risk is topical in portfolio investment; unfortunately, it 
remains a distant concept for management and ownership and less relevant than the impact that economic dynamics exert on the firm's risk and Net Profit volatility, risks that predominate in a non-diversifiable portfolio.

The paper has four main paragraphs: paragraph 2 deals with some minor issues; paragraph 3 investigates the possibility of using DOL in the sensitivity analysis of the factor and product markets to replace the concept of supply and demand elasticity; paragraph 4 deals with the implications of the DOL-DFL nexus on firm's risk, providing a new and original perspective. In paragraph 5, the conclusions follow while Appendix A shows the financial statements, the variables and the parameters used for processing Figures 3 to 8 and Table 2 .

Before reading the present paper, we suggest reading in advance Paganini (2021), paragraphs 4 and 5 particularly.

\section{DOL and DFL Minor Topics}

\subsection{Oversimplifications}

Most of the didactic literature on the Operating Leverage and DOL contains a series of simplifications to make the topic completely unrealistic.

The essential simplification lies in the choice of the variables used to model the DOL function:

1) It disregards the product mix;

2) The quantity sold changes between two periods, evidently with the same product mix;

3) The unit contribution margin remains curiously constant.

Based on such hypotheses, starting from the definition of DOL, we can reach the following result:

$$
\begin{aligned}
& \mathrm{DOL}_{\mathrm{t}}=\frac{\Delta \% \mathrm{EBIT}_{\mathrm{t}}}{\Delta \% \mathrm{~S}_{\mathrm{t}}}=\frac{1}{\frac{\mathrm{EBIT}_{\mathrm{t}-1}}{\mathrm{~S}_{\mathrm{t}-1}}} * \frac{\Delta \mathrm{S}_{\mathrm{t}}-\Delta \mathrm{VC}_{\mathrm{t}}-\Delta \mathrm{FC}_{\mathrm{t}}}{\Delta \mathrm{S}_{\mathrm{t}}}=\frac{1}{\frac{\mathrm{EBIT}_{\mathrm{t}-1}}{\mathrm{~S}_{\mathrm{t}-1}}} * \frac{\Delta \mathrm{Q}_{\mathrm{t}} *(\mathrm{up}-\mathrm{uvc})-\Delta \mathrm{FC}_{\mathrm{t}}}{\Delta \mathrm{Q}_{\mathrm{t}^{*}} \mathrm{up}} \\
& =\frac{\mathrm{S}_{\mathrm{t}-1}}{\mathrm{EBIT}_{\mathrm{t}-1}} *\left[\left(\frac{\mathrm{up}-\mathrm{uvc}}{\mathrm{up}}\right)-\frac{\Delta \mathrm{FC}_{\mathrm{t}}}{\Delta \mathrm{S}_{\mathrm{t}}}\right]=\frac{\mathrm{S}_{\mathrm{t}-1}}{\mathrm{EBIT}_{\mathrm{t}-1}} *\left(\frac{\mathrm{CM}_{\mathrm{t}-1}}{\mathrm{~S}_{\mathrm{t}-1}}-\frac{\Delta \mathrm{FC}_{\mathrm{t}}}{\Delta \mathrm{S}_{\mathrm{t}}}\right)
\end{aligned}
$$

where:

$\Delta \% \mathrm{~S}_{\mathrm{t}}=$ Revenue percentage growth for the period $t$ compared to the previous period;

$\Delta \% \mathrm{EBIT}_{\mathrm{t}}=\mathrm{EBIT}$ percentage growth for the period $t$ compared to the previous period;

$\mathrm{S}_{\mathrm{t}-1}=$ Revenue for the period $t-1$

$\mathrm{CM}_{\mathrm{t}-1}=$ Contribution Margin for the period $t-1$

$\mathrm{EBIT}_{\mathrm{t}-1}=$ EBIT for the period $t-1$

$\Delta \mathrm{S}_{\mathrm{t}}=$ Revenue growth for the period $t$ compared to the previous period;

$\Delta \mathrm{VC}_{\mathrm{t}}=$ Variable Costs growth for the period $t$ compared to the previous period;

$\Delta \mathrm{FC}_{\mathrm{t}}=$ Fixed Costs growth for the period $t$ compared to the previous period;

$\Delta \mathrm{Q}_{\mathrm{t}}=$ quantity growth for the period $t$ compared to the previous period;

up $=$ unit price for the periods $t$ and $t-1$;

uvc $=$ unit variable cost for the periods $t$ and $t-1$.

If the Fixed Costs growth $\Delta \mathrm{FC}_{\mathrm{t}}$ between two periods were zero, equation (1) would transform at most into the ratio between the Contribution Margin and the EBIT of the previous period, i.e. $\mathrm{CM}_{\mathrm{t}-1} / \mathrm{EBIT}_{\mathrm{t}-1}$, definitely not the $\mathrm{CM}_{t} / \mathrm{EBIT}_{\mathrm{t}}$ in the current period, even introducing a set of simplifications does not remain constant over the two financial periods. When we compare two scenarios of the same period, we can conclude that DOL is equal to the ratio between Contribution Margin and the EBIT of the base scenario, provided that Fixed Costs does not change.

On this topic, we can refer to Brigham et al. (2011), Chiladze (2017), Dudycz (2020) and Li et al. (2014).

Consequently, by covertly introducing a series of undeclared conditions, it is possible to define the DOL as a ratio between such variables, transforming it into a potential or expected measure of DOL if only the Fixed Costs do not change between two periods or scenarios. Besides, $\mathrm{DOL}_{\mathrm{t}}$ for the period $t$ is equal only to the ratio 
$\mathrm{CM}_{\mathrm{t}-1} / \mathrm{EBIT}_{\mathrm{t}-1}$ of the previous period, not to the same ratio of the current period $\mathrm{CM}_{\mathrm{t}} / \mathrm{EBIT}_{\mathrm{t}}$. Here is the first simplification.

In reality, the conditions are many more; let us see them in detail:

1) The quantity sold does not include the mix whose effect spills on the unit price;

2) The unit price does not vary between two periods or scenarios because both the product mix is invariant and the unit price itself does not change;

3) The unit variable cost does not change;

4) Consequently, even the unit contribution margin does not change;

5) The Fixed costs do not vary.

The result is that DOL cannot be the ratio of Contribution Margin to EBIT in the real world. Equation (1) in its final form is oversimplified and does not analytically comply with its definition of the ratio between EBIT and Revenue percentage growth. DOL becomes misrepresented, warped and weakened, preventing the understanding of the underlying market and business dynamics. The five conditions mentioned above cannot fulfil simultaneously; consequently, the conclusion reached about DOL is not operational using the simplified approach proposed by equation (1). For a general, complete and operative methodology, we must refer to equations ( 3 ) and ( 3 ter) below.

\subsection{DOL as a Relationship between Costs}

The second topic concerns the supposed definition of operating leverage as the ratio between fixed and variable costs, borrowed from mechanical lever as the relationship between arms of different lengths that allows a weight $\mathrm{P}$ to be lifted by applying a lower force $\mathrm{F}$ and exploiting the amplification given by the ratio between the resistant and agent arms:

$$
\mathrm{F}=P * \frac{\mathrm{r}_{\mathrm{r}}}{\mathrm{r}_{\mathrm{a}}}
$$

From equation (2), we obtain that the lever effect is advantageous when the ratio between the two arms is lower than 1: the acting arm $r_{a}$ must be longer than the resistant arm $r_{r}$.

Borrowed from the example of the mechanical lever, the comparison in economics is traditionally associated with costs rather than margins, operating an inversion that appears unusual. On the topic, we can refer to Brigham et al. (2011), Dudycz (2020), Li et al. (2014) and Sinha (2012). In mechanics, the goal is to determine the force to apply to the acting arm to lift a weight on the resistant arm or the necessary acting arm, given the force F. In economics, the equivalent question should be: what Revenue or quantity/mix growth do we need to reach a specific EBIT growth, given market and firm characteristics of Variable and Fixed Costs? Using equation (3):

$$
\mathrm{DOL}_{\mathrm{t}}=\frac{\Delta \% \mathrm{EBIT}_{\mathrm{t}}}{\Delta \% \mathrm{~S}_{\mathrm{t}}}=\mathrm{PDOL}_{\mathrm{t}} *\left(\frac{\mathrm{S}_{\mathrm{t}-1}}{\mathrm{CM}_{\mathrm{t}-1}}-\frac{\mathrm{VC}_{\mathrm{t}-1} * \Delta \% \mathrm{VC}_{\mathrm{t}}+\mathrm{FC}_{\mathrm{t}-1} * \Delta \% \mathrm{~F}_{\mathrm{t}}}{\mathrm{CM}_{\mathrm{t}-1} * \Delta \% \mathrm{~S}_{\mathrm{t}}}\right)=\mathrm{PDOL}_{\mathrm{t}} * \mathrm{~K}_{\mathrm{t}}
$$

where:

$\mathrm{PDOL}_{\mathrm{t}}=$ Potential DOL for the period $t$ as the ratio between $\mathrm{CM}_{\mathrm{t}-1} / \mathrm{EBIT}_{\mathrm{t}-1}$;

$\mathrm{VC}_{\mathrm{t}-1}=$ Variable Costs for the period $t-1$;

$\Delta \% \mathrm{VC}_{\mathrm{t}}=$ Variable Costs percentage growth for the period $t$ compared to the previous period.

$\mathrm{FC}_{\mathrm{t}-1}=$ Fixed Costs for the period $t-1$;

$\Delta \% \mathrm{~F}_{\mathrm{t}}=$ Fixed Costs percentage growth for the period $t$ compared to the previous period.

the answer is as follows:

$$
\Delta \% \mathrm{~S}_{\mathrm{t}}=\frac{\Delta \% \mathrm{EBIT}_{\mathrm{t}}}{\mathrm{PDOL}_{\mathrm{t}} \mathrm{K}_{\mathrm{t}}}=\frac{\Delta \% \mathrm{EBIT}_{\mathrm{t}}}{\mathrm{K}_{\mathrm{t}}} * \frac{\mathrm{EBIT}_{\mathrm{t}-1}}{\mathrm{CM}_{\mathrm{t}-1}}
$$

From ( 3 bis), you can see the similarity between arms and Margins. The DOL effect is based on Margins, Contribution and Operating or EBIT, not on costs. The amplification effect is owed to the Margins, not to the Costs: the Contribution Margin is used to increase the EBIT and ensure that its percentage growth is higher than the Revenue one, obtaining an energy balance advantageous.

In essence, the Margins serve to lift costs and not vice versa. In particular, the Contribution Margin has the task to levitate the Fixed Costs. We can focus on the dual aspect of the Margins, the Costs, but from a logical perspective, it is more complex. 


\subsection{PDOL as a Link}

A third aspect concerns the Potential DOL or PDOL, defined as the ratio between the Contribution Margin and EBIT of the previous period that plays an essential role to set the DOL value in the current period. The difference between the PDOLs of two financial periods $t+1$ and $t$ gives rise to the following relationship:

$$
\mathrm{PDOL}_{\mathrm{t}+1}-\mathrm{PDOL}_{\mathrm{t}}=\frac{\mathrm{CM}_{\mathrm{t}}}{\mathrm{EBIT}_{\mathrm{t}}}-\frac{\mathrm{CM}_{\mathrm{t}-1}}{\mathrm{EBIT}_{\mathrm{t}-1}}=\mathrm{PDOL}_{\mathrm{t}+1} *\left(1-\frac{1+\Delta \% \mathrm{EBIT}_{\mathrm{t}}}{1+\Delta \% \mathrm{CM}_{\mathrm{t}}}\right)
$$

from which it follows that:

$$
\mathrm{PDOL}_{\mathrm{t}+1}=\mathrm{PDOL}_{\mathrm{t}} * \frac{1+\Delta \% \mathrm{CM}_{\mathrm{t}}}{1+\Delta \% \mathrm{EBIT}_{\mathrm{t}}}
$$

By induction from (5), we obtain that:

$$
\mathrm{PDOL}_{\mathrm{n}+1}=\mathrm{PDOL}_{\mathrm{k}} * \frac{\prod_{t=k}^{n}\left(1+\Delta \% \mathrm{CM}_{\mathrm{t}}\right)}{\prod_{t=k}^{n}\left(1+\Delta \% \mathrm{EBIT}_{\mathrm{t}}\right)}
$$

Therefore exists a long-term relationship in the PDOL time series that are not independent of each other: that is the crucial aspect.

Instead, they are closely related as an ex-ante DOL measure. Even other economic quantities, such as Revenue, are linked by their growth rate, but here the difference lies in the fact that these quantities are ex-post while PDOL is ex-ante.

What are the economic consequences?

The first consequence is that the financial periods are not independent of each other, the starting conditions influence the performance of the following period, and this memory of the past remains indelible even in the distant future. This condition always operates, and in any case, in all firms.

It is possible to mix the cards in such a relationship through mergers or splits, but an imprint of the past remains, and this is quite strange as we are used to thinking that once the financial period is closed, perhaps poorly economically, there is no sign of this in the forthcoming Income Statement, but only in the Balance Sheet. Unfortunately, the Income Statement is also affected by past events: the latter weighs on the future.

The second consequence is precisely the inertia of the past influencing the Income Statements, like the Balance Sheet. A bad earnings performance in period $t$ may not even be entirely unfavourable: let us assume that the Contribution Margin was in line with previous years, but unfortunate conjunction drive Fixed Costs up as a result of one-off restructuring operation cutting the EBIT acutely; what impact would generate for the subsequent period $t+1$ ? PDOL $_{t+1}$, depending on the Contribution Margin and EBIT ratio of the period $t$, would assume a higher value than usual and would increase one of the factors that severely impacts DOL value for the period $t+1$. In addition, in period $t+1$, the Fixed Costs growth $\Delta \% \mathrm{~F}_{\mathrm{t}}$ will increase less due to an excessive increase in the previous period, reducing its negative impact on DOL. The reverse would happen in the event of a one-off reduction in Fixed Costs. The transmission mechanism operates in a more complex way on the Variable Costs growth also.

We remind that the definition of DOL implies the following relationship:

$$
\mathrm{DOL}_{\mathrm{t}}=\frac{\Delta \% \mathrm{EBIT}_{\mathrm{t}}}{\Delta \% \mathrm{~S}_{\mathrm{t}}}=\mathrm{PDOL}_{\mathrm{t}} *\left(\frac{\mathrm{s}_{\mathrm{t}-1}}{\mathrm{CM}_{\mathrm{t}-1}}-\frac{\mathrm{VC}_{\mathrm{t}-1} * \Delta \% \mathrm{VC}_{\mathrm{t}}+\mathrm{FC}_{\mathrm{t}-1} * \Delta \% \mathrm{~F}_{\mathrm{t}}}{\mathrm{CM}_{\mathrm{t}-1} * \Delta \% \mathrm{~S}_{\mathrm{t}}}\right)=\mathrm{PDOL}_{\mathrm{t}} *\left(\frac{\mathrm{s}_{\mathrm{t}-1}}{\mathrm{CM}_{\mathrm{t}-1}}-\mathrm{EVOL}_{\mathrm{t}}\right)
$$

It is not so important what overall effect have given negative or positive changes on the Income Statement, as it is to find out its existence: it is as a roll of the dice were affected by the previous one; the ex-ante link that makes the Income Statements dependent one another is mainly PDOL, which is not a simple relationship, it is the synthesis of how the firm reacts and manages market forces, its product mix, organisation and planning.

\subsection{DFL and Investment and Financial Decisions}

The fourth issue deserving further study is the relationship between Debt and DFL.

The Debt growth (or decrease) affects only DFL, leaving DOL untouched, in the DOL-DFL Nexus proposed by Paganini (2021).

The reason depends on the fact that the Debt growth can only arise from a need to finance higher liquidity, net working capital (NWC) or fixed investments.

A fortuitous combination of events, such as a delay in the collection of receivables, can increase the liquidity needs resorting in the short period to a line of credit, i.e. higher Debt, refundable at the end of the incident. Such a new Debt does not determine any impact on DOL, which remains untouched. DFL shrinks in the first period 
owing to higher Interest Expenses and grows in the following one when the Debt is refunded, returning to its long-term trend only two periods after the shock.

On the other hand, when Fixed Investments are involved, it is certainly possible that an investment decision needs an almost simultaneous financial decision to resort to Debt and Equity. The investment decision affects DOL and DFL, while the financial one impacts only the latter.

The investment decision may depend on three reasons:

1) market development: the investment decision has a long-term impact on Revenue, Variable and Fixed Costs, and Invested Capital;

2) manufacturing streamlining: it could impact only on Variable and Fixed Costs and Invested Capital, leaving the Revenue structure untouched;

3) staff process streamlining: it could involve only Fixed Costs and Invested Capital, leaving the Revenue and Variable Costs structure unchanged.

The three hypotheses modify the Invested Capital and the financing mix, but they affect DOL differently because they do not impact homogeneously on the same variables. The impact on DOL could be very different, but it would depend on the "real" side of the investment, not on the one assumed with the financial decision. It is also necessary to consider the impact exerted on DFL by DOL at the infra and inter-annual levels.

Also, in this case, the financial decision leaves the DOL unchanged and directly impacts DFL, while the investment decision acts on DOL and indirectly on DFL. Prezas (1987) reached a different conclusion with a model in which it is possible to keep the "real" and "financial" sides interacting or not. When they are not interacting, the impact on DOL owed to higher Debt is nil.

Let us see the variables that come into play:

1) DOL will change due to a different mix of Revenue, Variable and Fixed Costs growth;

2) the sensitivity of the Invested Capital $\psi$ owed to Revenue growth will change, even when the former is not affected by the latter;

3) the Debt Ratio DFL* could change;

4) the EBIT allocation among Interest Expenses, Taxes and Net Profit will also change over time.

Only the first point above affects DOL and indirectly DFL, while all others influence only the latter. The third point can affect both Debt and DFL but is unable to generate any impact on DOL. In this perspective, when investment and financial decisions interact, we must take their effects into account separately.

\section{DOL as Sensitivity}

The fifth issue concerns the elasticity of supply and demand glimpsing from the DOL equation:

$$
\mathrm{DOL}_{\mathrm{t}}=\frac{\Delta \% \mathrm{EBIT}_{\mathrm{t}}}{\Delta \% \mathrm{~S}_{\mathrm{t}}}=\mathrm{PDOL}_{\mathrm{t}} *\left\{\frac{\mathrm{S}_{\mathrm{t}-1}}{\mathrm{CM}_{\mathrm{t}-1}}-\frac{\mathrm{VC}_{\mathrm{t}-1} *\left[\left(1+\Delta \% \mathrm{uvc}_{\mathrm{t}}\right) *\left(1+\Delta \% \mathrm{qmvc}_{\mathrm{t}}\right)-1\right]+\mathrm{FC}_{\mathrm{t}-1} * \Delta \% \mathrm{~F}_{\mathrm{t}}}{\mathrm{CM}_{\mathrm{t}-1} *\left[\left(1+\Delta \% \mathrm{up}_{\mathrm{t}}\right) *\left(1+\Delta \% \mathrm{qms}_{\mathrm{t}}\right)-1\right]}\right\}
$$

which we reformulate as follows:

$$
\mathrm{DOL}_{\mathrm{t}}=\mathrm{PDOL}_{\mathrm{t}} *\left[\frac{\mathrm{S}_{\mathrm{t}-1}}{\mathrm{CM}_{\mathrm{t}-1}}-\frac{\mathrm{vc}_{\mathrm{t}-1} * \Delta \% \mathrm{uvc}_{\mathrm{t}} *\left(1+\Delta \% \mathrm{qmvc}_{\mathrm{t}}+\frac{\Delta \% \mathrm{qmvc}_{\mathrm{t}}}{\Delta \% \mathrm{uvc}_{\mathrm{t}}}\right)+\mathrm{FC}_{\mathrm{t}-1} * \Delta \% \mathrm{~F}_{\mathrm{t}}}{\mathrm{CM}_{\mathrm{t}-1} * \Delta \% \mathrm{up}_{\mathrm{t}} *\left(1+\Delta \% \mathrm{qms}_{\mathrm{t}}+\frac{\Delta \% \mathrm{qmms}_{\mathrm{t}}}{\Delta \% \mathrm{up}_{\mathrm{t}}}\right)}\right]
$$

For more details, we must refer to paragraph 3 of the paper by Paganini (2021).

At this point, we introduce two simplifications as the ratios between the quantity/mix percentage growth of Revenue and Variable Costs compared to unit price and variable cost percentage growth resemble without being equal to the definition of supply and demand elasticity. In both ratios, we have the quantity/mix percentage growth compared to the unit value one.

In the case under analysis, we cannot use the concept of elasticity as we do not know whether between the two periods the supply and demand curves have remained unchanged or have undergone shifts; moreover, the quantity/mix concept replaces the quantity one to allow the unit value percentage growth to be "mix independent". It is worth reminding that the quantity/mix percentage growth is the Revenue (or Variable Costs) percentage growth that we can obtain without changes in the unit price (or unit variable cost) compared to the previous period.

Nevertheless, nothing prevents to define such a ratio as the sensitivity of quantity/mix growth to the unit value growth, introducing the following definitions: 


$$
\eta_{\mathrm{vfm}}=\frac{\Delta \% \mathrm{qmvc}_{\mathrm{t}}}{\Delta \% \mathrm{uvc}_{\mathrm{t}}}
$$

and

$$
\eta_{\mathrm{pm}}=\frac{\Delta \% \mathrm{qms}_{\mathrm{t}}}{\Delta \% \mathrm{up}_{\mathrm{t}}}
$$

where $\eta_{\mathrm{vfm}}$ is the sensitivity of the unit variable costs in the factor market, and similarly, $\eta_{\mathrm{pm}}$ is the sensitivity of the unit price in the product market.

At this point, it is also possible to appropriately modify the Fixed Costs percentage growth $\Delta \% \mathrm{~F}_{\mathrm{t}}$ as a variable dependent on the quantity/mix and the unit value percentage growth of the factors that generate Fixed Costs, obtaining the following equation:

$$
\Delta \% \mathrm{~F}_{\mathrm{t}}=\left[\left(1+\Delta \% \mathrm{ufc}_{\mathrm{t}}\right) *\left(1+\Delta \% \mathrm{qmfc}_{\mathrm{t}}\right)-1\right]=\Delta \% \mathrm{ufc}_{\mathrm{t}} *\left(1+\Delta \% \mathrm{qmfc}_{\mathrm{t}}+\frac{\Delta \% \mathrm{qmfc}_{\mathrm{t}}}{\Delta \% \mathrm{ufc}_{\mathrm{t}}}\right)
$$

where:

$\Delta \% \mathrm{ufc}_{\mathrm{t}}=$ unit cost percentage growth of the Fixed Cost factors for the period $t$ compared to the previous one;

$\Delta \% \mathrm{qmfc}_{\mathrm{t}}=$ quantity/mix percentage growth of the Fixed Cost factors for the period $t$ compared to the previous one.

Also, for Fixed Costs, we can define the market sensitivity of fixed cost factors $\eta_{\mathrm{ffm}}$ as the ratio between quantity/mix growth and their unit value growth:

$$
\eta_{\mathrm{ffm}}=\frac{\Delta \% \mathrm{qmfc}_{\mathrm{t}}}{\Delta \% \mathrm{ufc}_{\mathrm{t}}}
$$

Consequently, we can rework DOL by highlighting the sensitivity of the quantity/mix to their unit values to comprehend the influence that the management and the product and factor markets exert on the firm's economic performance. The equation that emerges is the following:

$$
\mathrm{DOL}_{\mathrm{t}}=\mathrm{PDOL}_{\mathrm{t}} *\left[\frac{\mathrm{s}_{\mathrm{t}-1}}{\mathrm{CM}_{\mathrm{t}-1}}-\frac{\mathrm{vC}_{\mathrm{t}-1} * \Delta \% \mathrm{uvc}_{\mathrm{t}} *\left(1+\Delta \% \mathrm{qmvc}_{\mathrm{t}}+\eta_{\mathrm{vfm}}\right)+\mathrm{FC}_{\mathrm{t}-1} * \Delta \% \mathrm{ufc}_{\mathrm{t}} *\left(1+\Delta \% \mathrm{qmfc}_{\mathrm{t}}+\eta_{\mathrm{ffm}}\right)}{\mathrm{CM}_{\mathrm{t}-1} * \Delta \% \mathrm{up}_{\mathrm{t}} *\left(1+\Delta \% \mathrm{qms}_{\mathrm{t}}+\eta_{\mathrm{pm}}\right)}\right] \quad \text { (3 quinquies) }
$$

Furthermore, $\Delta \% \mathrm{qmfc}_{\mathrm{t}}$ can be related to any potential economies or diseconomies of scale by linking them to the Revenue or Variable Costs quantity/mix. An increase of $\Delta \% \mathrm{qms}_{\mathrm{t}}$ should give rise to an approximately equivalent growth of $\Delta \% \mathrm{qmvc}_{\mathrm{t}}$, remembering that the variation between the two quantities can be ascribable to mix differences while any economies of scale in Variable Costs impact only the unit variable cost. As far as Fixed Costs are concerned, we could expect a lower value both in the quantity/mix and the unit cost of the factors used by the firm.

We suppose to relate all the quantity/mix percentage growths to $\Delta \% \mathrm{qms}_{\mathrm{t}}$ and that the economies of scale can impact only $\Delta \% \mathrm{qmfc}_{\mathrm{t}}$, assuming that:

$$
\begin{gathered}
\Delta \% \mathrm{qms}_{\mathrm{t}}=\Delta \% \mathrm{qmvc}_{\mathrm{t}} \\
\Delta \% \mathrm{qms}_{\mathrm{t}}=\Delta \% \mathrm{qmfc}_{\mathrm{t}} *\left(1+\mathrm{X}_{\mathrm{t}}\right)
\end{gathered}
$$

where:

$$
\mathrm{X}_{\mathrm{t}}=\text { Economies of scale of the period } t
$$

Then, equation (3 quinquies) would take the following form:

$$
\begin{aligned}
\text { DOL }_{\mathrm{t}} & =\mathrm{PDOL}_{\mathrm{t}} *\left[\frac{\mathrm{s}_{\mathrm{t}-1}}{\mathrm{CM}_{\mathrm{t}-1}}-\frac{\mathrm{vC}_{\mathrm{t}-1} * \Delta \% \mathrm{uvc}_{\mathrm{t}} *\left(1+\Delta \% \mathrm{qms}_{\mathrm{t}}+\eta_{\mathrm{vfm}}\right)+\mathrm{FC}_{\mathrm{t}-1} * \Delta \% \mathrm{ufc}_{\mathrm{t}} *\left(1+\frac{\Delta \% \mathrm{qms}_{\mathrm{t}}}{1+\mathrm{X}_{\mathrm{t}}}+\eta_{\text {ffim }}\right)}{\mathrm{CM}_{\mathrm{t}-1} * \Delta \mathrm{up}_{\mathrm{t}} *\left(1+\Delta \% \mathrm{qms}_{\mathrm{t}}+\eta_{\mathrm{pm}}\right)}\right] \\
= & {\left[\frac{\mathrm{s}_{\mathrm{t}-1}}{\mathrm{EBIT}_{\mathrm{t}-1}}-\frac{\mathrm{VC}_{\mathrm{t}-1} * \Delta \% \mathrm{uvc}_{\mathrm{t}} *\left(1+\Delta \% \mathrm{qms}_{\mathrm{t}}+\eta_{\mathrm{vfm}}\right)+\mathrm{FC}_{\mathrm{t}-1} * \Delta \% \mathrm{ufc}_{\mathrm{t}} *\left(1+\frac{\Delta \% \mathrm{qms}_{\mathrm{t}}}{1+\mathrm{X}_{\mathrm{t}}}+\eta_{\text {ffim }}\right)}{\mathrm{EBIT}_{\mathrm{t}-1} * \Delta \mathrm{up}_{\mathrm{t}} *\left(1+\Delta \% \mathrm{qms}_{\mathrm{t}}+\eta_{\mathrm{pm}}\right)}\right] }
\end{aligned}
$$


Table 1. Quantitative example of how the sensitivities of product and factor markets impact DOL. The starting data are in light green (or light grey) fields; all others are computed data

\begin{tabular}{|c|c|c|c|c|c|c|}
\hline Item & $\begin{array}{c}\text { Starting Condition } \\
\mathrm{t}-1\end{array}$ & $\begin{array}{c}\text { Case } 1 \\
t\end{array}$ & $\begin{array}{c}\text { Case } 2 \\
t\end{array}$ & $\begin{array}{c}\text { Case } 3 \\
t\end{array}$ & $\begin{array}{c}\text { Case } 4 \\
t\end{array}$ & Note \\
\hline Revenue & $1,000,000 €$ & $1,089,000 €$ & $1,089,000 €$ & $1,089,000 €$ & $1,115,714 €$ & \\
\hline Variable Costs & $550,000 €$ & $598,950 €$ & $611,050 €$ & $609,033 €$ & $596,357 €$ & \\
\hline Contribution Margin & $450,000 €$ & $490,050 €$ & $477,950 €$ & $479,967 €$ & $519,357 €$ & \\
\hline Fixed Costs & $250,000 €$ & $272,250 €$ & $277,750 €$ & $267,852 €$ & $271,071 €$ & \\
\hline EBIT & $200,000 €$ & $217,800 €$ & $200,200 €$ & $212,115 €$ & $248,286 €$ & \\
\hline$\Delta \% \mathrm{~S}$ & & $8.900 \%$ & $8.900 \%$ & $8.900 \%$ & $11.571 \%$ & \\
\hline$\Delta \% \mathrm{VC}$ & & $8.900 \%$ & $11.100 \%$ & $10.733 \%$ & $8.429 \%$ & \\
\hline$\Delta \% \mathrm{CM}$ & & $8.900 \%$ & $6.211 \%$ & $6.659 \%$ & $15.413 \%$ & \\
\hline$\Delta \% \mathrm{~F}$ & & $8.900 \%$ & $11.100 \%$ & $7.141 \%$ & $8.429 \%$ & \\
\hline$\Delta \%$ EBIT & & $8.900 \%$ & $0.100 \%$ & $6.057 \%$ & $24.143 \%$ & \\
\hline$\Delta \%$ qms & & $10.000 \%$ & $10.000 \%$ & $10.000 \%$ & $10.000 \%$ & \\
\hline$\Delta \%$ up & & $-1.000 \%$ & $-1.000 \%$ & $-1.000 \%$ & $1.429 \%$ & \\
\hline$\Delta \% q m v c$ & & $10.000 \%$ & $10.000 \%$ & $10.000 \%$ & $10.000 \%$ & \\
\hline$\Delta \%$ uvc & & $-1.000 \%$ & $1.000 \%$ & $0.667 \%$ & $-1.429 \%$ & \\
\hline$\Delta \% q m f c$ & & $10.000 \%$ & $10.000 \%$ & $6.667 \%$ & $10.000 \%$ & \\
\hline$\Delta \%$ ufc & & $-1.000 \%$ & $1.000 \%$ & $0.444 \%$ & $-1.429 \%$ & \\
\hline PDOL & & $225.000 \%$ & $225.000 \%$ & $225.000 \%$ & $225.000 \%$ & \\
\hline $\mathrm{S} / \mathrm{CM}$ & & $222.222 \%$ & $222.222 \%$ & $222.222 \%$ & $222.222 \%$ & \\
\hline Evolution & & $-177.778 \%$ & $-221.723 \%$ & $-191.973 \%$ & $-129.492 \%$ & \\
\hline S/CM-Evolution & & $44.444 \%$ & $0.499 \%$ & $30.249 \%$ & $92.730 \%$ & \\
\hline DOL & & $100.000 \%$ & $1.124 \%$ & $68.061 \%$ & $208.642 \%$ & \\
\hline$\eta_{\mathrm{pm}}$ & & -10.000 & -10.000 & -10.000 & 7.000 & Sensitivity of the Product Market \\
\hline$\eta_{\mathrm{vfm}}$ & & -10.000 & 10.000 & 15.000 & -7.000 & Sensitivity of the Variable Factor Market \\
\hline$\eta_{\text {ffm }}$ & & -10.000 & 10.000 & 15.000 & -7.000 & Sensitivity of the Fixed Factor Market \\
\hline $\mathrm{x}$ & & 0.000 & 0.000 & 0.500 & 0.000 & Economies of scale \\
\hline
\end{tabular}

From (3 sexies) it is clear that:

1) if the percentage growths of the unit values were equal to each other;

2) if the percentage growths of the quantity/mix were identical to each other;

3) if the economies of scale were non-existent $\left(X_{t}=0\right)$;

(3 sexies) would simplify in (3 septies), so DOL would be $100 \%$.

These conditions translate into a very stringent requirement that all the sensitivities are equal to each other with no economies of scale:

$$
\mathrm{DOL}_{t}=\left[\frac{\mathrm{S}_{\mathrm{t}-1}}{\mathrm{EBIT}_{\mathrm{t}-1}}-\frac{\mathrm{VC}_{\mathrm{t}-1}+\mathrm{FC}_{\mathrm{t}-1}}{\mathrm{EBIT}_{\mathrm{t}-1}}\right]=\frac{\mathrm{S}_{\mathrm{t}-1}-\mathrm{VC}_{\mathrm{t}-1}-\mathrm{FC}_{\mathrm{t}-1}}{\mathrm{EBIT}_{\mathrm{t}-1}}=\frac{\mathrm{EBIT}_{\mathrm{t}-1}}{\mathrm{EBIT}_{\mathrm{t}-1}}=100 \%
$$

Table 1 shows some examples of growths caused by various situations of sensitivity and economies of scale. Case 1 is the one reported above.

When DOL diverges from $100 \%$, it means that different sensitivities are involved or economies of scale play a role or both; if DOL were higher than 1, then the overall balance would be positive; if it were less than 1, it would be negative. All this is in the presence of managerial behaviour oriented towards the optimal decision.

Consequently, a revenue development policy to be as profitable as possible should aim at:

1) have management conduct inclined to the optimal decision and shared goals;

2) verify the existence of sensitivity of Revenue, Variable and Fixed Costs facilitating or hindering EBIT growth;

3) verify the existence of economies of scale;

4) have a DOL higher than or very close to 1.

The second point appears decisive as it conditions the fourth one. Let us suppose that a $\Delta \% \mathrm{up}_{\mathrm{t}}$ reduction equal to $1 \%$ can increase the quantity/mix $\Delta \% \mathrm{qms}_{\mathrm{t}}$ by $10 \%$ : we can reach a sensitivity $\eta_{\mathrm{pm}}$ equal to $-10 \%$. However, if this sensitivity pairs the absence of economies of scale, the increase in the quantity/mix of Variable and Fixed Costs by $10 \%$ and an increase in their unit value by $1 \%$, the sensitivity of Variable and Fixed Costs will be equal to $+10 \%$, generating a DOL of $1.124 \%$. To summarise, a $10 \%$ increase in the Revenue quantity/mix grows Revenue by $8.90 \%$ that, in turn, generates a meagre increase of $0.10 \%$ on EBIT, as the Total Costs grow by $11.1 \%$, eroding the Revenue growth deeply: see Case 2 of Table 1. 


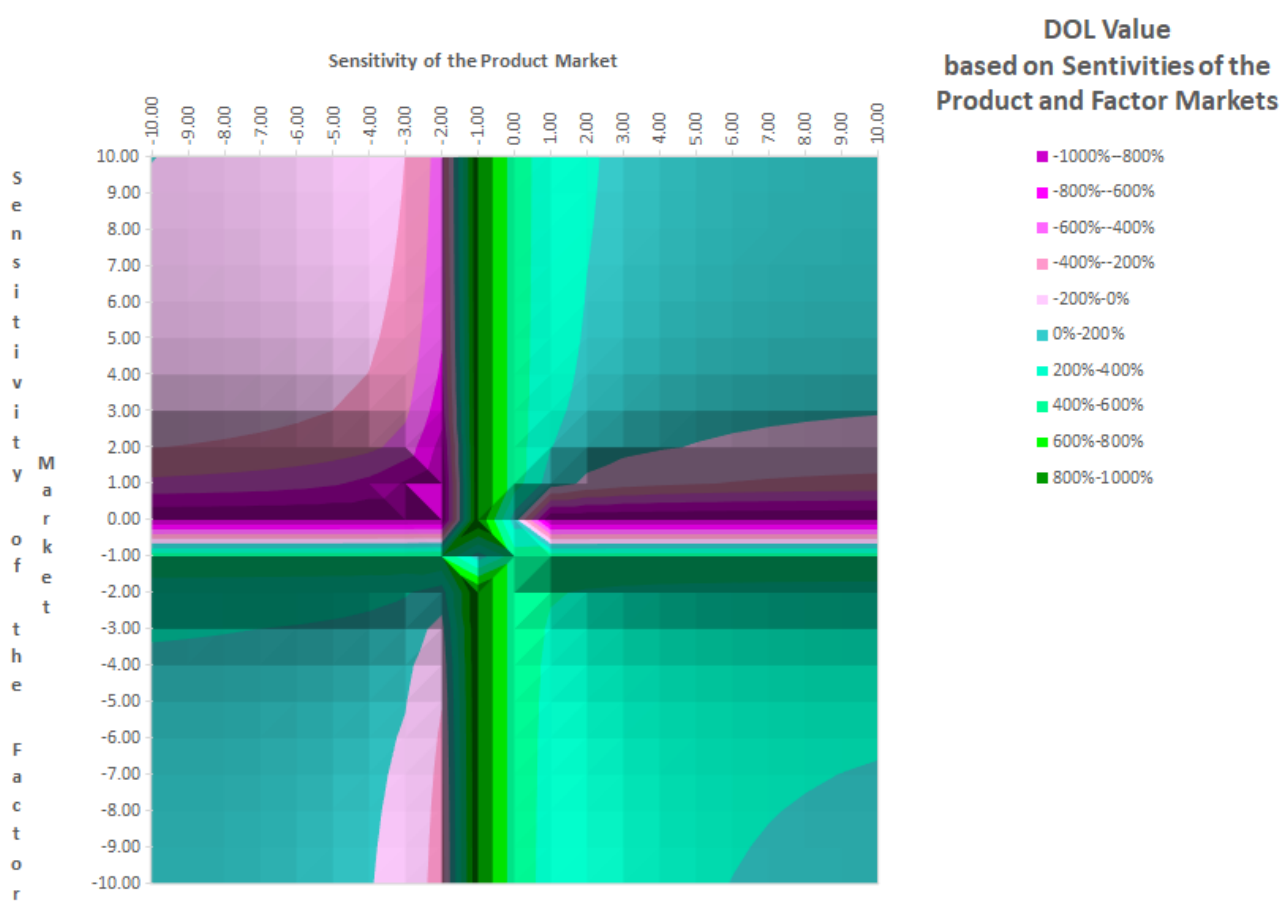

Figure 1. Two-dimensional representation of DOL as a function of different sensitivities of the product and factor market

A Revenue growth paired with a moderate unit price decrease is part of the rules of business. Nevertheless, if such expansion coupled with a significant increase in unit costs and the absence of economies of scale, it may not translate into a balanced growth of EBIT and Net Profit.

Figure 1 shows a surface representing DOL values for different sensitivities of the product and factor market $\eta_{\mathrm{pm}}$ and $\eta_{\mathrm{fm}}$, respectively, assuming for simplicity that the sensitivity of both variable and fixed cost factors are the same. Furthermore, economies of scale are supposed to be non-existent.

The graph shows that DOL assumes the highest values in two geometric loci along the line where:

A. the product market sensitivity $\eta_{\mathrm{pm}}$ is slightly negative, regardless of the value of the factor market sensitivity $\eta_{\text {fm }}$ (dark green crest in Figure 2);

B. the factor market sensitivity $\eta_{\mathrm{fm}}$ is slightly negative, regardless of the value assumed by the product market sensitivity $\eta_{\mathrm{pm}}$ (sage green crest in Figure 2);

while DOL assumes the lowest in correspondence where:

C. the factor market sensitivity $\eta_{\text {fm }}$ is slightly positive, regardless of the value of the product market sensitivity $\eta_{\mathrm{pm}}$ (in Figure 2, the dark purple trough);

D. the product market sensitivity $\eta_{\mathrm{pm}}$ is slightly lower than the value of the geometric locus defined in the previous point A (in Figure 2, the light purple through).

The intersection of all the geometric loci from A to D induces a transition area from very high to low DOL values, which generate strong instability with unpredictable results. For better visibility of the surface, Figure 2 shows a three-dimensional view.

Figures 1 and 2 show that four zones or plateaux, corresponding to the four Cartesian quadrants, are formed with the following combinations:

- Quadrant I: $\eta_{\mathrm{pm}}$ and $\eta_{\mathrm{fm}}$ positive with positive DOL tending to $200 \%$;

- Quadrant II: negative $\eta_{\mathrm{pm}}$ and positive $\eta_{\mathrm{fm}}$ with negative DOL;

- Quadrant III: negative $\eta_{\mathrm{pm}}$ and $\eta_{\mathrm{fm}}$ with positive DOL greater than $100 \%$;

- Quadrant IV: positive $\eta_{\mathrm{pm}}$ and negative $\eta_{\mathrm{fm}}$ with positive DOL greater than $200 \%$. 


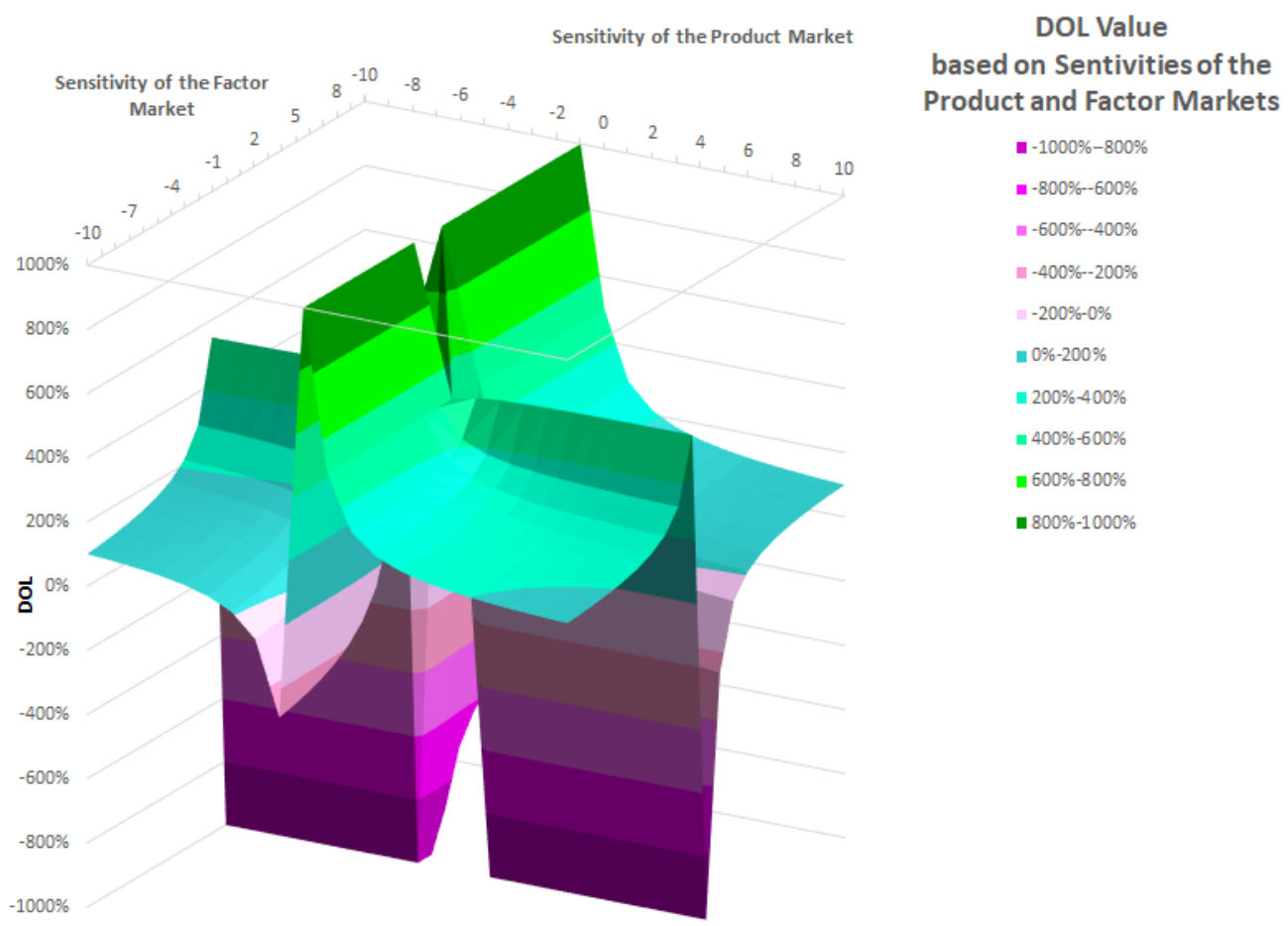

Figure 2. A three-dimensional representation of DOL as a function of different sensitivities of the product and factor market

The worst possible combination occurs in Quadrant II where the product market sensitivity $\eta_{\mathrm{pm}}$ is negative, which is quite normal in a rapidly growing market, matching a positive factor market sensitivity $\eta_{\text {fm: }}$ a quantity/mix growth coupled by a unit price cut and a unit costs increase, both variable and fixed, if not paired by relevant economies of scale, can have serious economic consequences and result in a worsening of the economic and financial situation. The situation could depend on manufacturing, supply chain or industry peculiarity and might set up a fragmented industry.

The best situation occurs in Quadrant IV, where the factor market sensitivity $\eta_{\mathrm{fm}}$ is negative facing the positive sensitivity $\eta_{\mathrm{pm}}$ of the product market, perhaps in an oligopolistic condition with sturdy demand.

\section{Implications of the DOL-DFL Nexus on Firm's Risk}

The sixth issue concerns the level of risk, defined as the volatility of the expected result of Revenue, EBIT and Net Profit growth. How do economic uncertainty impact Revenue, EBIT and Net Profit growths? How do such risks relate to DOL and DFL?

We suppose that all the economic variables follow a normal distribution where $\mu$ and $\sigma$ are the mean and the standard deviation: the expected result $\mu$ and its uncertainty $\sigma$ can influence the EBIT and Net Profit percentage growth $\Delta \% \mathrm{EBIT}_{\mathrm{t}}$ and $\Delta \% \pi_{\mathrm{t}}$ through a random process in which DOL and DFL could play a role. The standard deviation $\sigma$ is considered a proxy of the risk. The economic variables are not always normal distributed, and in such a case, we have to consider kurtosis and skewness that can affect the risk level. To define whether the distribution is normal or not, we can use the Shapiro-Wilk W-test with the Royston method in the more complex models. We refer to Shapiro et al. (1965) and Royston (1992) for detailed studies.

When we observe the risk issue related to the quantity/mix growth $\Delta \% \mathrm{qms}_{\mathrm{t}}$, we can point out that the Revenue, EBIT and Net Profit percentage growth align with the expected result $\mu$. Furthermore, such values are related to DOL and DFL baseline values. DOL explains the average EBIT growth due to the average Revenue growth, and DFL, in turn, explains the average Net Profit due to the average EBIT.

When we move to the standard deviation $\sigma$ that measures the volatility around the mean $\mu$, we find they are unrelated to the DOL and DFL baseline values. In particular, the EBIT and Net Profit percentage growth volatility appeared much greater than the Revenue growth one. Why is the volatility amplified, and what does it on depend? Such a volatility increase does not seem at first ascribable to the values assumed by DOL and DFL. 
In the following paragraphs, we shall try to answer that question by changing one factor at a time (OAT) to observe the effects produced on the output, namely $\Delta \% \mathrm{EBIT}_{\mathrm{t}}, \Delta \% \pi_{\mathrm{t}}$, DOL and DFL. Such an OAT approach disregards interactions between input variables to enhance the local perspective of small perturbations or changes (Czitrom, 1999).

For more details about DOL and DFL, we must refer to the papers by Paganini $(2019,2021)$.

\subsection{EBIT Volatility Due to Quantity/Mix Growth Uncertainty}

First, it is necessary to define the volatility of the Revenue and Variable Costs growths, $\Delta \% \mathrm{~S}_{\mathrm{t}}$ and $\Delta \% \mathrm{VC}_{\mathrm{t}}$ respectively, with the following equations:

$$
\begin{gathered}
\Delta \% \mathrm{~S}_{\mathrm{t}}=\left[\left(1+\Delta \% \mathrm{qms}_{\mathrm{t}}\right) *\left(1+\Delta \% \mathrm{up}_{\mathrm{t}}\right)-1\right] \\
\Delta \% \mathrm{VC}_{\mathrm{t}}=\left[\left(1+\Delta \% \mathrm{qmvc}_{\mathrm{t}}\right) *\left(1+\Delta \% \mathrm{uvc}_{\mathrm{t}}\right)-1\right]=\left[\left(1+\Delta \% \mathrm{qms}_{\mathrm{t}}-\varepsilon_{\mathrm{t}}\right) *\left(1+\Delta \% \mathrm{uvc}_{\mathrm{t}}\right)-1\right]
\end{gathered}
$$

From the previous definitions, it is easy to obtain the standard deviations of $\Delta \% \mathrm{~S}_{\mathrm{t}}$ and $\Delta \% \mathrm{VC}_{\mathrm{t}}$ originating from the $\Delta \% \mathrm{qms}_{\mathrm{t}}$ uncertainty while $\Delta \% \mathrm{up}_{\mathrm{t}}$ and $\Delta \% \mathrm{uvc}_{\mathrm{t}}$ are not random variables for the time being:

$$
\begin{gathered}
\sigma\left(\Delta \% \mathrm{~S}_{\mathrm{t}} \mid \Delta \% \mathrm{qms}_{\mathrm{t}}\right)=\left(1+\Delta \% \mathrm{up}_{\mathrm{t}}\right) * \sigma\left(\Delta \% \mathrm{qms}_{\mathrm{t}}\right) \\
\sigma\left(\Delta \% \mathrm{VC}_{\mathrm{t}} \mid \Delta \% \mathrm{qms}_{\mathrm{t}}\right)=\left(1+\Delta \% \mathrm{uvc}_{\mathrm{t}}\right) * \sigma\left(\Delta \% \mathrm{qmvc}_{\mathrm{t}}\right) \\
=\left(1+\Delta \% \mathrm{uvc}_{\mathrm{t}}\right) * \sigma\left(\Delta \% \mathrm{qms}_{\mathrm{t}}-\varepsilon_{\mathrm{t}}\right)=\left(1+\Delta \% \mathrm{uvc}_{\mathrm{t}}\right) * \sigma\left(\Delta \% \mathrm{qms}_{\mathrm{t}}\right)
\end{gathered}
$$

In equation (16), we suppose that the $\varepsilon_{\mathrm{t}}$ uncertainty is zero.

Let us analyse the standard deviation of the EBIT percentage growth $\Delta \% \mathrm{EBIT}_{\mathrm{t}}$ starting from its definition:

$$
\begin{aligned}
\Delta \% \text { EBIT }_{\mathrm{t}} & =\Delta \% \mathrm{~S}_{\mathrm{t}} * \mathrm{DOL}_{\mathrm{t}}=\Delta \% \mathrm{~S}_{\mathrm{t}} * \text { PDOL }_{\mathrm{t}} *\left(\frac{\mathrm{S}_{\mathrm{t}-1}}{\mathrm{CM}_{\mathrm{t}-1}}-\frac{\mathrm{VC}_{\mathrm{t}-1} * \Delta \% \mathrm{VC}_{\mathrm{t}}+\mathrm{FC}_{\mathrm{t}-\mathrm{S}} * \Delta \% \mathrm{~F}_{\mathrm{t}}}{\mathrm{CM}_{\mathrm{t}-1} * \Delta \mathrm{S}_{\mathrm{t}}}\right) \\
& =\frac{\mathrm{S}_{\mathrm{t}-1}}{\mathrm{EBIT}_{\mathrm{t}-1}} *\left(\Delta \% \mathrm{~S}_{\mathrm{t}}-\frac{\mathrm{VC}_{\mathrm{t}-1}}{\mathrm{~S}_{\mathrm{t}-1}} * \Delta \% \mathrm{VC}_{\mathrm{t}}-\frac{\mathrm{FC}_{\mathrm{t}-1}}{\mathrm{~S}_{\mathrm{t}-1}} * \Delta \% \mathrm{~F}_{\mathrm{t}}\right)
\end{aligned}
$$

Its variance in the general case descends from the previous definition:

$$
\begin{gathered}
\operatorname{Var}\left(\Delta \% \operatorname{EBIT}_{\mathrm{t}}\right)=\left(\frac{\mathrm{s}_{\mathrm{t}-1}}{\mathrm{EBIT}_{\mathrm{t}-1}}\right)^{2} *\left[\operatorname{Var}\left(\Delta \% \mathrm{~S}_{\mathrm{t}}\right)+\left(\frac{\mathrm{vC}_{\mathrm{t}-1}}{\mathrm{~S}_{\mathrm{t}-1}}\right)^{2} * \operatorname{Var}\left(\Delta \% \mathrm{VC}_{\mathrm{t}}\right)+\left(\frac{\mathrm{FC}_{\mathrm{t}-1}}{\mathrm{~s}_{\mathrm{t}-1}}\right)^{2} * \operatorname{Var}\left(\Delta \% \mathrm{~F}_{\mathrm{t}}\right)+\right. \\
\left.-2 * \frac{\mathrm{vC}_{\mathrm{t}-1}}{\mathrm{~S}_{\mathrm{t}-1}} * \operatorname{Cov}\left(\Delta \% \mathrm{~S}_{\mathrm{t}}, \Delta \% \mathrm{VC}_{\mathrm{t}}\right)-2 * \frac{\mathrm{FC}_{\mathrm{t}-1}}{\mathrm{~S}_{\mathrm{t}-1}} * \operatorname{Cov}\left(\Delta \% \mathrm{~S}_{\mathrm{t}}, \Delta \% \mathrm{FC}_{\mathrm{t}}\right)+2 * \frac{\mathrm{VC}_{\mathrm{t}-1} \mathrm{FC}_{\mathrm{t}-1}}{\mathrm{~S}_{\mathrm{t}-1}} * \operatorname{Cov}\left(\Delta \% \mathrm{VC}_{\mathrm{t}}, \Delta \% \mathrm{FC}_{\mathrm{t}}\right)\right]
\end{gathered}
$$

Since we are dealing with a case in which the volatility is due to the Revenue quantity/mix, covariances of the Revenue and Variable Costs percentage growths compared to the Fixed Costs one are zero; besides, the Fixed Costs variance $\operatorname{Var}\left(\Delta \% \mathrm{~F}_{\mathrm{t}}\right)$ is zero.

Therefore (18) can simplify into the following:

$$
\begin{gathered}
\operatorname{Var}\left(\Delta \% \mathrm{EBIT}_{\mathrm{t}} \mid \Delta \% \mathrm{qms}_{\mathrm{t}}\right)=\left(\frac{\mathrm{S}_{\mathrm{t}-1}}{\mathrm{EBIT}_{\mathrm{t}-1}}\right)^{2} * \\
{\left[\operatorname{Var}\left(\Delta \% \mathrm{~S}_{\mathrm{t}} \mid \Delta \% \mathrm{qms}_{\mathrm{t}}\right)+\left(\frac{\mathrm{VC}_{\mathrm{t}-1}}{\mathrm{~S}_{\mathrm{t}-1}}\right)^{2} * \operatorname{Var}\left(\Delta \% \mathrm{VC}_{\mathrm{t}} \mid \Delta \% \mathrm{qms}_{\mathrm{t}}\right)-2 * \frac{\mathrm{VC}_{\mathrm{t}-1}}{\mathrm{~S}_{\mathrm{t}-1}} * \operatorname{Cov}\left(\Delta \% \mathrm{~S}_{\mathrm{t}}\left|\Delta \% \mathrm{qms}_{\mathrm{t}}, \Delta \% \mathrm{VC}_{\mathrm{t}}\right| \Delta \% \mathrm{qms}_{\mathrm{t}}\right)\right]} \\
=\left(\frac{1}{\mathrm{EBIT}_{\mathrm{t}-1}}\right)^{2} *\left\{\left[\mathrm{~S}_{\mathrm{t}-1} *\left(1+\Delta \% \mathrm{up}_{\mathrm{t}}\right)\right]^{2} * \operatorname{Var}\left(\Delta \% \mathrm{qms}_{\mathrm{t}}\right)+\left[\mathrm{VC}_{\mathrm{t}-1} *\left(1+\Delta \% \mathrm{uvc}_{\mathrm{t}}\right)\right]^{2} * \operatorname{Var}\left(\Delta \% \mathrm{qms}_{\mathrm{t}}\right)+\right. \\
\left.-2 * \mathrm{~S}_{\mathrm{t}-1} * \mathrm{VC}_{\mathrm{t}-1} *\left(1+\Delta \% \mathrm{up}_{\mathrm{t}}\right) *\left(1+\Delta \% \mathrm{uvc}_{\mathrm{t}}\right) * \operatorname{Cov}\left(\Delta \% \mathrm{qms}_{\mathrm{t}}, \Delta \% \mathrm{qms}_{\mathrm{t}}\right)\right\} \\
=\left[\frac{\mathrm{CM}_{\mathrm{t}-1}+\mathrm{S}_{\mathrm{t}-1} * \Delta \% \mathrm{up}_{\mathrm{t}}-\mathrm{VC}_{\mathrm{t}-1} * \Delta \% \mathrm{uvc}_{\mathrm{t}}}{\mathrm{EBIT}_{\mathrm{t}-1}}\right]^{2} * \operatorname{Var}\left(\Delta \% \mathrm{qms}_{\mathrm{t}}\right)
\end{gathered}
$$

Equation (18 bis) highlights the following elements:

1) The variances of $\Delta \% \mathrm{~S}_{\mathrm{t}}$ and $\Delta \% \mathrm{VC}_{\mathrm{t}}$ depend on the same determinants as their essential variables, that is, on the quantity/mix percentage growths of Revenue and Variable Costs and the unit price and variable cost percentage growths.

2) The percentage growths of unit price $\Delta \% \mathrm{up}_{\mathrm{t}}$ and variable cost $\Delta \% \mathrm{uvc}_{\mathrm{t}}$ are not stochastic variables.

At this point, we can compare the standard deviation from (18 bis) and relate to the Revenue standard deviation $\sigma\left(\Delta \% \mathrm{~S}_{\mathrm{t}} \mid \Delta \% \mathrm{qms}_{\mathrm{t}}\right)$ depending on quantity/mix growth, obtaining the following result: 


$$
\begin{gathered}
\zeta\left(\mathrm{DOL}_{\mathrm{t}} \mid \Delta \% \mathrm{qms}_{\mathrm{t}}\right)=\frac{\sigma\left(\Delta \% \mathrm{EBIT}_{\mathrm{t}} \mid \Delta \% \mathrm{qms}_{\mathrm{t}}\right)}{\sigma\left(\Delta \% \mathrm{~S}_{\mathrm{t}} \mid \Delta \% \mathrm{qms}_{\mathrm{t}}\right)}=\frac{\left[\frac{\mathrm{CM}_{\mathrm{t}-1}+\mathrm{S}_{\mathrm{t}-1} * \Delta \% \mathrm{up}_{\mathrm{t}}-\mathrm{vC}_{\mathrm{t}-1} * \Delta \% \mathrm{uvc}_{\mathrm{t}}}{\mathrm{EBIT}_{\mathrm{t}-1}}\right] * \sigma\left(\Delta \% \mathrm{qms}_{\mathrm{t}}\right)}{\left(1+\Delta \% \mathrm{up}_{\mathrm{t}}\right) * \sigma\left(\Delta \% \mathrm{qms}_{\mathrm{t}}\right)} \\
=\mathrm{PDOL}_{\mathrm{t}} *\left[\frac{\mathrm{CM}_{\mathrm{t}-1}+\mathrm{S}_{\mathrm{t}-1} * \Delta \% \mathrm{up}_{\mathrm{t}}-\mathrm{vc}_{\mathrm{t}-1} * \Delta \% \mathrm{uvc}_{\mathrm{t}}}{\mathrm{Cm}_{\mathrm{t}-1} *\left(1+\Delta \% \mathrm{up}_{\mathrm{t}}\right)}\right]
\end{gathered}
$$

The result reached is interesting for several reasons since the relative EBIT volatility due to the quantity/mix compared to the Revenue one is based on the business characteristics that occurred in the previous period and on the unit price and variable cost percentage growth of the current one compared to the previous one.

Such volatility does not depend on the quantity/mix, neither Revenue nor Variable Costs of the current period.

If we assume a sufficiently narrow range of these percentage growths, we can suppose a steadiness of the Fixed Costs: such an index precisely represents the intrinsic firm's risk depending on the quantity/mix uncertainty.

Such a risk is independent of the Revenue volatility chosen range and its symmetry around the ordinate axis and is also valid for an asymmetric range of the kind $\mathrm{X} \leq \Delta \% \mathrm{qms}_{\mathrm{t}} \leq \mathrm{Y}$ for any value of $\mathrm{X}$ and $\mathrm{Y}$. We shall deal with the topic after presenting the Net Profit volatility.

Before deepening the issue, we should preface that the domain of the DOL and DFL functions exists in the field $[-1,+\infty]$ of the Revenue growth $\Delta \% \mathrm{~S}_{\mathrm{t}}$ or better, its quantity/mix growth $\Delta \% \mathrm{qms}_{\mathrm{t}}$. Infinite growth of the Revenue quantity/mix is theoretically possible only in their positive domain, while in the negative one, it would have the meaning of writing off all the Revenue obtained from the start. For this reason, we believe that it would be realistic to stop the Revenue decrease up to the point of not writing off any quantity/mix of the previous period, equivalent to a $100 \%$ reduction: any further reduction exceeding this limit would have the meaning of "product/service to be returned" decreasing the Revenue for periods preceding $t$. Now removing such a hypothesis, we could theoretically examine the behaviour of DOL and DFL for $\Delta \% \mathrm{qms}_{\mathrm{t}}$ approaching $-\infty$. There is no doubt that DOL and DFL assume different values at the limits of their domains $[-1,+\infty]$. When we examined the larger one $[-\infty,+\infty]$, we would discover that DOL tends towards the same asymptote showing a certain symmetry that we do not wish to investigate. We can define this DOL propriety as central symmetry around its discontinuity at $\Delta \% \mathrm{~S}_{\mathrm{t}}=0$.

Instead, DFL presents two asymptotes because the function $\psi_{\mathrm{t}}$ does not operate symmetrically as $\Delta \% \mathrm{qms}_{\mathrm{t}}$ varies, and also the variable $\mathrm{K} 3_{\mathrm{t}}$, which affects New Fixed Investments, has a highly asymmetrical behaviour inside the positive or negative $\Delta \% \mathrm{~S}_{\mathrm{t}}$ domain. The reason why the ratio $\sigma\left(\Delta \% \mathrm{EBIT}_{\mathrm{t}} \mid \Delta \% \mathrm{qms}_{\mathrm{t}}\right) / \sigma\left(\Delta \% \mathrm{~S}_{\mathrm{t}} \mid \Delta \% \mathrm{qms}_{\mathrm{t}}\right)$ is independent of the $\Delta \% \mathrm{qms}_{\mathrm{t}}$ uncertainty depends on the DOL central symmetry propriety while all this holds much less for DFL: consequently, we expect that the ratio $\sigma\left(\Delta \% \pi_{\mathrm{t}} \mid \Delta \% \mathrm{qms}_{\mathrm{t}}\right) / \sigma\left(\Delta \% \mathrm{EBIT}_{\mathrm{t}} \mid \Delta \% \mathrm{qms}_{\mathrm{t}}\right)$ will be partially depending on the $\Delta \% \mathrm{qms}_{\mathrm{t}}$ uncertainty. DFL has an imperfect axial symmetry around its discontinuity at $\Delta \% \mathrm{EBIT}_{\mathrm{t}}=0$.

From a mathematical perspective, equation (19) represents the limit of DOL for $\Delta \% \mathrm{qms}_{\mathrm{t}}$ approaching $\infty$, that is, the asymptote of DOL for the Revenue quantity/mix growth. This limit takes on the following form:

$$
\lim _{\Delta \% \mathrm{qms}_{\mathrm{t}} \rightarrow \infty} \mathrm{DOL}_{\mathrm{t}}=\mathrm{PDOL}_{\mathrm{t}} *\left[\frac{\mathrm{CM}_{\mathrm{t}-1}+\mathrm{s}_{\mathrm{t}-1} * \Delta \% \mathrm{up}_{\mathrm{t}}-\mathrm{vc}_{\mathrm{t}-1} * \Delta \% \mathrm{uvc}_{\mathrm{t}}}{\mathrm{CM}_{\mathrm{t}-1} *\left(1+\Delta \% \mathrm{up}_{\mathrm{t}}\right)}\right]=\mathrm{DOL}_{\mathrm{t}}^{\mathrm{a}} \mid \Delta \% \mathrm{qms}_{\mathrm{t}}=\zeta\left(\mathrm{DOL}_{\mathrm{t}} \mid \Delta \% \mathrm{qms}_{\mathrm{t}}\right)
$$

Therefore, the DOL asymptote $\mathrm{DOL}_{\mathrm{t}}^{\mathrm{a}} \mid \Delta \% \mathrm{qms}_{\mathrm{t}}$ represents the firm's risk due to DOL owed to $\Delta \% \mathrm{qms}_{\mathrm{t}}$ uncertainty, essentially based on PDOL, which we recall is the ratio between the Contribution Margin and EBIT of the previous period, which must be applied some corrections due to the unit price and variable cost percentage growth of the current period. In the absence of such variations, the firm's risk due to the quantity/mix growth uncertainty is equal to PDOL, which takes on an essential relevance at the firm level as it also represents the value towards DOL could tend under very restricted conditions: please refer to the paragraph 1 for more details. Furthermore, the $\mathrm{DOL}_{\mathrm{t}}^{\mathrm{a}} \mid \Delta \% \mathrm{qms}_{\mathrm{t}}$ is independent of the value assumed by the Fixed Costs percentage growth, having supposed that they are negligible compared to a theoretical $\Delta \% \mathrm{qms}_{\mathrm{t}}$ approaching infinity.

Considering that the information relating to unit price and variable cost growths are not always available in the financial statement; so in the absence of better information, PDOL represents the approximate firm's risk due to DOL owed to quantity/mix growth uncertainty. The lower the marginality in the previous financial period, the higher is the risk in the current one.

\subsection{Net Profit Volatility Due to Quantity/Mix Growth Uncertainty}

As regards the Net Profit growth volatility, the considerations made so far also apply to DFL: the ratio between 
the Net Profit and EBIT percentage growth volatility measured by their standard deviations is approximatively the DFL asymptote, but since DFL has an imperfect axial symmetry, the choice of the $\Delta \% \mathrm{qms}_{\mathrm{t}}$ uncertainty range affects its final value. DFL imperfect axial symmetry is due to the parameter $\mathrm{K} 3_{\mathrm{t}}$ that assumes zero value for negative $\Delta \% \mathrm{~S}_{\mathrm{t}}$ while it becomes $\gamma *(1-\theta)$ for the positive ones. Recall that $\gamma$ is the sensitivity of New Fixed Investments to the Revenue growth, and $\theta$ represents their depreciation rate. In the case of an entirely positive range of $\Delta \% \mathrm{~S}_{\mathrm{t}}$, the implicit risk ascribable to DFL is its positive asymptote for $\Delta \% \mathrm{qms}_{\mathrm{t}}$ approaching $+\infty$; vice versa for a $\Delta \% \mathrm{~S}_{\mathrm{t}}$ range entirely negative, the risk is the negative DFL asymptote for $\Delta \% \mathrm{qms}_{\mathrm{t}}$ approaches $-\infty$.

It is necessary to start from the definition of Net Profit percentage growth $\Delta \% \pi_{\mathrm{t}}$ to explain why the DFL asymptotes capture such a risk :

$$
\Delta \% \pi_{\mathrm{t}}=\mathrm{N}_{\mathrm{t}} *\left(1+\mathrm{DOL}_{\mathrm{t}} * \Delta \% \mathrm{~S}_{\mathrm{t}}\right)-\mathrm{Q}_{\mathrm{t}} *\left(1+\Delta \% \mathrm{~S}_{\mathrm{t}}\right)-1
$$

The variance of the Net Profit percentage growth due to the $\Delta \% \mathrm{qms}_{\mathrm{t}}$ uncertainty is the following:

$$
\begin{gathered}
\operatorname{Var}\left(\Delta \% \pi_{\mathrm{t}} \mid \Delta \% \mathrm{qms}_{\mathrm{t}}\right)=\mathrm{N}_{\mathrm{t}}^{2} * \operatorname{Var}\left(\Delta \% \mathrm{EBIT}_{\mathrm{t}} \mid \Delta \% \mathrm{qms}_{\mathrm{t}}\right)+\operatorname{Var}\left(\mathrm{Q}_{\mathrm{t}} \mid \Delta \% \mathrm{qms}_{\mathrm{t}}\right)+\operatorname{Var}\left[\left(\mathrm{Q}_{\mathrm{t}} * \Delta \% \mathrm{~S}_{\mathrm{t}}\right) \mid \Delta \% \mathrm{qms}_{\mathrm{t}}\right]+ \\
-2 * \mathrm{~N}_{\mathrm{t}} * \operatorname{Cov}\left(\Delta \% \mathrm{EBIT}_{\mathrm{t}}\left|\Delta \% \mathrm{qms}_{\mathrm{t}} \mathrm{Q}_{\mathrm{t}}\right| \Delta \% \mathrm{qms}_{\mathrm{t}}\right)-2 * \mathrm{~N}_{\mathrm{t}} * \operatorname{Cov}\left[\Delta \% \mathrm{EBIT}_{\mathrm{t}}\left|\Delta \% \mathrm{qms}_{\mathrm{t}^{\prime}}\left(\mathrm{Q}_{\mathrm{t}} * \Delta \% \mathrm{~S}_{\mathrm{t}}\right)\right| \Delta \% \mathrm{qms}_{\mathrm{t}}\right]+ \\
+2 * \operatorname{Cov}\left[\mathrm{Q}_{\mathrm{t}}\left|\Delta \% \mathrm{qms}_{\mathrm{t}},\left(\mathrm{Q}_{\mathrm{t}} * \Delta \% \mathrm{~S}_{\mathrm{t}}\right)\right| \Delta \% \mathrm{qms}_{\mathrm{t}}\right]
\end{gathered}
$$

The ratio between the variances of the Net Profit and EBIT percentage growth generates the following equation:

$$
\begin{gathered}
\frac{\operatorname{Var}\left(\Delta \% \pi_{\mathrm{t}} \mid \Delta \% \mathrm{qms}_{\mathrm{t}}\right)}{\operatorname{Var}\left(\Delta \% \mathrm{EBIT}_{\mathrm{t}} \mid \Delta \% \mathrm{qms}_{\mathrm{t}}\right)}=\mathrm{N}_{\mathrm{t}}^{2}+\frac{\operatorname{Var}\left(\mathrm{Q}_{\mathrm{t}} \mid \Delta \% \mathrm{qms}_{\mathrm{t}}\right)}{\operatorname{Var}\left(\Delta \% \mathrm{EBIT}_{\mathrm{t}} \mid \Delta \% \mathrm{qms}_{\mathrm{t}}\right)}+\frac{\operatorname{Var}\left(\mathrm{Q}_{\mathrm{t}} * \Delta \% \mathrm{~S}_{\mathrm{t}} \mid \Delta \% \mathrm{qms}_{\mathrm{t}}\right)}{\operatorname{Var}\left(\Delta \% \mathrm{EBIT}_{\mathrm{t}} \mid \Delta \% \mathrm{qms}_{\mathrm{t}}\right)}+ \\
+2 * \frac{\operatorname{Cov}\left(\mathrm{Q}\left|\Delta \% \mathrm{qms}_{\mathrm{t}} \mathrm{Q}_{\mathrm{t}} * \Delta \% \mathrm{~S}_{\mathrm{t}}\right| \Delta \% \mathrm{qms}_{\mathrm{t}}\right)}{\operatorname{Var}\left(\Delta \% \mathrm{EBIT}_{\mathrm{t}} \mid \Delta \% \mathrm{qms}_{\mathrm{t}}\right)}+ \\
-2 * \mathrm{~N}_{\mathrm{t}} * \frac{\operatorname{Cov}\left(\Delta \% \mathrm{EBIT}_{\mathrm{t}}\left|\Delta \% \mathrm{qms}_{\mathrm{t}}, \mathrm{Q}_{\mathrm{t}}\right| \Delta \% \mathrm{qms}_{\mathrm{t}}\right)+\operatorname{Cov}\left(\Delta \% \mathrm{EBIT}_{\mathrm{t}}\left|\Delta \% \mathrm{qms}_{\mathrm{t}}, \mathrm{Q}_{\mathrm{t}} * \Delta \% \mathrm{~S}_{\mathrm{t}}\right| \Delta \% \mathrm{qms}_{\mathrm{t}}\right)}{\operatorname{Var}\left(\Delta \% \mathrm{EBIT}_{\mathrm{t}} \mid \Delta \% \mathrm{qms}_{\mathrm{t}}\right)} \\
=\mathrm{N}_{\mathrm{t}}{ }^{2}+\mathrm{VV}_{\mathrm{t}}{ }^{2} * \frac{\operatorname{Var}\left(\mathrm{H}_{\mathrm{t}} \mid \Delta \% \mathrm{qms}_{\mathrm{t}}\right)}{\operatorname{Var}\left(\Delta \% \mathrm{qms}_{\mathrm{t}}\right)}-2 * \mathrm{~N}_{\mathrm{t}} * \mathrm{VVl}_{\mathrm{t}} * \frac{\operatorname{Cov}\left(\Delta \% \mathrm{qms}_{\mathrm{t}}, \mathrm{H}_{\mathrm{t}} \mid \Delta \% \mathrm{qms}_{\mathrm{t}}\right)}{\operatorname{Var}\left(\Delta \% \mathrm{qms}_{\mathrm{t}}\right)} \\
=\frac{\operatorname{Var}\left(\mathrm{N}_{\mathrm{t}} * \Delta \% \mathrm{qms}_{\mathrm{t}}-\mathrm{VVI}_{\mathrm{t}} * \mathrm{H}_{\mathrm{t}} \mid \Delta \% \mathrm{qms}_{\mathrm{t}}\right)}{\operatorname{Var}\left(\Delta \% \mathrm{qms}_{\mathrm{t}}\right)}
\end{gathered}
$$

where:

$$
\begin{aligned}
& \mathrm{VV} 1_{\mathrm{t}}=\frac{\mathrm{Z}_{\mathrm{t}}}{\mathrm{DFL}_{\mathrm{t}-1}^{*}} * \frac{1}{\left(1+\Delta \% \mathrm{up}_{\mathrm{t}}\right) * \mathrm{DOL}_{\mathrm{t}}^{\mathrm{a}} \mid \Delta \% \mathrm{qms}_{\mathrm{t}}} \\
& Z_{t}=\frac{A_{t-1} * M_{t} * T_{t}}{1-i_{t} *\left(1-\alpha_{t}\right)} \\
& \mathrm{H}_{\mathrm{t}}=\psi_{\mathrm{t}} *\left(1+\Delta \% \mathrm{~S}_{\mathrm{t}}\right)-\frac{\mathrm{AA}_{\mathrm{t}-1}}{\mathrm{CI}_{\mathrm{t}-1}}-\mathrm{ROI}_{\mathrm{t}-1} *\left(1-\alpha_{\mathrm{t}}\right) *\left(1+\Delta \% \mathrm{EBIT}_{\mathrm{t}}\right) \\
& \psi_{\mathrm{t}}=\frac{1+\Delta \% \mathrm{CI}_{\mathrm{t}}}{1+\Delta \% \mathrm{~S}_{\mathrm{t}}}=\mathrm{K} 1_{\mathrm{t}-1} * \mathrm{~K} 2_{\mathrm{t}}+\frac{1}{1+\Delta \% \mathrm{~S}_{\mathrm{t}}} *\left[\mathrm{~K} 1_{\mathrm{t}-1} * \mathrm{~K} 3_{\mathrm{t}} * \Delta \% \mathrm{~S}_{\mathrm{t}}+\mathrm{K} 4_{\mathrm{t}}\right] \\
& \frac{\mathrm{AA}_{\mathrm{t}-1}}{\mathrm{CI}_{\mathrm{t}-1}}=\frac{\mathrm{E}_{\mathrm{t}-1}-\mathrm{Div}_{\mathrm{t}-1}}{\mathrm{CI}_{\mathrm{t}-1}} \\
& \mathrm{ROI}_{\mathrm{t}-1}=\frac{\mathrm{EBIT}_{\mathrm{t}-1}}{\mathrm{CI}_{\mathrm{t}-1}}
\end{aligned}
$$

Equation (23) depends on the $\Delta \% \mathrm{qms}_{\mathrm{t}}$ uncertainty; therefore, the choice of its range and the resulting $\Delta \% \mathrm{~S}_{\mathrm{t}}$ range will influence the ratio $\sigma\left(\Delta \% \pi_{\mathrm{t}} \mid \Delta \% \mathrm{qms}_{\mathrm{t}}\right) / \sigma\left(\Delta \% \mathrm{EBIT}_{\mathrm{t}} \mid \Delta \% \mathrm{qms}_{\mathrm{t}}\right)$ that measures the firm's risk due to DFL owed to $\Delta \% \mathrm{qms}_{\mathrm{t}}$ uncertainty. The variable $\mathrm{H}_{\mathrm{t}}$ in equation (26) implicates such a situation, owing to $\psi_{\mathrm{t}}$, that changes as $\Delta \% \mathrm{~S}_{\mathrm{t}}$ varies. As already anticipated, for $\Delta \% \mathrm{~S}_{\mathrm{t}}$ values higher than or equal to zero, the parameter $\mathrm{K} 3_{\mathrm{t}}$, by definition, is positive and constant, while for negative values becomes nil. Only when the range of Revenue percentage growth $\Delta \% \mathrm{~S}_{\mathrm{t}}$ is between negative and positive values, then $\mathrm{K}_{\mathrm{t}}$ ceases to be constant and significantly affects $\sigma\left(\Delta \% \pi_{\mathrm{t}} \mid \Delta \% \mathrm{qms}_{\mathrm{t}}\right) / \sigma\left(\Delta \% \mathrm{EBIT}_{\mathrm{t}} \mid \Delta \% \mathrm{qms}_{\mathrm{t}}\right)$ that becomes a random variable.

Before going into the detailed examination of this condition, it is necessary to deepen the meaning of the random 
variable $\mathrm{H}_{\mathrm{t}}$, which determines the risk due to DFL:

1) the first term, $\psi_{t} *\left(1+\Delta \% \mathrm{~S}_{\mathrm{t}}\right)$, is the Invested Capital ratio between two financial periods, that is $\left(1+\Delta \% \mathrm{CI}_{\mathrm{t}}\right)=\mathrm{CI}_{\mathrm{t}} / \mathrm{CI}_{\mathrm{t}-1}$;

2) the second term, $\mathrm{AA}_{\mathrm{t}-1} / \mathrm{CI}_{\mathrm{t}-1}$, measures the Equity percentage decrease resulting from the payment of dividends generated in the previous period;

3) the third term, $\mathrm{ROI}_{\mathrm{t}-1} *\left(1-\alpha_{\mathrm{t}}\right) *\left(1+\Delta \% \mathrm{EBIT}_{\mathrm{t}}\right)$, measures the percentage profitability after taxes for the current period related to the Capital Invested of the previous period.

Now the algebraic sum of these terms measures the Gross Debt Ratio of the current period, considering that all the terms refer to the Invested Capital of the previous period: it follows that $H_{t}$ measures the Gross Debt Ratio before the impact of interest expenses, even on taxes.

What happens if $\mathrm{K} 3_{\mathrm{t}}$ can be considered constant in the presence of a positive or negative uncertainty range of the Revenue percentage growth $\Delta \% \mathrm{~S}_{\mathrm{t}}$ ? equation (23) would turn into the following form:

$$
\frac{\operatorname{Var}\left(\Delta \% \pi_{\mathrm{t}} \mid \Delta \% \mathrm{qms}_{\mathrm{t}}\right)}{\operatorname{Var}\left(\Delta \% \mathrm{BBI} \mathrm{T}_{\mathrm{t}} \mid \Delta \% \mathrm{qms} \mathrm{s}_{\mathrm{t}}\right)}=\mathrm{N}_{\mathrm{t}}^{2}+\mathrm{VV}_{\mathrm{t}}{ }^{2} * \frac{\operatorname{Var}\left(\mathrm{H}_{\mathrm{t}}\right)}{\operatorname{Var}\left(\Delta \% \mathrm{qms} \mathrm{s}_{\mathrm{t}}\right)}-2 * \mathrm{~N}_{\mathrm{t}} * \operatorname{VV} 1_{\mathrm{t}} * \frac{\operatorname{Cov}\left(\Delta \% \mathrm{qms}_{\mathrm{t}} \mathrm{H}_{\mathrm{t}}\right)}{\operatorname{Var}\left(\Delta \% \mathrm{qm}_{\mathrm{t}}\right)}=\left(\mathrm{N}_{\mathrm{t}}-\mathrm{VV} 1_{\mathrm{t}} * \mathrm{DD}_{\mathrm{t}}\right)^{2}
$$

where:

$$
\mathrm{DD}_{\mathrm{t}}=\left[\mathrm{K} 1_{\mathrm{t}-1} *\left(\mathrm{~K}_{\mathrm{t}}+\mathrm{K} 3_{\mathrm{t}}\right) *\left(1+\Delta \% \mathrm{up}_{\mathrm{t}}\right)\right]-\mathrm{ROI}_{\mathrm{t}-1} *\left(1-\alpha_{\mathrm{t}}\right) *\left(1+\Delta \% \mathrm{up}_{\mathrm{t}}\right) * \mathrm{DOL}_{\mathrm{t}}^{\mathrm{a}} \mid \Delta \% \mathrm{qms}_{\mathrm{t}}
$$

Developing (23 bis) in less cryptic terms, the following formulation emerges:

$$
\zeta\left(\mathrm{DFL}_{\mathrm{t}} \mid \Delta \% \mathrm{qms}_{\mathrm{t}}\right)=\frac{\sigma\left(\Delta \% \pi_{\mathrm{t}} \mid \Delta \% \mathrm{qms}_{\mathrm{t}}\right)}{\sigma\left(\Delta \% \mathrm{EBIT}_{\mathrm{t}} \mid \Delta \% \mathrm{qms}_{\mathrm{t}}\right)}=\mathrm{N}_{\mathrm{t}}-\frac{\mathrm{Z}_{\mathrm{t}}}{\mathrm{DFL}_{\mathrm{t}-1}^{*}} *\left[\frac{\mathrm{K}_{\mathrm{t}-1} *\left(\mathrm{~K}_{\mathrm{t}}+\mathrm{K}_{\mathrm{t}}\right)}{\mathrm{DOL}_{\mathrm{t}}^{\mathrm{a}} \mid \Delta \% \mathrm{qms}_{\mathrm{t}}}-\mathrm{ROI}_{\mathrm{t}-1} *\left(1-\alpha_{\mathrm{t}}\right)\right]
$$

Equation (23 ter) states the firm's risk due to DFL owed to the $\Delta \% \mathrm{qms}_{\mathrm{t}}$ uncertainty when the $\Delta \% \mathrm{~S}$ volatility range is only positive or only negative, determining the steadiness of $\mathrm{K}_{\mathrm{t}}$, which could become nil in case of negative $\Delta \% \mathrm{~S}_{\mathrm{t}}$ range. It is worth observing how these conditions determine a risk independent of the value assumed by both $\Delta \% \mathrm{qms}_{\mathrm{t}}$ and its uncertainty range. Secondly, similarly to what has already occurred with DOL, the risk thus obtained coincides with the DFL asymptotes for $\Delta \% \mathrm{qms}_{\mathrm{t}}$ approaching $\pm \infty$.

Such DFL limits for $\Delta \% \mathrm{qms}_{\mathrm{t}}$ approaching $\pm \infty$ take the following forms:

$$
\begin{gathered}
\lim _{\Delta \% \mathrm{qms}_{\mathrm{t}} \rightarrow+\infty} \mathrm{DFL}_{\mathrm{t}}=\mathrm{N}_{\mathrm{t}}-\frac{\mathrm{Z}_{\mathrm{t}}}{\mathrm{DFL}_{\mathrm{t}-1}^{*}} *\left[\frac{\mathrm{K}_{\mathrm{t}-1}^{*}\left(\mathrm{~K}_{\mathrm{t}}+\mathrm{K}_{\mathrm{t}}\right)}{\mathrm{DOL}_{\mathrm{t}}^{\mathrm{a}} \mid \Delta \% \mathrm{qms}_{\mathrm{t}}}-\mathrm{ROI}_{\mathrm{t}-1} *\left(1-\alpha_{\mathrm{t}}\right)\right]=\mathrm{DFL}_{\mathrm{t}}^{\mathrm{a}+} \mid \Delta \% \mathrm{qms}_{\mathrm{t}} \\
\lim _{\Delta \% \mathrm{qms}_{\mathrm{t}} \rightarrow-\infty} \mathrm{DFL}_{\mathrm{t}}=\mathrm{N}_{\mathrm{t}}-\frac{\mathrm{Z}_{\mathrm{t}}}{\mathrm{DFL}_{\mathrm{t}-1}^{*}} *\left[\frac{\mathrm{K}_{\mathrm{t}-1}^{*} \mathrm{~K}_{\mathrm{t}}}{\mathrm{DOL}_{\mathrm{t}}^{\mathrm{a}} \mid \Delta \% \mathrm{qms}_{\mathrm{t}}}-\mathrm{ROI}_{\mathrm{t}-1} *\left(1-\alpha_{\mathrm{t}}\right)\right]=\mathrm{DFL}_{\mathrm{t}}^{\mathrm{a}-} \mid \Delta \% \mathrm{qms}_{\mathrm{t}}
\end{gathered}
$$

As already mentioned, DFL admits two asymptotes at the limits of its domain, unlike DOL.

We have to point out that $\zeta\left(\mathrm{DFL}_{\mathrm{t}} \mid \Delta \% \mathrm{qms}_{\mathrm{t}}\right)$ varies exclusively owing to the DFL imperfect axial symmetry previously defined. Furthermore, $\mathrm{K} 3_{\mathrm{t}}$ is subject to dampening due to other parameters and variables, as can be seen from the difference between equations (32) and (31):

$$
\mathrm{DFL}_{\mathrm{t}}^{\mathrm{a}-}\left|\Delta \% \mathrm{qms}_{\mathrm{t}}-\mathrm{DFL}_{\mathrm{t}}^{\mathrm{a}+}\right| \Delta \% \mathrm{qms}_{\mathrm{t}}=\frac{\mathrm{Z}_{\mathrm{t}}}{\mathrm{DFL}_{\mathrm{t}-1}{ }^{*}} * \frac{\mathrm{K}_{\mathrm{t}-1}{ }^{*} \mathrm{~K}_{\mathrm{t}}}{\operatorname{DOL}_{\mathrm{t}}^{\mathrm{a}} \mid \Delta \% \mathrm{qms}_{\mathrm{t}}}
$$

The overall result is to limit the $\zeta\left(\mathrm{DFL}_{\mathrm{t}} \mid \Delta \% \mathrm{qms}_{\mathrm{t}}\right)$ swing in a sufficiently narrow range that we can take indifferently one of the two DFL asymptotes presented with the equations (31) or (32), as a clue of the firm's risk due to DFL owed to the $\Delta \% \mathrm{qms}_{\mathrm{t}}$ uncertainty. More important $\zeta\left(\mathrm{DFL}_{\mathrm{t}} \mid \Delta \% \mathrm{qms}_{\mathrm{t}}\right)$ is mainly due to the $\mathrm{N}_{\mathrm{t}}$ variable equals to the ratio $\left[\mathrm{EBIT}_{\mathrm{t}-1} *\left(1-\alpha_{\mathrm{t}}\right) / \pi_{\mathrm{t}-1}\right.$ ], which represents the ratio between the Net Profit of the previous period with the current taxation in the absence of interest expenses or Debt and the "real" Net Profit of the same period.

What happens if the range of Revenue growth $\Delta \% \mathrm{~S}$ is only partially positive? The $\zeta\left(\mathrm{DFL}_{\mathrm{t}} \mid \Delta \% \mathrm{qms}_{\mathrm{t}}\right)$ value is the square root of equation (23) and is included within the limits of the two DFL asymptotes, reducing non-linearly to $\mathrm{DFL}_{\mathrm{t}}^{\mathrm{a}+} \mid \Delta \% \mathrm{qms}_{\mathrm{t}}$ from $\mathrm{DFL}_{\mathrm{t}}^{\mathrm{a}-} \mid \Delta \% \mathrm{qms}_{\mathrm{t}}$ as the range of Revenue growth $\Delta \% \mathrm{~S}$ volatility becomes more and more positive. The result is the following:

$$
\zeta\left(\mathrm{DFL}_{\mathrm{t}} \mid \Delta \% \mathrm{qms}_{\mathrm{t}}\right)=\left[\frac{\operatorname{Var}\left(\mathrm{N}_{\mathrm{t}} * \Delta \% \mathrm{qms}_{\mathrm{t}}-\mathrm{VVl}_{\mathrm{t}} * \mathrm{H}_{\mathrm{t}} \mid \Delta \% \mathrm{qms}_{\mathrm{t}}\right)}{\operatorname{Var}\left(\Delta \% \mathrm{qms}_{\mathrm{t}}\right)}\right]^{1 / 2}
$$


We briefly recap with Figure 3 what illustrated so far. The Figures from 3 to 8 are processed using the financial data shown in Appendix A.

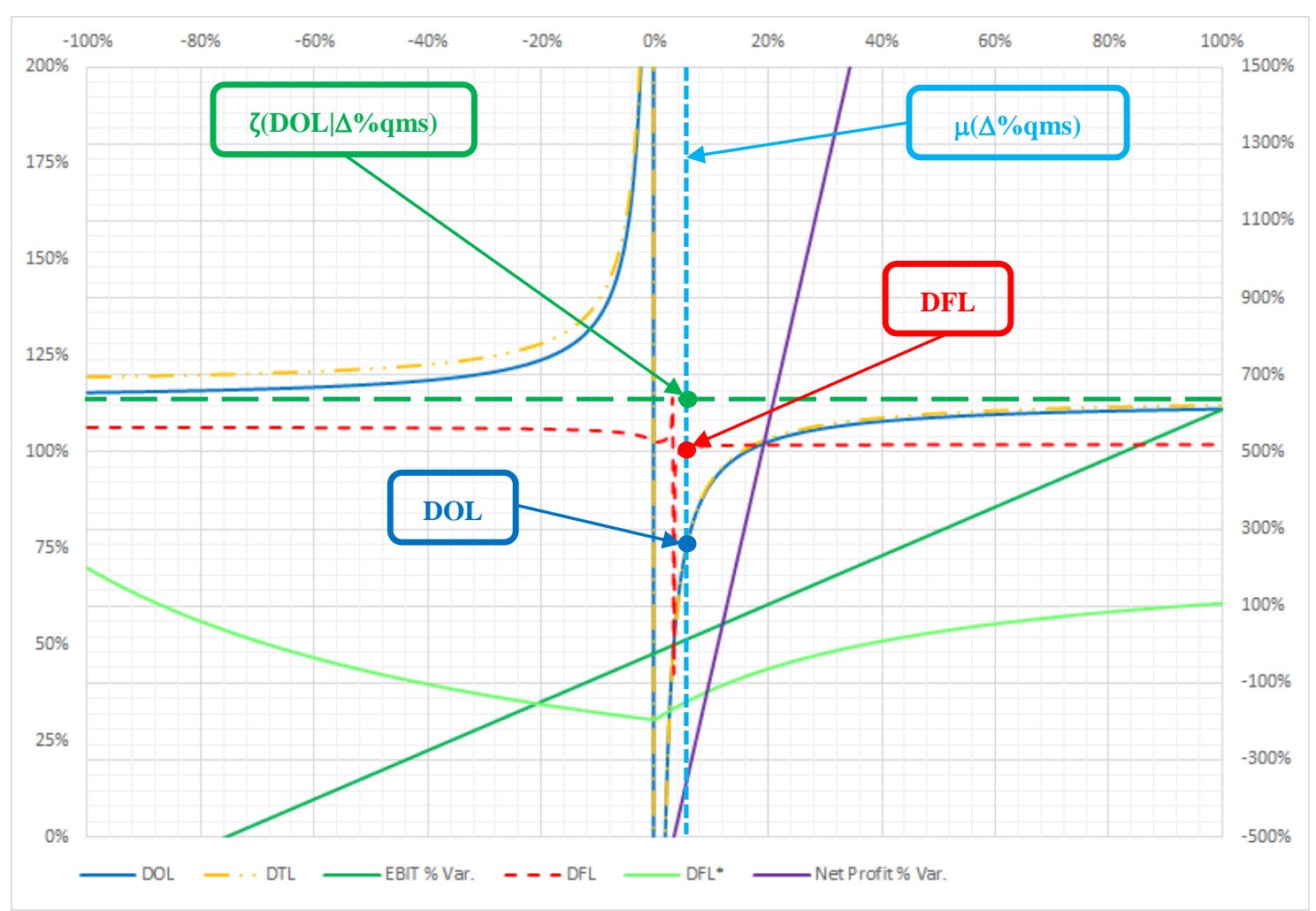

Figure 3. The trend of the variables under analysis: DOL, DTL, and $\Delta \% \mathrm{EBIT}_{\mathrm{t}}$ scale on the right, all the other variables scale on the left $\left(\Delta \% \mathrm{qms}_{\mathrm{t}}\right.$ domain between $-100 \%$ and $\left.+100 \%\right)$

The quantity/mix value $\mu\left(\Delta \% \mathrm{qms}_{\mathrm{t}}\right)$ determines the operating point on which to position the firm on the light blue vertical line. Given the DOL and DFL curves that are firm characteristics for the current period, the DOL and DFL values are at the intersections with the light blue vertical line, the blue and the red dots, respectively. The firm's risk due to DOL and DFL, determined by the $\Delta \% \mathrm{qms}_{\mathrm{t}}$ uncertainty, will not be found on such curves but their asymptotes: we have reported in Figure 3 the point of DOL, DFL and $\zeta\left(\mathrm{DOL}_{\mathrm{t}} \mid \Delta \% \mathrm{qms}_{\mathrm{t}}\right)$, the latter represented by a dashed green horizontal line.

The intersection between the light blue vertical line representing $\mu\left(\Delta \% \mathrm{qms}_{\mathrm{t}}\right)$ and the dashed green horizontal line representing $\zeta\left(\mathrm{DOL}_{\mathrm{t}} \mid \Delta \% \mathrm{qms}_{\mathrm{t}}\right)$ is the green dot representing the DOL intrinsic firm's risk, which appears higher than the DOL value on the blue dot. The same explanation holds, also for DFL, even though for overlapping reasons, $\zeta\left(\mathrm{DFL}_{\mathrm{t}} \mid \Delta \% \mathrm{qms}_{\mathrm{t}}\right)$ is not represented, which would appear indistinguishably above the DFL red dot.

The mystery becomes clear: given the quantity/mix percentage growth $\mu\left(\Delta \% \mathrm{qms}_{\mathrm{t}}\right)$, represented by the light blue vertical line, DOL and DFL values are still traceable at the interception between such DOL and DFL curves with this vertical line, but the firm's risk related to DOL and DFL will appear at the interception with their asymptotes, generating different values.

The risk rates owed to $\Delta \% \mathrm{qms}_{\mathrm{t}}$, namely $\zeta\left(\mathrm{DOL}_{\mathrm{t}} \mid \Delta \% \mathrm{qms}_{\mathrm{t}}\right)$ and $\zeta\left(\mathrm{DFL}_{\mathrm{t}} \mid \Delta \% \mathrm{qms}_{\mathrm{t}}\right)$, are firm-specific and largely independent by their value and uncertainty range. The global risk will be higher, the higher the uncertainty range will be, but its rate of change will be constant.

It is interesting to note that in quadrant I, the DOL curve is always below its asymptote; in quadrant II, it is always above. It means that DOL underrates the firm's risk deriving from the positive quantity/mix growth uncertainty, the opposite when it is negative. When we talk about risk, the worst view is the best. We recall that the shape of the DOL curve under examination typifies nil unit price and variable cost growths.

When we pass to analyse DFL, we can point out that DFL asymptotes have the task to cut the risk owing to DFL discontinuity corresponding to the point in which both DOL and $\Delta \% \mathrm{EBIT}_{\mathrm{t}}$ are nil. In such a perspective, DFL 
performs the function of the firm's risk containment. A large chunk of the $\zeta\left(\mathrm{DFL}_{t} \mid \Delta \% \mathrm{qms}_{t}\right)$ is due to the $\mathrm{N}_{t}$ variable, which, in the absence of better information, represents the approximate firm's risk due to DFL, regardless of the source of uncertainty.

\subsection{EBIT Volatility Due to Unit Price Growth Uncertainty}

We know that the Revenue growth $\Delta \% \mathrm{~S}_{\mathrm{t}}$ is ascribable to the percentage growth of the quantity/mix $\Delta \% \mathrm{qms}_{\mathrm{t}}$ and the percentage growth (or decrease) of the unit price $\Delta \% \mathrm{up}_{\mathrm{t}}$ between two periods through the following relationship:

$$
\Delta \% \mathrm{~S}_{\mathrm{t}}=\left[\left(1+\Delta \% \mathrm{qms}_{\mathrm{t}}\right) *\left(1+\Delta \% \mathrm{up}_{\mathrm{t}}\right)-1\right]
$$

How does the firm's risk due to DOL and DFL change in case of unit price growth $\Delta \% \mathrm{up}_{\mathrm{t}}$ uncertainty instead of the $\Delta \% \mathrm{qms}_{\mathrm{t}}$ one?

Assuming that $\Delta \% \mathrm{up}_{\mathrm{t}}$ has $\mu$ and $\sigma$ as mean and standard deviation, the $\Delta \% \mathrm{~S}$ volatility will be given by the following relation considering that $\Delta \% \mathrm{qms}_{\mathrm{t}}$ is not a random variable:

$$
\sigma\left(\Delta \% \mathrm{~S}_{\mathrm{t}} \mid \Delta \% \mathrm{up}_{\mathrm{t}}\right)=\left(1+\Delta \% \mathrm{qms}_{\mathrm{t}}\right) * \sigma\left(\Delta \% \mathrm{up}_{\mathrm{t}}\right)
$$

Turning to the $\Delta \% \mathrm{EBIT}_{\mathrm{t}}$ volatility, using equation (17) and assuming that the unit price growth $\Delta \% \mathrm{up}_{\mathrm{t}}$ is a variable independent by Variable and Fixed Costs, we obtain:

$$
\begin{gathered}
\operatorname{Var}\left(\Delta \% \text { EBIT }_{\mathrm{t}} \mid \Delta \% \mathrm{up}_{\mathrm{t}}\right)=\operatorname{Var}\left[\frac{\mathrm{s}_{\mathrm{t}-1}}{\mathrm{EBIT}_{\mathrm{t}-1}} *\left(\Delta \% \mathrm{~S}_{\mathrm{t}}-\frac{\mathrm{VC}_{\mathrm{t}-1}}{\mathrm{~S}_{\mathrm{t}-1}} * \Delta \% \mathrm{VC}_{\mathrm{t}}-\frac{\mathrm{FC}_{\mathrm{t}-1}}{\mathrm{~S}_{\mathrm{t}-1}} * \Delta \% \mathrm{~F}_{\mathrm{t}}\right)\right]= \\
=\operatorname{Var}\left[\frac{\mathrm{s}_{\mathrm{t}-1}}{\mathrm{EBIT}_{\mathrm{t}-1}} * \Delta \% \mathrm{~S}_{\mathrm{t}}\right]=\left(\frac{\mathrm{S}_{\mathrm{t}-1}}{\mathrm{EBIT}_{\mathrm{t}-1}}\right)^{2} * \operatorname{Var}\left(\Delta \% \mathrm{~S}_{\mathrm{t}} \mid \Delta \% \mathrm{up}_{\mathrm{t}}\right)
\end{gathered}
$$

Equation (36) gives rise to the following characteristic relationship:

$$
\zeta\left(\mathrm{DOL}_{\mathrm{t}} \mid \Delta \% \mathrm{up}_{\mathrm{t}}\right)=\frac{\sigma\left(\Delta \% \mathrm{EBIT}_{\mathrm{t}} \mid \Delta \% \mathrm{up}_{\mathrm{t}}\right)}{\sigma\left(\Delta \% \mathrm{~S}_{\mathrm{t}} \mid \Delta \% \mathrm{up}_{\mathrm{t}}\right)}=\frac{\mathrm{S}_{\mathrm{t}-1}}{\mathrm{EBIT}_{\mathrm{t}-1}}=\mathrm{PDOL}_{\mathrm{t}} * \frac{\mathrm{s}_{\mathrm{t}-1}}{\mathrm{CM}_{\mathrm{t}-1}}
$$

The DOL volatility due to $\Delta \% \mathrm{up}_{\mathrm{t}}$ does not depend on its uncertainty range but entirely on parameters set in the financial period preceding the current one and coincides with the inverse of the operating margin. The risk $\zeta\left(\mathrm{DOL}_{\mathrm{t}} \mid \Delta \% \mathrm{up}_{\mathrm{t}}\right)$ appears inversely related to the firm profitability as the lower the latter, the greater the risk deriving from the $\Delta \% \mathrm{up}_{\mathrm{t}}$ uncertainty. Furthermore, such a risk is much more important than the risk coming from the $\Delta \% \mathrm{qms}_{\mathrm{t}}$ uncertainty: with the same standard deviation, the $\Delta \% \mathrm{EBIT}_{\mathrm{t}}$ volatility is more sensitive to $\Delta \% \mathrm{up}_{\mathrm{t}}$ uncertainty than the $\Delta \% \mathrm{qms}_{\mathrm{t}}$ one, which is often overrated.

We have to point out that the value of $\Delta \% \mathrm{up}_{\mathrm{t}}$ approaching $\pm \infty$ appears impossible from the business perspective but is theoretically possible as the $\Delta \% \mathrm{qms}_{\mathrm{t}}$ tending to $\pm \infty$. What would happen to DOL in case of unit price growth $\Delta \% \mathrm{up}_{\mathrm{t}}$ approaching $\pm \infty$ ? Let us calculate the limit:

$$
\lim _{\Delta \% \mathrm{up}_{\mathrm{t}} \rightarrow \infty} \mathrm{DOL}_{\mathrm{t}}=\mathrm{PDOL}_{\mathrm{t}} * \frac{\mathrm{s}_{\mathrm{t}-1}}{\mathrm{CM}_{\mathrm{t}-1}}=\mathrm{DOL}_{\mathrm{t}}^{\mathrm{a}} \mid \Delta \% \mathrm{up}_{\mathrm{t}}=\zeta\left(\mathrm{DOL}_{\mathrm{t}} \mid \Delta \% \mathrm{up}_{\mathrm{t}}\right)
$$

Also, for the $\Delta \% \mathrm{up}_{\mathrm{t}}$ uncertainty, the risk due to DOL $\zeta\left(\mathrm{DOL}_{\mathrm{t}} \mid \Delta \% \mathrm{up}_{\mathrm{t}}\right)$ coincides with the DOL horizontal asymptote for the unit price growth $\Delta \% \mathrm{up}_{\mathrm{t}}$ approaching $\pm \infty$.

\subsection{Net Profit Volatility Due to Unit Price Growth Uncertainty}

Now we will evaluate the impact determined by $\Delta \% \mathrm{up}_{\mathrm{t}}$ uncertainty on Net Profit growth $\Delta \% \pi_{\mathrm{t}}$ and DFL ones. The starting point is the equation (21) of the Net Profit growth (or decrease) $\Delta \% \pi_{\mathrm{t}}$ to which we will apply the $\Delta \% \mathrm{up}_{\mathrm{t}}$ uncertainty, obtaining the following compact formulation:

$$
\begin{aligned}
\frac{\operatorname{Var}\left(\Delta \% \pi_{\mathrm{t}} \mid \Delta \% \mathrm{up}_{\mathrm{t}}\right)}{\operatorname{Var}\left(\Delta \% \mathrm{EBIT}_{\mathrm{t}} \mid \Delta \% \mathrm{up}_{\mathrm{t}}\right)}=\mathrm{N}_{\mathrm{t}}^{2} & +\mathrm{VV} 2_{\mathrm{t}}^{2} * \frac{\operatorname{Var}\left(\mathrm{H}_{\mathrm{t}} \mid \Delta \% \mathrm{up}_{\mathrm{t}}\right)}{\operatorname{Var}\left(\Delta \% \mathrm{up}_{\mathrm{t}}\right)}-2 * \mathrm{~N}_{\mathrm{t}} * \mathrm{VV} 2_{\mathrm{t}} * \frac{\operatorname{Cov}\left(\Delta \% \mathrm{up}_{\mathrm{t}}, \mathrm{H}_{\mathrm{t}} \mid \Delta \% \mathrm{up}_{\mathrm{t}}\right)}{\operatorname{Var}\left(\Delta \% \mathrm{up}_{\mathrm{t}}\right)}= \\
& =\frac{\operatorname{Var}\left(\mathrm{N}_{\mathrm{t}} * \Delta \% \mathrm{up}_{\mathrm{t}}-\mathrm{VVV}_{\mathrm{t}} * \mathrm{H}_{\mathrm{t}} \mid \Delta \% \mathrm{up}_{\mathrm{t}}\right)}{\operatorname{Var}\left(\Delta \% \mathrm{up}_{\mathrm{t}}\right)}
\end{aligned}
$$

where:

$$
\mathrm{VV}_{\mathrm{t}}=\frac{\mathrm{Z}_{\mathrm{t}}}{\mathrm{DFL}_{\mathrm{t}-1}^{*}} * \frac{1}{\left(1+\Delta \% \mathrm{qms}_{\mathrm{t}}\right) * \mathrm{DOL}_{\mathrm{t}}^{\mathrm{a}} \mid \Delta \% \mathrm{up}_{\mathrm{t}}}
$$

The $\mathrm{H}_{\mathrm{t}}$ volatility, which we recall indicates the Gross Debt Ratio before the impact of the interest expenses, will be evaluated on the $\Delta \% \mathrm{up}_{\mathrm{t}}$ uncertainty which in case of Revenue growth $\Delta \% \mathrm{~S}_{\mathrm{t}}$ range only negative or positive is simplifiable into the following, by considering that $\mathrm{K}_{\mathrm{t}}$ ceases to be a random variable: 


$$
\zeta\left(\mathrm{DFL}_{\mathrm{t}} \mid \Delta \% \mathrm{up}_{\mathrm{t}}\right)=\frac{\sigma\left(\Delta \% \Pi_{\mathrm{t}} \mid \Delta \% \mathrm{up}_{\mathrm{t}}\right)}{\sigma\left(\Delta \% \mathrm{EBIT}_{\mathrm{t}} \mid \Delta \% \mathrm{up}\right)}=\mathrm{N}_{\mathrm{t}}-\frac{\mathrm{Z}_{\mathrm{t}}}{\mathrm{DFL}_{\mathrm{t}-1}^{*}} *\left[\frac{\mathrm{K} 1_{\mathrm{t}-1} *\left(\mathrm{~K}_{\mathrm{t}}+\mathrm{K}_{\mathrm{t}}\right)}{\mathrm{DOL}_{\mathrm{t}}^{\mathrm{a}} \mid \Delta \% \mathrm{up}_{\mathrm{t}}}-\mathrm{ROI}_{\mathrm{t}-1} *\left(1-\alpha_{\mathrm{t}}\right)\right]
$$

Similarly to what we have already verified for the risk originated by DFL for $\Delta \% \mathrm{qms}_{\mathrm{t}}$ uncertainty, also the risk deriving from the $\Delta \% \mathrm{up}_{\mathrm{t}}$ one, in case of $\Delta \% \mathrm{~S}_{\mathrm{t}}$ volatility range only negative or positive coincides with one of the DFL horizontal asymptotes:

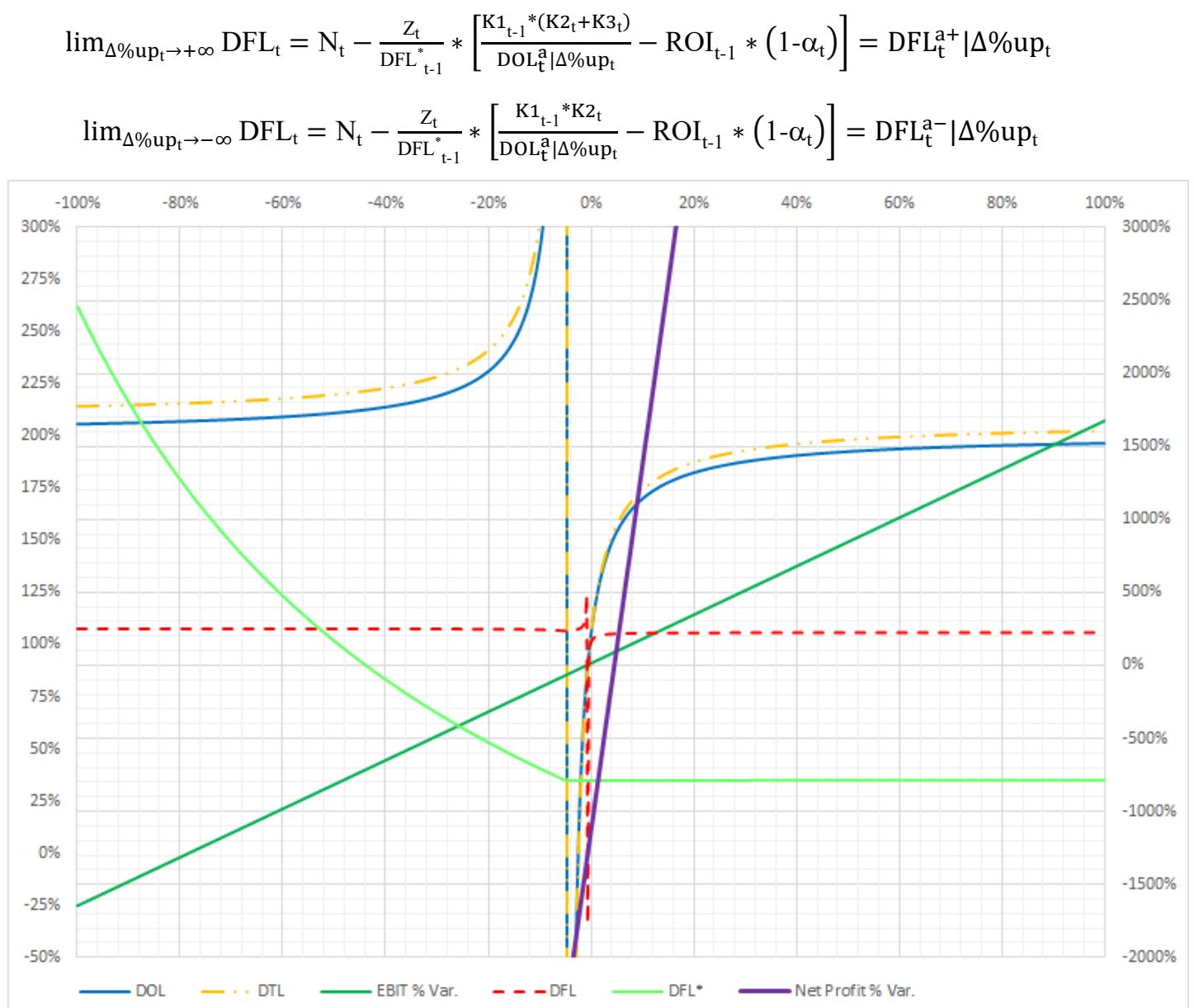

Figure 4 . The trend of the variables under analysis: DOL, DTL, and $\Delta \% \mathrm{EBIT}_{\mathrm{t}}$ scale on the right, all the other variables scale on the left $\left(\Delta \% \mathrm{up}_{\mathrm{t}}\right.$ domain between $-100 \%$ and $\left.+100 \%\right)$

What happens if the volatility range $\Delta \% \mathrm{~S}_{\mathrm{t}}$ is only partially positive? The value of $\zeta\left(\mathrm{DFL}_{\mathrm{t}} \mid \Delta \% \mathrm{up}_{\mathrm{t}}\right)$ is the square root of equation (38) and is included within the limits of the two DFL asymptotes, reducing non-linearly to $\mathrm{DFL}_{\mathrm{t}}^{\mathrm{a}+} \mid \Delta \% \mathrm{up}_{\mathrm{t}}$ from $\mathrm{DFL}_{\mathrm{t}}^{\mathrm{a}-} \mid \Delta \% \mathrm{up}_{\mathrm{t}}$ as the range of Revenue growth $\Delta \% \mathrm{~S}$ volatility becomes more and more positive. The result is the following:

$$
\zeta\left(\mathrm{DFL}_{\mathrm{t}} \mid \Delta \% \mathrm{up}_{\mathrm{t}}\right)=\left[\frac{\operatorname{Var}\left(\mathrm{N}_{\mathrm{t}} * \Delta \mathrm{up}_{\mathrm{t}}-\mathrm{VV}_{\mathrm{t}} * \mathrm{H}_{\mathrm{t}} \mid \Delta \% \mathrm{up}_{\mathrm{t}}\right)}{\operatorname{Var}\left(\Delta \% \mathrm{up}_{\mathrm{t}}\right)}\right]^{1 / 2}
$$

We have to point out that $\zeta\left(\mathrm{DFL}_{\mathrm{t}} \mid \Delta \% \mathrm{up}_{\mathrm{t}}\right)$ varies exclusively owing to the DFL imperfect axial symmetry previously defined. Furthermore, $\mathrm{K}_{\mathrm{t}}$ is subject to dampening due to other parameters and variables, as can be seen from the difference between equations (42) and (41):

$$
\mathrm{DFL}_{\mathrm{t}}^{\mathrm{a}-}\left|\Delta \% \mathrm{up}_{\mathrm{t}}-\mathrm{DFL}_{\mathrm{t}}^{\mathrm{a}+}\right| \Delta \% \mathrm{up}_{\mathrm{t}}=\frac{\mathrm{Z}_{\mathrm{t}}}{\mathrm{DFL}_{\mathrm{t}-1}^{*}} * \frac{\mathrm{K}_{\mathrm{t}-1}{ }^{*} \mathrm{~K}_{\mathrm{t}}}{\mathrm{DOL}_{\mathrm{t}}^{\mathrm{a}} \mid \Delta \% \mathrm{up}_{\mathrm{t}}}
$$

The overall result is to limit the $\zeta\left(\mathrm{DFL}_{\mathrm{t}} \mid \Delta \% \mathrm{up}_{\mathrm{t}}\right)$ swing in a sufficiently narrow range that it can be a clue of the firm's risk determined by the $\Delta \% \mathrm{up}_{\mathrm{t}}$ uncertainty on DFL, indifferently one of the two DFL asymptotes presented with the equations (41) or (42).

We briefly summarise with Figure 4 what illustrated so far. The unit price value $\mu\left(\Delta \% \mathrm{up}_{t}\right)$ determines the operating point on which to position the firm. Given the DOL and DFL curves that are firm characteristics for 
the current period, the DOL and DFL values are readily determinable on the ordinate in correspondence with the abscissa value $\mu\left(\Delta \% \mathrm{up}_{\mathrm{t}}\right)$. The firm's risk due to DOL and DFL owed to the $\Delta \% \mathrm{up}_{\mathrm{t}}$ uncertainty will not be on such curves but their asymptotes.

\subsection{EBIT Volatility Due to Unit Variable Cost Uncertainty}

We know that the Variable Costs growth $\Delta \% \mathrm{VC}_{\mathrm{t}}$ is ascribable both to the percentage growth of the quantity/mix $\Delta \% \mathrm{qmvc}_{\mathrm{t}}$ and the percentage growth (or decrease) of the unit variable cost $\Delta \% \mathrm{uvc}_{\mathrm{t}}$ between two periods through the following relationship:

$$
\Delta \% \mathrm{VC}_{\mathrm{t}}=\left[\left(1+\Delta \% \mathrm{qms}_{\mathrm{t}}-\varepsilon_{\mathrm{t}}\right) *\left(1+\Delta \% \mathrm{uvc}_{\mathrm{t}}\right)-1\right]
$$

How does the firm's risk due to the DOL and DFL change before $\Delta \% \mathrm{uvc}_{\mathrm{t}}$ uncertainty?

Assuming that $\Delta \% \mathrm{uvc}_{\mathrm{t}}$ has $\mu$ and $\sigma$ as mean and standard deviation, the $\Delta \% \mathrm{VC}_{\mathrm{t}}$ volatility will be given by the following relation assuming that $\Delta \% \mathrm{qms}_{\mathrm{t}}$ is not a random variable and $\varepsilon_{\mathrm{t}}$ is nil:

$$
\sigma\left(\Delta \% \mathrm{VC}_{\mathrm{t}} \mid \Delta \% \mathrm{uvc}_{\mathrm{t}}\right)=\left(1+\Delta \% \mathrm{qms}_{\mathrm{t}}\right) * \sigma\left(\Delta \% \mathrm{uvc}_{\mathrm{t}}\right)
$$

Turning to the $\Delta \% \mathrm{EBIT}_{\mathrm{t}}$ volatility, using equation (17) and assuming that the unit variable cost growth $\Delta \% \mathrm{uvc}_{\mathrm{t}}$ is a variable independent by Revenue and Fixed Costs, we obtain:

$$
\begin{gathered}
\operatorname{Var}\left(\Delta \% \operatorname{EBIT}_{\mathrm{t}} \mid \Delta \% \mathrm{uvc}_{\mathrm{t}}\right)=\operatorname{Var}\left[\frac{\mathrm{S}_{\mathrm{t}-1}}{\mathrm{EBIT}_{\mathrm{t}-1}} *\left(\Delta \% \mathrm{~S}_{\mathrm{t}}-\frac{\mathrm{vC}_{\mathrm{t}-1}}{\mathrm{~S}_{\mathrm{t}-1}} * \Delta \% \mathrm{VC}_{\mathrm{t}}-\frac{\mathrm{FC}_{\mathrm{t}-1}}{\mathrm{~S}_{\mathrm{t}-1}} * \Delta \% \mathrm{~F}_{\mathrm{t}}\right)\right]= \\
=\left[-\frac{\mathrm{vC}_{\mathrm{t}-1}}{\mathrm{EBIT}_{\mathrm{t}-1}}\left(1+\Delta \% \mathrm{qms}_{\mathrm{t}}\right)\right]^{2} * \operatorname{Var}\left(\Delta \% \mathrm{uvc}_{\mathrm{t}}\right)
\end{gathered}
$$

Unlike the Revenue percentage growth $\Delta \% \mathrm{~S}_{\mathrm{t}}$ and its volatility, the Variable Costs growth $\Delta \% \mathrm{VC}_{\mathrm{t}}$ and its volatility induced by $\Delta \% \mathrm{uvc}_{\mathrm{t}}$ affect only the DOL numerator; consequently, the $\Delta \% \mathrm{uvc}_{\mathrm{t}}$ uncertainty does not generate any volatility on the DOL denominator, so it will not be possible to determine the impact on the DOL volatility.

Unlike $\Delta \% \mathrm{qms}_{\mathrm{t}}$ and $\Delta \% \mathrm{up}_{\mathrm{t}}$, which generate DOL horizontal asymptotes for their values approaching $\pm \infty$, a similar $\Delta \% \mathrm{uvc}_{\mathrm{t}}$ trend causes a DOL negatively sloped with an oblique asymptote since:

$$
\lim _{\Delta \% \mathrm{uvc}_{\mathrm{t}} \rightarrow+\infty} \mathrm{DOL}_{\mathrm{t}}=-\infty
$$

It is necessary to solve the following limit to verify whether the DOL oblique asymptote exists and determine its slope:

$$
\lim _{\Delta \% \mathrm{uvc}_{\mathrm{t}} \rightarrow+\infty} \frac{\mathrm{DOL}_{\mathrm{t}}}{\Delta \% \mathrm{uvc}_{\mathrm{t}}}=-\frac{\mathrm{vc}_{\mathrm{t}-1}}{\mathrm{EBIT}_{\mathrm{t}-1}} * \frac{1+\Delta \% \mathrm{qms}_{\mathrm{t}}}{\Delta \% \mathrm{~S}_{\mathrm{t}}}
$$

With this result, we can calculate the intercept:

$$
\lim _{\Delta \% \mathrm{uvc}_{\mathrm{t}} \rightarrow+\infty}\left[\mathrm{DOL}_{\mathrm{t}}-\left(-\frac{\mathrm{vc}_{\mathrm{t}-1}}{\mathrm{EBIT}_{\mathrm{t}-1}} * \frac{1+\Delta \% \mathrm{qms}_{\mathrm{t}}}{\Delta \% \mathrm{~S}_{\mathrm{t}}} * \Delta \% \mathrm{uvc}_{\mathrm{t}}\right)\right]=\mathrm{PDOL}_{\mathrm{t}} *\left(\frac{\mathrm{s}_{\mathrm{t}-1}}{\mathrm{CM}_{\mathrm{t}-1}}-\frac{\mathrm{vc}_{\mathrm{t}-1} * \Delta \% \mathrm{qms}_{\mathrm{t}}+\mathrm{FC}_{\mathrm{t}-1} * \Delta \% \mathrm{~F}_{\mathrm{t}}}{\mathrm{CM}_{\mathrm{t}-1} * \Delta \% \mathrm{~S}_{\mathrm{t}}}\right)
$$

Consequently, the DOL oblique asymptote generated by $\Delta \% \mathrm{uvc}_{\mathrm{t}}$ will have the following equation corresponding to the DOL function, being a linear relationship with $\Delta \% \mathrm{uvc}_{\mathrm{t}}$ :

$$
\mathrm{DOL}_{\mathrm{t}}^{\mathrm{a}} \mid \Delta \% \mathrm{uvc}_{\mathrm{t}}=\mathrm{PDOL}_{\mathrm{t}} *\left(\frac{\mathrm{S}_{\mathrm{t}-1}}{\mathrm{CM}_{\mathrm{t}-1}}-\frac{\mathrm{VC}_{\mathrm{t}-1} * \Delta \% \mathrm{qms}_{\mathrm{t}}+\mathrm{FC}_{\mathrm{t}-1} * \Delta \% \mathrm{~F}_{\mathrm{t}}}{\mathrm{CM}_{\mathrm{t}-1} * \Delta \% \mathrm{~S}_{\mathrm{t}}}\right)-\frac{\mathrm{VC}_{\mathrm{t}-1}}{\mathrm{EBIT}_{\mathrm{t}-1}} * \frac{1+\Delta \% \mathrm{qms}_{\mathrm{t}}}{\Delta \% \mathrm{~S}_{\mathrm{t}}} * \Delta \% \mathrm{uvc}_{\mathrm{t}}
$$

Nevertheless, if we would indicate the firm's risk due to the $\Delta \%$ EBIT volatility owed to the unit variable cost growth $\Delta \% \mathrm{uvc}_{\mathrm{t}}$, we should use the following ratios, preserving the negative sign coming from (46):

$$
\begin{gathered}
\frac{\sigma\left(\Delta \% \mathrm{EBIT}_{\mathrm{t}} \mid \Delta \% \mathrm{uvc}_{\mathrm{t}}\right)}{\sigma\left(\Delta \% \mathrm{VC}_{\mathrm{t}} \mid \Delta \% \mathrm{uvc}_{\mathrm{t}}\right)}=-\frac{\mathrm{vc}_{\mathrm{t}-1}}{\mathrm{EBIT}_{\mathrm{t}-1}} \\
\frac{\sigma\left(\Delta \% \mathrm{EBIT}_{\mathrm{t}} \mid \Delta \% \mathrm{uvc}_{\mathrm{t}}\right)}{\sigma\left(\Delta \% \mathrm{uvc}_{\mathrm{t}}\right)}=-\frac{\mathrm{vC}_{\mathrm{t}-1}}{\mathrm{EBIT}_{\mathrm{t}-1}} *\left(1+\Delta \% \mathrm{qms}_{\mathrm{t}}\right)
\end{gathered}
$$

The negative sign depends on the inverse relationship between EBIT and Variable Costs: when the latter increase, the former shrinks and vice-versa.

Also, the $\Delta \%$ EBIT $_{\mathrm{t}}$ volatility induced by the uncertainty of the unit variable cost growth $\Delta \% \mathrm{uvc}_{\mathrm{t}}$ takes on a significant meaning, helping to raise the overall firm's risk. Such volatility depends exclusively on the parameters of the previous period, as in (51), multiplied by the quantity/mix Revenue percentage growth $\Delta \% \mathrm{qms}_{\mathrm{t}}$ induced in the current period, as in (52). Also, in the case under analysis, the impact of the $\Delta \% \mathrm{uvc}_{\mathrm{t}}$ uncertainty is higher the lower the firm percentage profitability occurred in the previous period and the greater the growth in the current period. 


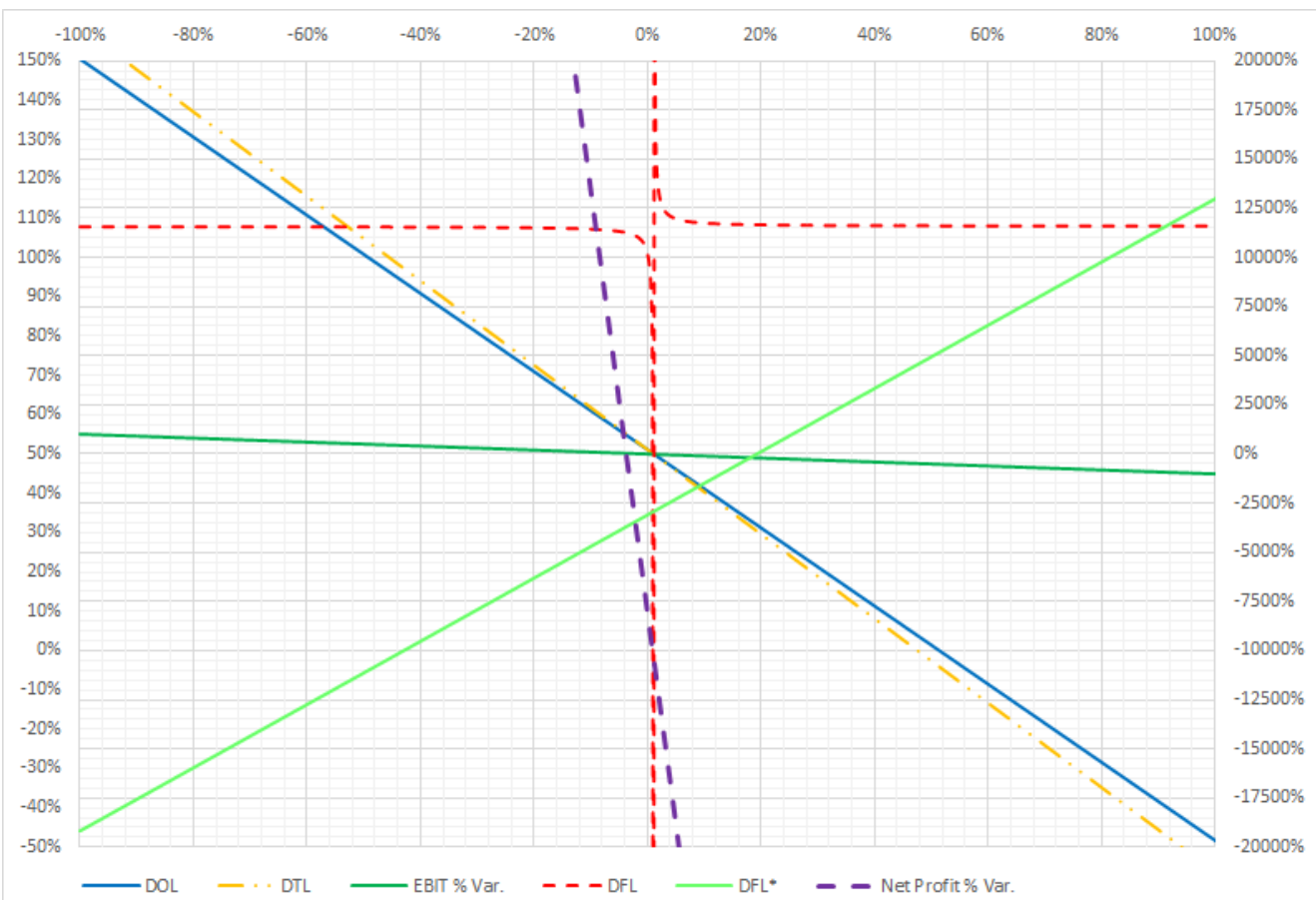

Figure 5. The trend of the variables under analysis: DOL, DTL, $\Delta \% \mathrm{EBIT}_{\mathrm{t}}$ scale on the right, all the other variables scale on the left $\left(\Delta \% \mathrm{uvc}_{\mathrm{t}}\right.$ domain between $-100 \%$ and $\left.+100 \%\right)$

\subsection{Net Profit Volatility Due to Unit Variable Cost Uncertainty}

Let us move on to evaluate the impact determined by $\Delta \% \mathrm{uvc}_{\mathrm{t}}$ uncertainty on Net Profit growth $\Delta \% \pi_{\mathrm{t}}$ and DFLvolatility. The starting point is the equation (21) of the Net Profit growth (or decrease) $\Delta \% \pi_{\mathrm{t}}$ to which we will apply the $\Delta \% \mathrm{uvc}_{\mathrm{t}}$ uncertainty, obtaining the following compact formulation:

$$
\begin{gathered}
\frac{\operatorname{Var}\left(\Delta \% \pi_{\mathrm{t}} \mid \Delta \% \mathrm{uvc}_{\mathrm{t}}\right)}{\operatorname{Var}\left(\Delta \% \mathrm{EBIT}_{\mathrm{t}} \mid \Delta \% \mathrm{uvc}_{\mathrm{t}}\right)}=\mathrm{N}_{\mathrm{t}}{ }^{2}+\mathrm{VV} 3_{\mathrm{t}}{ }^{2} * \frac{\operatorname{Var}\left(\mathrm{H}_{\mathrm{t}} \mid \Delta \% \mathrm{uvc}_{\mathrm{t}}\right)}{\operatorname{Var}\left(\Delta \% \mathrm{uvc}_{\mathrm{t}}\right)}+2 * \mathrm{~N}_{\mathrm{t}} * \mathrm{VV} 3_{\mathrm{t}} * \frac{\operatorname{Cov}\left(\Delta \% \mathrm{uvc}_{\mathrm{t}}, \mathrm{H}_{\mathrm{t}} \mid \Delta \% \mathrm{uvc}_{\mathrm{t}}\right)}{\operatorname{Var}\left(\Delta \% \mathrm{uvc}_{\mathrm{t}}\right)}= \\
=\frac{\operatorname{Var}\left(\mathrm{N}_{\mathrm{t}} * \Delta \% \mathrm{uvc}_{\mathrm{t}}+\mathrm{VV}_{\mathrm{t}_{\mathrm{t}}} * \mathrm{H}_{\mathrm{t}} \mid \Delta \% \mathrm{uvc}_{\mathrm{t}}\right)}{\operatorname{Var}\left(\Delta \% \mathrm{uvc}_{\mathrm{t}}\right)}
\end{gathered}
$$

where:

$$
\mathrm{VV}_{\mathrm{t}}=\frac{\mathrm{Z}_{\mathrm{t}}}{\mathrm{DFL}_{\mathrm{t}-1}^{*}} * \frac{1}{\frac{\mathrm{VC}_{\mathrm{t}-1}}{\mathrm{EBIT}_{\mathrm{t}-1}} *\left(1+\Delta \% \mathrm{qms}_{\mathrm{t}}\right)}
$$

The $\mathrm{H}_{\mathrm{t}}$ volatility, which we recall indicates the Gross Debt Ratio before the impact of the interest expenses, will not be assessed on the Revenue growth $\Delta \% \mathrm{~S}_{\mathrm{t}}$ volatility, which in this paragraph cease to be a random variable. Therefore (53) can be simplified in the following form:

$$
\frac{\operatorname{Var}\left(\Delta \% \pi_{\mathrm{t}} \mid \Delta \% \mathrm{uvc}_{\mathrm{t}}\right)}{\operatorname{Var}\left(\Delta \% \mathrm{EBIT}_{\mathrm{t}} \mid \Delta \% \mathrm{uvc}_{\mathrm{t}}\right)}=\left[\mathrm{N}_{\mathrm{t}}+\frac{\mathrm{Z}_{\mathrm{t}}}{\operatorname{DFL}_{\mathrm{t}-1}^{*}} * \mathrm{ROI}_{\mathrm{t}-1} *\left(1-\alpha_{\mathrm{t}}\right)\right]^{2}
$$

From (53 bis), we can derive the firm's risk due to DFL owed to the $\Delta \% \mathrm{uvc}_{\mathrm{t}}$ uncertainty:

$$
\zeta\left(\mathrm{DFL}_{\mathrm{t}} \mid \Delta \% \mathrm{uvc}_{\mathrm{t}}\right)=\frac{\sigma\left(\Delta \% \pi_{\mathrm{t}} \mid \Delta \% \mathrm{uvc}_{\mathrm{t}}\right)}{\sigma\left(\Delta \% \mathrm{EBIT}_{\mathrm{t}} \mid \Delta \% \mathrm{uvc}_{\mathrm{t}}\right)}=\mathrm{N}_{\mathrm{t}}+\frac{\mathrm{Z}_{\mathrm{t}}}{\mathrm{DFL}_{\mathrm{t}-1}^{*}} * \mathrm{ROI}_{\mathrm{t}-1} *\left(1-\alpha_{\mathrm{t}}\right)
$$

that is independent of any $\Delta \% \mathrm{uvc}_{\mathrm{t}}$ chosen range; it mainly depends on the parameters of the previous period, except for the Cost of Debt $i_{t}$ and the Tax Rate $\alpha_{t}$ and their trends encapsulated in the variables $N_{t}$ and $Z_{t}$ or directly in (55).

Similarly to what we have already verified for the firm's risk due to DFL owed to the $\Delta \% \mathrm{qms}_{\mathrm{t}}$ and $\Delta \% \mathrm{up}_{\mathrm{t}}$ uncertainty, the risk deriving from $\Delta \% \mathrm{uvc}_{\mathrm{t}}$ uncertainty coincides with the following DFL horizontal asymptote:

$$
\lim _{\Delta \% \mathrm{uvc}_{\mathrm{t}} \rightarrow \infty} \mathrm{DFL}_{\mathrm{t}}=\mathrm{N}_{\mathrm{t}}-\left[-\frac{\mathrm{z}_{\mathrm{t}}}{\mathrm{DFL}_{\mathrm{t}-1}^{*}} * \mathrm{ROI}_{\mathrm{t}-1} *\left(1-\alpha_{\mathrm{t}}\right)\right]=\mathrm{DFL}_{\mathrm{t}}^{\mathrm{a}} \mid \Delta \% \mathrm{uvc}_{\mathrm{t}}
$$

From equations (55) and (56), we obtain the generic formulation of the firm's risk due to DFL owed to the $\Delta \% \mathrm{uvc}_{\mathrm{t}}$ uncertainty: 


$$
\zeta\left(\mathrm{DFL}_{\mathrm{t}} \mid \Delta \% \mathrm{uvc}_{\mathrm{t}}\right)=\frac{\sigma\left(\Delta \% \pi_{\mathrm{t}} \mid \Delta \% \mathrm{uvc}_{\mathrm{t}}\right)}{\sigma\left(\Delta \% \mathrm{EBIT}_{\mathrm{t}} \mid \Delta \% \mathrm{uvc}_{\mathrm{t}}\right)}=\mathrm{N}_{\mathrm{t}}+\frac{\mathrm{Z}_{\mathrm{t}}}{\mathrm{DFL}_{\mathrm{t}-1}^{*}} * \mathrm{ROI}_{\mathrm{t}-1} *\left(1-\alpha_{\mathrm{t}}\right)=\mathrm{DFL}_{\mathrm{t}}^{\mathrm{a}} \mid \Delta \% \mathrm{uvc}_{\mathrm{t}}
$$

We briefly recap with Figure 5 what illustrated so far. First of all, we point out that the DOL is a negative straight line of which we have already determined its equation through the (50). It is necessary to calculate the unit variable cost mean $\mu\left(\Delta \% \mathrm{uvc}_{\mathrm{t}}\right)$ to determine the point at which the firm operates. Given the DOL and DFL curves that are firm characteristics for the current period, the DOL and DFL values are readily determinable on the ordinate in correspondence with the abscissa value $\mu\left(\Delta \% \mathrm{uvc}_{\mathrm{t}}\right)$. The firm's risk due to DFL, coming from the

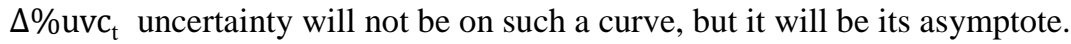

\subsection{EBIT Volatility Due to Fixed Costs Growth Uncertainty}

The Fixed Costs growth $\Delta \% \mathrm{~F}_{\mathrm{t}}$ uncertainty depends directly, without further decomposition, on such a variable, to be considered random in the present and the following paragraph.

The $\Delta \%$ EBIT volatility, using equation (17) and assuming that Fixed Costs are independent of Revenue and Variable Costs, is as follows:

$$
\operatorname{Var}\left(\Delta \% \mathrm{EBIT}_{\mathrm{t}} \mid \Delta \% \mathrm{~F}_{\mathrm{t}}\right)=\operatorname{Var}\left[\frac{\mathrm{s}_{\mathrm{t}-1}}{\mathrm{EBIT}_{\mathrm{t}-1}} *\left(\Delta \% \mathrm{~S}_{\mathrm{t}}-\frac{\mathrm{VC}_{\mathrm{t}-1}}{\mathrm{~S}_{\mathrm{t}-1}} * \Delta \% \mathrm{VC}_{\mathrm{t}}-\frac{\mathrm{FC}_{\mathrm{t}-1}}{\mathrm{~S}_{\mathrm{t}-1}} * \Delta \% \mathrm{~F}_{\mathrm{t}}\right)\right]=\left[-\frac{\mathrm{FC}_{\mathrm{t}-1}}{\mathrm{EBIT}_{\mathrm{t}-1}}\right]^{2} * \operatorname{Var}\left(\Delta \% \mathrm{~F}_{\mathrm{t}}\right)
$$

Unlike the Revenue percentage growth $\Delta \% \mathrm{~S}_{\mathrm{t}}$ and its volatility, the Fixed Costs percentage growth $\Delta \% \mathrm{~F}_{\mathrm{t}}$ affects only the DOL numerator; consequently, the $\Delta \% \mathrm{~F}_{\mathrm{t}}$ uncertainty does not generate any volatility on the DOL denominator; so, it will not be possible to determine the impact on the DOL volatility. Like $\Delta \% \mathrm{uvc}_{\mathrm{t}}$, also $\Delta \% \mathrm{~F}$ generates a negatively sloped $\mathrm{DOL}$ with an oblique asymptote for values approaching $\pm \infty$, since:

$$
\lim _{\Delta \% \mathrm{~F}_{\mathrm{t}} \rightarrow+\infty} \mathrm{DOL}_{\mathrm{t}}=-\infty
$$

It is necessary to solve the following limit to verify whether the DOL oblique asymptote exists and determine its slope:

$$
\lim _{\Delta \% \mathrm{~F}_{\mathrm{t}} \rightarrow+\infty} \frac{\mathrm{DOL}_{\mathrm{t}}}{\Delta \% \mathrm{~F}_{\mathrm{t}}}=-\frac{\mathrm{FC}_{\mathrm{t}-1}}{\mathrm{EBIT}_{\mathrm{t}-1}} * \frac{1}{\Delta \% \mathrm{~S}_{\mathrm{t}}}
$$

With this result, we can calculate the intercept:

$$
\lim _{\Delta \% \mathrm{~F}_{\mathrm{t}} \rightarrow+\infty}\left[\mathrm{DOL}_{\mathrm{t}}-\left(-\frac{\mathrm{FC}_{\mathrm{t}-1}}{\mathrm{EBIT}_{\mathrm{t}-1}} * \frac{1}{\Delta \% \mathrm{~S}_{\mathrm{t}}} * \Delta \% \mathrm{~F}_{\mathrm{t}}\right)\right]=\mathrm{PDOL}_{\mathrm{t}} *\left(\frac{\mathrm{s}_{\mathrm{t}-1}}{\mathrm{CM}_{\mathrm{t}-1}}-\frac{\mathrm{VC}_{\mathrm{t}-1} * \Delta \% \mathrm{VC}_{\mathrm{t}}}{\mathrm{CM}_{\mathrm{t}-1} * \Delta \% \mathrm{~S}_{\mathrm{t}}}\right)
$$

Consequently, the DOL oblique asymptote generated by $\Delta \% \mathrm{~F}_{\mathrm{t}}$ will have the following equation that corresponds to the DOL function, being a linear relationship with $\Delta \% \mathrm{~F}_{\mathrm{t}}$ :

$$
\mathrm{DOL}_{\mathrm{t}}^{\mathrm{a}} \mid \Delta \% \mathrm{~F}_{\mathrm{t}}=\mathrm{PDOL}_{\mathrm{t}} *\left(\frac{\mathrm{S}_{\mathrm{t}-1}}{\mathrm{CM}_{\mathrm{t}-1}}-\frac{\mathrm{VC}_{\mathrm{t}-1} * \Delta \% \mathrm{VC}_{\mathrm{t}}}{\mathrm{CM}_{\mathrm{t}-1} * \Delta \% \mathrm{~S}_{\mathrm{t}}}\right)-\frac{\mathrm{FC}_{\mathrm{t}-1}}{\mathrm{EBIT}_{\mathrm{t}-1}} * \frac{1}{\Delta \% \mathrm{~S}_{\mathrm{t}}} * \Delta \% \mathrm{~F}_{\mathrm{t}}
$$

However, if we would indicate the firm's risk due to the $\Delta \%$ EBIT volatility caused by the Fixed Costs uncertainty, the following ratio should be used, preserving the negative sign coming from (57):

$$
\frac{\sigma\left(\Delta \% \text { EBIT }_{t} \mid \Delta \% \mathrm{~F}_{\mathrm{t}}\right)}{\sigma\left(\Delta \% \mathrm{~F}_{\mathrm{t}}\right)}=-\frac{\mathrm{FC}_{\mathrm{t}-1}}{\mathrm{EBIT}_{\mathrm{t}-1}}
$$

The negative sign depends on the inverse relationship between EBIT and Fixed Costs: when the latter increase, the former shrinks and vice-versa.

Also, the $\Delta \% \mathrm{EBIT}_{\mathrm{t}}$ volatility induced by the $\Delta \% \mathrm{~F}_{\mathrm{t}}$ uncertainty takes on a significant meaning because it raises the overall firm's risk. Such volatility depends exclusively on the parameters of the previous period as in (62). The lower the percentage profitability occurred in the previous period, the higher the impact of the $\Delta \% \mathrm{~F}_{\mathrm{t}}$ uncertainty will be.

\subsection{Net Profit Volatility Due to Fixed Costs Growth Uncertainty}

Let us move on to evaluate the impact determined by $\Delta \% \mathrm{~F}_{\mathrm{t}}$ uncertainty on the Net Profit growth $\Delta \% \pi_{\mathrm{t}}$ and DFL volatility. The starting point is the equation (21) of the Net Profit growth (or decrease) $\Delta \% \pi_{\mathrm{t}}$ to which we will apply the $\Delta \% \mathrm{~F}_{\mathrm{t}}$ uncertainty, obtaining the following compact formulation:

$$
\frac{\operatorname{Var}\left(\Delta \% \pi_{\mathrm{t}} \mid \Delta \% \mathrm{~F}_{\mathrm{t}}\right)}{\operatorname{Var}\left(\Delta \% \mathrm{EBIT}_{\mathrm{t}} \mid \Delta \mathrm{F}_{\mathrm{t}}\right)}=\mathrm{N}_{\mathrm{t}}^{2}+\mathrm{VV}_{\mathrm{t}}^{2} * \frac{\operatorname{Var}\left(\mathrm{H}_{\mathrm{t}} \mid \Delta \% \mathrm{~F}_{\mathrm{t}}\right)}{\operatorname{Var}\left(\Delta \% \mathrm{~F}_{\mathrm{t}}\right)}+2 * \mathrm{~N}_{\mathrm{t}} * \operatorname{VV} 4_{\mathrm{t}} * \frac{\operatorname{Cov}\left(\Delta \% \mathrm{~F}_{\mathrm{t}}, \mathrm{H}_{\mathrm{t}} \mid \Delta \% \mathrm{~F}_{\mathrm{t}}\right)}{\operatorname{Var}\left(\Delta \% \mathrm{~F}_{\mathrm{t}}\right)}=\frac{\operatorname{Var}\left(\mathrm{N}_{\mathrm{t}} * \Delta \% \mathrm{~F}_{\mathrm{t}}+\mathrm{VV}_{\mathrm{t}} * \mathrm{H}_{\mathrm{t}} \mid \Delta \% \mathrm{~F}_{\mathrm{t}}\right)}{\operatorname{Var}\left(\Delta \% \mathrm{~F}_{\mathrm{t}}\right)}
$$

where:

$$
\mathrm{VV}_{\mathrm{t}}=\frac{\mathrm{Z}_{\mathrm{t}}}{\mathrm{DFL}_{\mathrm{t}-1}^{*}} * \frac{1}{\frac{\mathrm{FC}_{\mathrm{t}-1}}{\mathrm{EBIT}_{\mathrm{t}-1}}}
$$


The $\mathrm{H}_{\mathrm{t}}$ volatility, which we recall indicates the Gross Debt Ratio before the impact of the interest expenses, will not be assessed on the Revenue growth $\Delta \% \mathrm{~S}_{\mathrm{t}}$ volatility, which in this paragraph cease to be a random variable. Therefore (63) can be simplified in the following form, just we did in equation (53 bis) for the DFL volatility induced by the $\Delta \% \mathrm{uvc}_{\mathrm{t}}$ uncertainty:

$$
\frac{\operatorname{Var}\left(\Delta \% \pi_{\mathrm{t}} \mid \Delta \% \mathrm{~F}_{\mathrm{t}}\right)}{\operatorname{Var}\left(\Delta \% \mathrm{EBIT}_{\mathrm{t}} \mid \Delta \% \mathrm{~F}_{\mathrm{t}}\right)}=\left[\mathrm{N}_{\mathrm{t}}+\frac{\mathrm{Z}_{\mathrm{t}}}{\operatorname{DFL}_{\mathrm{t}-1}^{*}} * \mathrm{ROI}_{\mathrm{t}-1} *\left(1-\alpha_{\mathrm{t}}\right)\right]^{2}
$$

From (63 bis), we can derive the firm's risk due to DFL owed to the $\Delta \% \mathrm{~F}_{\mathrm{t}}$ uncertainty:

$$
\zeta\left(\mathrm{DFL}_{\mathrm{t}} \mid \Delta \% \mathrm{~F}_{\mathrm{t}}\right)=\frac{\sigma\left(\Delta \% \pi_{\mathrm{t}} \mid \Delta \% \mathrm{~F}_{\mathrm{t}}\right)}{\sigma\left(\Delta \% \mathrm{EBIT}_{\mathrm{t}} \mid \Delta \mathrm{F}_{\mathrm{t}}\right)}=\mathrm{N}_{\mathrm{t}}+\frac{\mathrm{Z}_{\mathrm{t}}}{\mathrm{DFL}_{\mathrm{t}-1}^{*}} * \mathrm{ROI}_{\mathrm{t}-1} *\left(1-\alpha_{\mathrm{t}}\right)
$$

Such a result is independent of any chosen range of $\Delta \% \mathrm{~F}_{t}$; it mainly depends on the parameters of the previous period, except for the Cost of Debt $i_{t}$ and the Tax Rate $\alpha_{t}$ and their trends encapsulated in the variables $N_{t}$ and $Z_{t}$ or directly in (65).

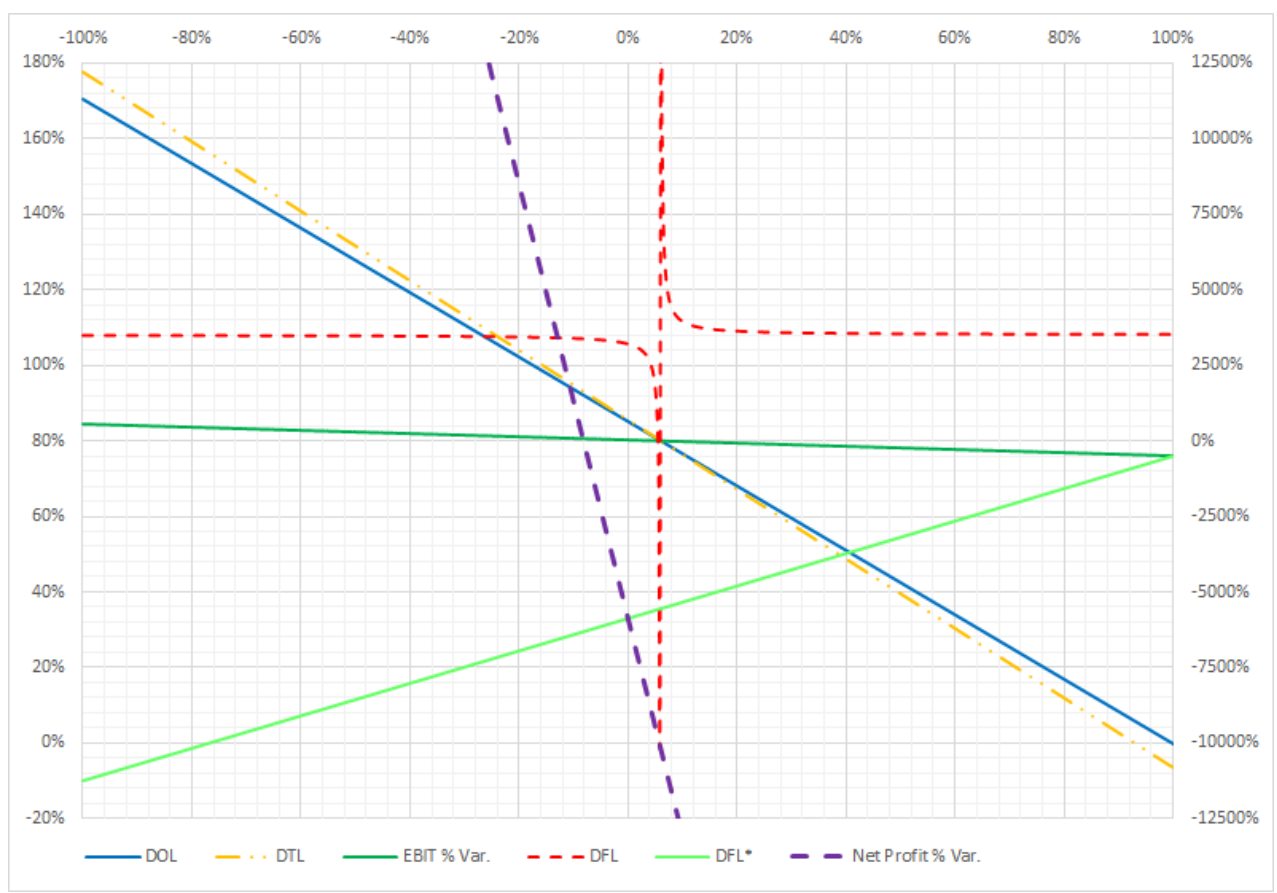

Figure 6. The trend of the variables under analysis: DOL, DTL, $\Delta \% \mathrm{EBIT}_{\mathrm{t}}$ scale on the right, all the other variables scale on the left $\left(\Delta \% \mathrm{~F}_{\mathrm{t}}\right.$ domain between $-100 \%$ and $\left.+100 \%\right)$

Similarly to what we have already verified for the firm's risk due to DFL for the $\Delta \% \mathrm{qms}_{\mathrm{t}}, \Delta \% \mathrm{up}_{\mathrm{t}}$ and $\Delta \% \mathrm{uvc}_{\mathrm{t}}$ uncertainty, also the risk deriving from the $\Delta \% \mathrm{~F}_{\mathrm{t}}$ one coincides with the following DFL horizontal asymptote:

$$
\lim _{\Delta \% \mathrm{~F}_{\mathrm{t}} \rightarrow \infty} \mathrm{DFL}_{\mathrm{t}}=\mathrm{N}_{\mathrm{t}}-\left[-\frac{\mathrm{Z}_{\mathrm{t}}}{\mathrm{DFL}_{\mathrm{t}-1}^{*}} * \mathrm{ROI}_{\mathrm{t}-1} *\left(1-\alpha_{\mathrm{t}}\right)\right]=\mathrm{DFL}_{\mathrm{t}}^{\mathrm{a}} \mid \Delta \% \mathrm{~F}_{\mathrm{t}}
$$

From equations (65) and (66), we obtain the generic formulation of the firm's risk due to DFL owed to the $\Delta \% \mathrm{~F}_{\mathrm{t}}$ uncertainty:

$$
\zeta\left(\mathrm{DFL}_{\mathrm{t}} \mid \Delta \% \mathrm{~F}_{\mathrm{t}}\right)=\frac{\sigma\left(\Delta \% \pi_{\mathrm{t}} \mid \Delta \% \mathrm{~F}_{\mathrm{t}}\right)}{\sigma\left(\Delta \% \mathrm{EBIT}_{\mathrm{t}} \mid \Delta \% \mathrm{~F}_{\mathrm{t}}\right)}=\mathrm{N}_{\mathrm{t}}+\frac{\mathrm{Z}_{\mathrm{t}}}{\mathrm{DFL}_{\mathrm{t}-1}^{*}} * \mathrm{ROI}_{\mathrm{t}-1} *\left(1-\alpha_{\mathrm{t}}\right)=\mathrm{DFL}_{\mathrm{t}}^{\mathrm{a}} \mid \Delta \% \mathrm{~F}_{\mathrm{t}}
$$

We briefly recap with Figure 6 what illustrated so far. First of all, we point out that the DOL is a negative straight line of which we have already determined its equation through the (61). It is necessary to calculate the Fixed Costs growth mean $\mu\left(\Delta \% \mathrm{~F}_{\mathrm{t}}\right)$ to determine the operating point at which the firm operates. Given the DOL and DFL curves that are firm characteristics for the current period, we can easily find the DOL and DFL values on the ordinate in correspondence with the abscissa value $\mu\left(\Delta \% \mathrm{~F}_{\mathrm{t}}\right)$. The firm's risk related to DFL, coming from the $\Delta \% \mathrm{~F}_{\mathrm{t}}$ uncertainty will not be on such a curve, but it will be its asymptote.

\subsection{Net Profit Volatility Due to the Cost of Debt Uncertainty}

Now we have to evaluate the impact determined in the current period by the Cost of Debt $i_{t}$ uncertainty on the Net Profit growth $\Delta \% \pi_{\mathrm{t}}$ and DFL volatility. It is evident that the Cost of Debt $i_{\mathrm{t}}$ cannot have any impact on $\Delta \% \mathrm{EBIT}_{\mathrm{t}}$ and its effect is only on the DFL numerator; consequently, $i_{t}$ uncertainty does not generate any 
volatility on the DFL denominator, and it will not be possible to determine the impact on the DFL volatility. Therefore, the Cost of Debt uncertainty will transfer in a calculable way only to the Net Profit percentage growth $\Delta \% \pi_{\mathrm{t}}$.

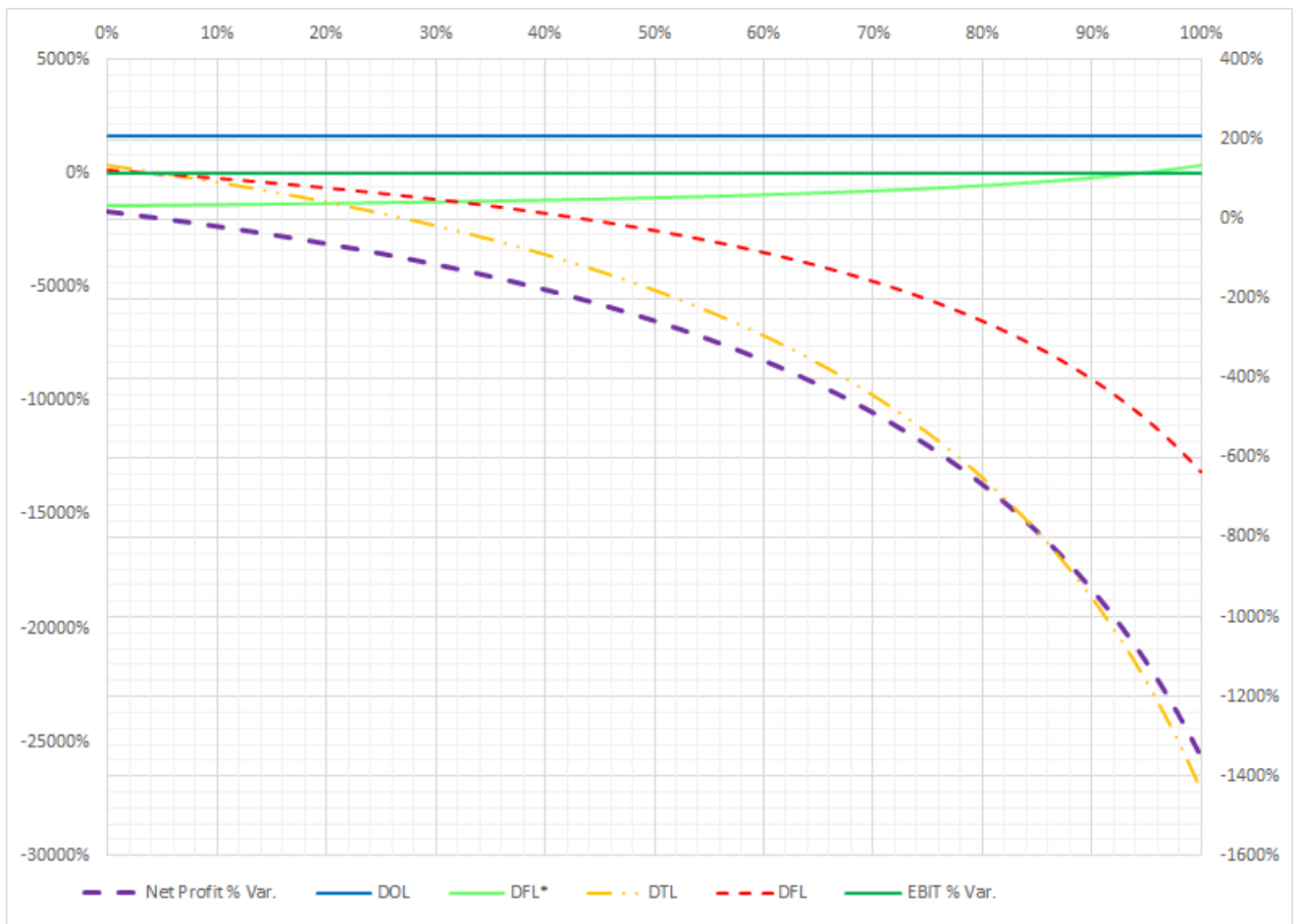

Figure 7. The trend of the variables under analysis: DFL, DTL and $\Delta \% \mathrm{EBIT}_{\mathrm{t}}$ on the left, all the other variables scale on the right (Cost of Debt $\mathrm{i}_{\mathrm{t}}$ domain between 0 and $+100 \%$ )

Given the $\Delta \% \mathrm{EBIT}_{\mathrm{t}}$ baseline value, by varying $\mathrm{i}_{\mathrm{t}}$ in the field $[0,100 \%]$, we can obtain Figure 7 , where we can point out the following:

1) the steadiness of $\triangle \% \mathrm{EBIT}$ and DOL;

2) the marked decline in DFL, DTL and the Net Profit percentage growth $\Delta \% \pi_{t}$ as the Cost of Debt $i_{t}$ increases;

3) the consistent increase of the Debt Ratio DFL* as the Cost of Debt $i_{t}$ increases.

The starting point is equation (21) of the Net Profit growth (or decrease) $\Delta \% \pi_{\mathrm{t}}$ to which we will apply the uncertainty due to the Cost of Debt $\mathrm{i}_{\mathrm{t}}$ :

$$
\begin{aligned}
\operatorname{Var}\left(\Delta \% \pi_{\mathrm{t}} \mid \mathrm{i}_{\mathrm{t}}\right) & =\operatorname{Var}\left[\mathrm{N}_{\mathrm{t}} *\left(1+\Delta \% \mathrm{EBIT}_{\mathrm{t}}\right)-\mathrm{Q}_{\mathrm{t}} \mid \mathrm{i}_{\mathrm{t}} *\left(1+\Delta \% \mathrm{~S}_{\mathrm{t}}\right)-1\right]= \\
= & \operatorname{Var}\left[\mathrm{Q}_{\mathrm{t}} \mid \mathrm{i}_{\mathrm{t}} *\left(1+\Delta \% \mathrm{~S}_{\mathrm{t}}\right)\right]=\left(\frac{\mathrm{W}_{\mathrm{t}}}{\mathrm{i}_{\mathrm{t}-1}}\right)^{2} * \operatorname{Var}\left[\frac{1}{\frac{1}{\mathrm{i}_{\mathrm{t}}}-\left(1-\alpha_{\mathrm{t}}\right)}\right]
\end{aligned}
$$

where:

$$
\mathrm{W}_{\mathrm{t}}=\frac{\mathrm{A}_{\mathrm{t}-1} * \mathrm{~T}_{\mathrm{t}} * \mathrm{H}_{\mathrm{t}}}{\mathrm{DFL}_{\mathrm{t}-1}^{*}}
$$

From the (67), we can conclude that $\left.\Delta \% \pi_{\mathrm{t}}\right|_{\mathrm{t}}$ volatility related to the Cost of Debt uncertainty is not independent by its range:

$$
\frac{\sigma\left(\Delta \% \pi_{\mathrm{t}} \mid \mathrm{i}_{\mathrm{t}}\right)}{\sigma\left(\mathrm{i}_{\mathrm{t}}\right)}=\frac{\mathrm{W}_{\mathrm{t}}}{\mathrm{i}_{\mathrm{t}-1}} * \frac{\sigma\left[\frac{1}{\frac{1}{\mathrm{i}_{\mathrm{t}}}-\left(1-\alpha_{\mathrm{t}}\right)}\right]}{\sigma\left(\mathrm{i}_{\mathrm{t}}\right)}
$$

We have to point out that the variable $\mathrm{H}_{\mathrm{t}}$ is not a random variable for the Cost of Debt uncertainty.

Turning to the mean impact $\mu$ on $\Delta \% \pi_{t}$, that is $\mu\left(\Delta \% \pi_{t} \mid i_{t}\right)$, in the range of the Cost of Debt $i_{t}$ uncertainty, the situation is relatively simple: 


$$
\begin{aligned}
\mu\left(\Delta \% \pi_{\mathrm{t}} \mid \mathrm{i}_{\mathrm{t}}\right)=\mu\left[\mathrm{N}_{\mathrm{t}} *\left(1+\Delta \% \mathrm{EBIT}_{\mathrm{t}}\right)-\mathrm{Q}_{\mathrm{t}} \mid \mathrm{i}_{\mathrm{t}} *\left(1+\Delta \% \mathrm{~S}_{\mathrm{t}}\right)-1\right]= \\
=\mathrm{N}_{\mathrm{t}} *\left(1+\Delta \% \mathrm{EBIT}_{\mathrm{t}}\right)-1-\frac{\mathrm{w}_{\mathrm{t}}}{\mathrm{i}_{\mathrm{t}-1}} * \mu\left[\frac{1}{\left.\frac{1}{\mathrm{i}_{\mathrm{t}}-\left(1-\alpha_{\mathrm{t}}\right)}\right]}\right.
\end{aligned}
$$

from which we can derive the DFL mean $\mu\left(\left.\mathrm{DFL}_{t}\right|_{t}\right)$ assumed in the Cost of Debt $i_{t}$ uncertainty range:

$$
\mu\left(\text { DFL }_{\mathrm{t}} \mid \mathrm{i}_{\mathrm{t}}\right)=\mathrm{N}_{\mathrm{t}}+\frac{\mathrm{N}_{\mathrm{t}}-1}{\Delta \% \mathrm{EBIT}_{\mathrm{t}}}-\frac{\mathrm{W}_{\mathrm{t}}}{\mathrm{i}_{\mathrm{t}-1}} * \frac{1}{\Delta \% \mathrm{EBIT}_{\mathrm{t}}} * \mu\left[\frac{1}{\mathrm{i}_{\mathrm{t}}-\left(1-\alpha_{\mathrm{t}}\right)}\right]
$$

The Cost of Debt impact severely on Net Profit in case of hyperinflation, with values higher than 20\%, for instance, even though it can play a significant role at a lower level with a high Debt Ratio.

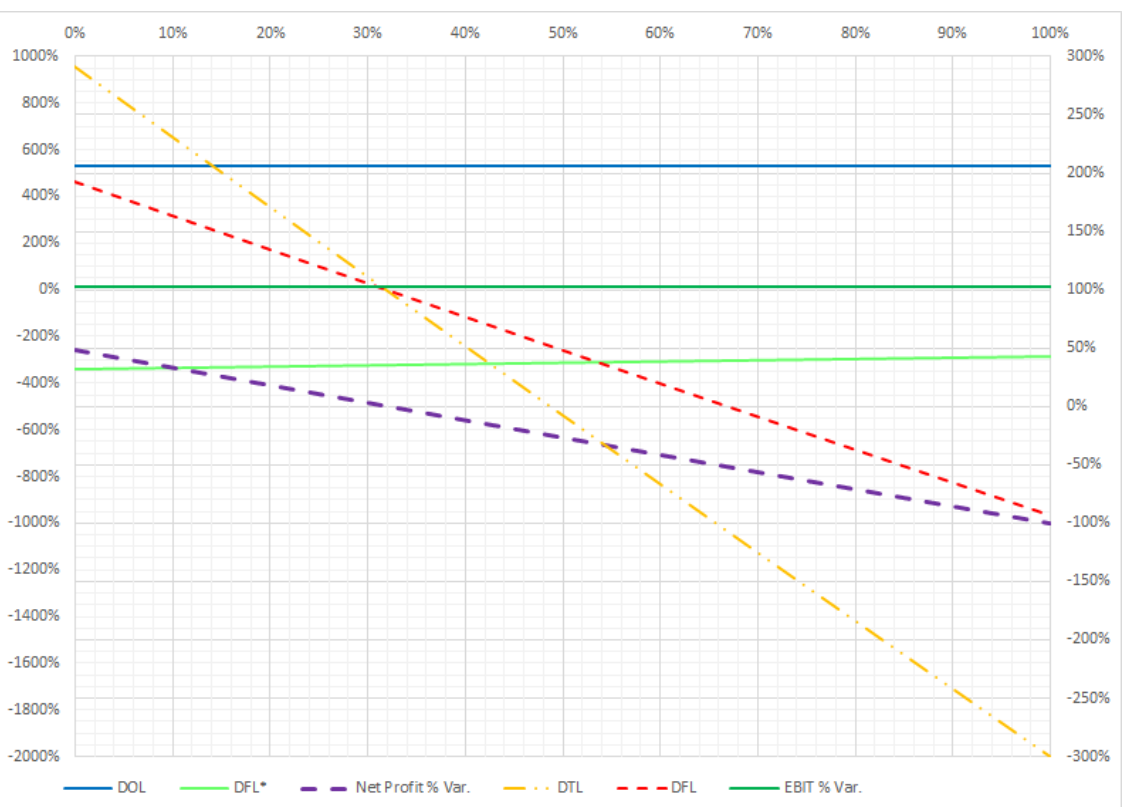

Figure 8. The trend of the variables under analysis: DFL, DTL and $\Delta \% \mathrm{EBIT}_{\mathrm{t}}$ on the left, all the other variables scale on the right (Corporate Tax Rate $\alpha_{t}$ domain between 0 and $+100 \%$ )

\subsection{Net Profit Volatility Due to the Corporate Tax Rate Uncertainty}

Let us move on to evaluate the impact determined in the current period by the Tax Rate $\alpha_{\mathrm{t}}$ uncertainty on the Net Profit growth $\Delta \% \pi_{\mathrm{t}}$ and DFL volatility. The Tax Rate cannot impact $\Delta \% \mathrm{EBIT}_{\mathrm{t}}$; moreover, its effect is only on the DFL numerator; consequently, its uncertainty does not generate any volatility on the DFL denominator, and it will not be possible to determine the impact on the DFL volatility. Therefore, the Tax Rate uncertainty will transfer in a calculable way only to the Net Profit percentage growth $\Delta \% \pi_{\mathrm{t}}$.

Given the $\Delta \% \mathrm{EBIT}_{\mathrm{t}}$ baseline value, by varying $\alpha_{\mathrm{t}}$ in the field $[0,100 \%]$, we can obtain Figure 8 , where we can point out the following:

1) the steadiness of $\triangle \% \mathrm{EBIT}$ and DOL;

2) the marked decline in DFL, DTL and the Net Profit percentage growth $\Delta \% \pi_{\mathrm{t}}$ as the Tax Rate $\alpha_{\mathrm{t}}$ increases;

3) the growth of the Debt Ratio DFL* as the Tax Rate $\alpha_{t}$ increases.

The starting point is equation (21) of the Net Profit growth (or decrease) $\Delta \% \pi_{\mathrm{t}}$ to which we will apply the uncertainty due to the Tax Rate $\alpha_{t}$ :

$$
\begin{gathered}
\operatorname{Var}\left(\Delta \% \pi_{\mathrm{t}} \mid \alpha_{\mathrm{t}}\right)=\operatorname{Var}\left[\mathrm{N}_{\mathrm{t}}\left|\alpha_{\mathrm{t}} *\left(1+\Delta \% \mathrm{EBIT}_{\mathrm{t}}\right)-\mathrm{Q}_{\mathrm{t}}\right| \alpha_{\mathrm{t}} *\left(1+\Delta \% \mathrm{~S}_{\mathrm{t}}\right)-1\right]= \\
=\left(\frac{\mathrm{EE}_{\mathrm{t}}}{1-\alpha_{\mathrm{t}-1}}\right)^{2} * \operatorname{Var}\left(\alpha_{\mathrm{t}}\right)+\left(\frac{\mathrm{J}_{\mathrm{t}}}{1-\alpha_{\mathrm{t}-1}}\right)^{2} * \operatorname{Var}\left[\frac{\mathrm{H}_{\mathrm{t}} \mid \alpha_{\mathrm{t}}}{\frac{1}{\left(1-\alpha_{\mathrm{t}}\right)}-\mathrm{i}_{\mathrm{t}}}\right]+2 * \frac{\mathrm{EE}_{\mathrm{t}} * \mathrm{~J}_{\mathrm{t}}}{\left(1-\alpha_{\mathrm{t}-1}\right)^{2}} * \operatorname{Cov}\left[\alpha_{\mathrm{t}} \frac{\mathrm{H}_{\mathrm{t}} \mid \alpha_{\mathrm{t}}}{\frac{1}{\left(1-\alpha_{\mathrm{t}}\right)}-\mathrm{i}_{\mathrm{t}}}\right]= \\
=\left(\frac{1}{1-\alpha_{\mathrm{t}-1}}\right)^{2} * \operatorname{Var}\left[\mathrm{EE}_{\mathrm{t}} * \alpha_{\mathrm{t}}+\mathrm{J}_{\mathrm{t}} * \frac{\mathrm{H}_{\mathrm{t}} \mid \alpha_{\mathrm{t}}}{\frac{1}{\left(1-\alpha_{\mathrm{t}}\right)^{-}}-\mathrm{i}_{\mathrm{t}}}\right]
\end{gathered}
$$


where:

$$
\begin{gathered}
\mathrm{EE}_{\mathrm{t}}=\left(1+\Delta \% \mathrm{EBIT}_{\mathrm{t}}\right) *\left(1+\mathrm{A}_{\mathrm{t}-1}\right) \\
\mathrm{J}_{\mathrm{t}}=\frac{\mathrm{A}_{\mathrm{t}-1} * \mathrm{M}_{\mathrm{t}}}{\mathrm{DFL}_{\mathrm{t}-1}^{*}}
\end{gathered}
$$

From the (71), we can conclude that $\Delta \% \pi_{t} \mid \alpha_{t}$ volatility related to the Tax Rate uncertainty is not independent by its range:

$$
\frac{\sigma\left(\Delta \% \pi_{\mathrm{t}} \mid \alpha_{\mathrm{t}}\right)}{\sigma\left(\alpha_{\mathrm{t}}\right)}=\frac{1}{1-\alpha_{\mathrm{t}-1}} * \frac{\sigma\left[\mathrm{EE}_{\mathrm{t}} * \alpha_{\mathrm{t}}+\mathrm{J}_{\mathrm{t}} * \frac{\mathrm{H}_{\mathrm{t}} \mid \alpha_{\mathrm{t}}}{\frac{1}{\left(1-\alpha_{\mathrm{t}}\right.}-\mathrm{i}_{\mathrm{t}}}\right]}{\sigma\left(\alpha_{\mathrm{t}}\right)}
$$

We have to point out that $H_{t}$ is still a random variable for the Tax Rate $\alpha_{t}$ uncertainty.

Turning to the mean impact $\mu$ on $\Delta \% \pi_{t}$, that is $\mu\left(\Delta \% \pi_{t} \mid \alpha_{t}\right)$, in the range of the Tax Rate $\alpha_{t}$ uncertainty, the situation is relatively complex:

$$
\mu\left(\Delta \% \pi_{t} \mid \alpha_{t}\right)=\mu\left(\Delta \% \mathrm{EBIT}_{\mathrm{t}} * \mathrm{DFL}_{\mathrm{t}} \mid \alpha_{\mathrm{t}}\right)=\Delta \% \mathrm{EBIT}_{\mathrm{t}} * \mu\left(\mathrm{DFL}_{\mathrm{t}} \mid \alpha_{\mathrm{t}}\right)
$$

from which we can derive the DFL mean $\mu\left(\mathrm{DFL}_{\mathrm{t}} \mid \alpha_{\mathrm{t}}\right)$ assumed in the range of the Tax Rate $\alpha_{\mathrm{t}}$ uncertainty:

$$
\mu\left(\mathrm{DFL}_{\mathrm{t}} \mid \alpha_{\mathrm{t}}\right)=\mathrm{FF}_{\mathrm{t}} * \mu\left(1-\alpha_{\mathrm{t}}\right)-\mathrm{GG}_{\mathrm{t}} * \mu\left[\frac{\mathrm{H}_{\mathrm{t}}}{1 /\left(1-\alpha_{\mathrm{t}}\right)-\mathrm{i}_{\mathrm{t}}}\right]-\frac{1}{\Delta \% \mathrm{EBIT}_{\mathrm{t}}}
$$

where:

$$
\begin{aligned}
\mathrm{FF}_{\mathrm{t}} & =\frac{\left(1+\mathrm{A}_{\mathrm{t}-1}\right) *\left(1+1 / \Delta \% \mathrm{EBIT}_{\mathrm{t}}\right)}{1-\mathrm{\alpha}_{\mathrm{t}-1}} \\
\mathrm{GG}_{\mathrm{t}} & =\frac{\mathrm{A}_{\mathrm{t}-1} * \mathrm{M}_{\mathrm{t}}}{\mathrm{DFL}_{\mathrm{t}-1}^{*} \Delta \% \mathrm{EBIT}_{\mathrm{t}} *\left(1-\alpha_{\mathrm{t}-1}\right)}
\end{aligned}
$$

\subsection{Summary of Firm's Risk}

To complete and recap the risk issue, we conducted a quantitative test on the financial data presented in Appendix A, which produced the results in Table 2. The simulation compares results coming from non-stochastic data and processes with the results coming from the random ones, with an uncertainty range of the six fundamental variables examined so far:

1) the primary ones, namely the percentage growths of quantity/mix, unit prices, unit variable costs and fixed costs,

2) the secondary ones, namely the Cost of Debt and the Tax Rate.

The simulations conducted with random processes on the six fundamental variables use non-normal distributions, symmetric to their mean $\mu$ and platykurtic. The mean $\mu$ of the random variables coincides with the baseline value of the non-stochastic data. Some uncertainty ranges are relatively narrow; others are wider due to the greater degree of uncertainty that could characterise, for example, the quantity/mix percentage growth.

The results produced with non-stochastic processes by the six fundamental variables on the EBIT and Net Profit percentage growths $\Delta \% \mathrm{EBIT}_{\mathrm{t}}$ and $\Delta \% \pi_{\mathrm{t}}$ respectively are equal to those produced by the random processes as long as the baseline values of the former process coincide with the corresponding means $\mu$ of the latter. In this way, no difference is predicted on $\mu\left(\Delta \% \mathrm{EBIT}_{\mathrm{t}}\right)$ and $\mu\left(\Delta \% \pi_{\mathrm{t}}\right)$ by the primary variables, while $\mu\left(\Delta \% \pi_{\mathrm{t}}\right)$ shows a modest difference in case of uncertainty coming from the secondary variables. The uncertainty range of the six fundamental variables affects $\Delta \% \mathrm{EBIT}_{\mathrm{t}}$ and $\Delta \% \pi_{\mathrm{t}}$ volatility range; the ratio between these ranges can be considered a broadly "range independent" measure only for the primary variables, not the secondary ones owing to non-linearity issues. Such ratios hinge upon the firm's peculiarity, as the managed business, the chosen organisation and the resulting profitability. 
Table 2. Summary table of the income statement analysis with nonrandom and random data and processes

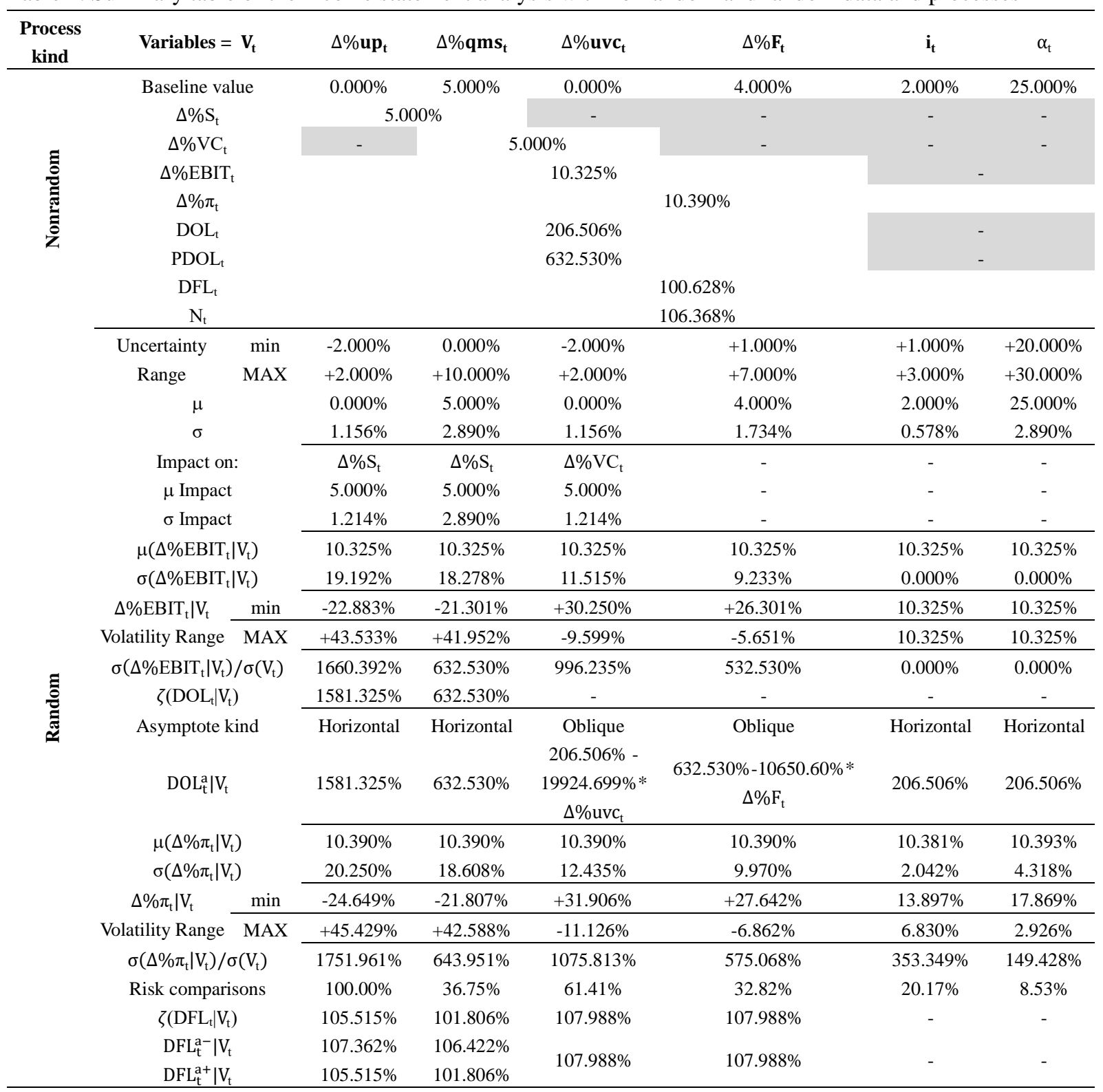

Through the ratio between the standard deviations $\sigma$ of $\Delta \% \mathrm{EBIT}_{\mathrm{t}}$ and $\Delta \% \pi_{\mathrm{t}}$ to the variable $\mathrm{V}_{\mathrm{t}}$ determining the volatility, we obtain values of $\sigma\left(\Delta \% \mathrm{EBIT}_{\mathrm{t}} \mid \mathrm{V}_{\mathrm{t}}\right) / \sigma\left(\mathrm{V}_{\mathrm{t}}\right)$ and $\sigma\left(\Delta \% \pi_{\mathrm{t}} \mid \mathrm{V}_{\mathrm{t}}\right) / \sigma\left(\mathrm{V}_{\mathrm{t}}\right)$ which depend on parameters of the previous period and the performance of a few variables of the current period, mainly $\Delta \% \mathrm{up}_{\mathrm{t}}$ and $\Delta \% \mathrm{uvc}_{\mathrm{t}}$, and determine the relative risk profile of the firm for the current period.

The impact of the uncertainty of the six fundamental variables on the relative risk linked to DOL and DFL is limited as some variables cannot influence the denominator or numerator of these ratios. There is no doubt that $\Delta \% \mathrm{qms}_{\mathrm{t}}$ and $\Delta \% \mathrm{up}_{\mathrm{t}}$ impact both DOL and DFL, the Cost of Debt $\mathrm{i}_{\mathrm{t}}$ and the Tax Rate $\alpha_{\mathrm{t}}$ impact neither while $\Delta \% \mathrm{uvc}_{\mathrm{t}}$ and $\Delta \% \mathrm{~F}_{\mathrm{t}}$ impact only DFL.

The relative risk contaminating DOL and DFL by the variable $V_{t}$ uncertainty always correspond to the DOL and DFL asymptotes, provided that the volatility range of the Revenue percentage growth $\Delta \% \mathrm{~S}_{\mathrm{t}}$ be in its positive or negative domain. Consequently, the operating point at which the firm carries out its business is essential for determining the DOL and DFL curves on which to locate the mean value $\mu$ of the four primary variables, but the relative risk is the asymptote of such curves, also determining significant deviations from the baseline value already identified.

We compared the risks owed to the six fundamental variables, measured by $\sigma\left(\Delta \% \pi_{\mathrm{t}} \mid \mathrm{V}_{\mathrm{t}}\right) / \sigma\left(\mathrm{V}_{\mathrm{t}}\right)$, to the highest, 
which means $\Delta \% \mathrm{up}_{\mathrm{t}}$. It emerges that the variables determining the highest impact on volatility and risk are the percentage growth of the unit price $\Delta \% \mathrm{up}_{\mathrm{t}}$ and the unit variable cost $\Delta \% \mathrm{uvc}_{\mathrm{t}}$ while all the other variables have a significantly lower impact, at least in the specific case. It comes to light the perspective that some variables such as the dynamics of Fixed Costs, quantity/mix and the Cost of Debt appear eminently a daily practice overestimated. Greater control of the Fixed Costs growth is more elementary than the control of the dynamics of unit variable costs, but the latter generates, in the specific business case, an impact of approximately 1.87 times greater than the former on the $\Delta \% \pi_{\mathrm{t}}$ volatility.

It is not currently under investigation the relationship between the firm's risk and the systematic one.

Table 3. Analytical reports of the impact on the DOL volatility and its asymptotes for values tending to $\pm \infty$ by the four primary variables

\begin{tabular}{|c|c|c|c|}
\hline$v_{t}$ & Variable name & $\zeta\left(\right.$ DOLt $\left.\mid \mathbf{V}_{t}\right)$ & DOL $_{\mathrm{t}}^{\mathrm{a}} \mid \mathbf{V}_{\mathrm{t}}$ \\
\hline$\Delta \% \mathrm{qms}_{\mathrm{t}}$ & $\begin{array}{c}\text { Quantity/Mix } \\
\text { percentage growth }\end{array}$ & $\mathrm{PDOL}_{\mathrm{t}} *\left[\frac{\mathrm{CM}_{\mathrm{t}-1}+\mathrm{S}_{\mathrm{t}-1} * \Delta \% \mathrm{up}_{\mathrm{t}}-\mathrm{VC}_{\mathrm{t}-1} * \Delta \% \mathrm{uvc}_{\mathrm{t}}}{\mathrm{CM}_{\mathrm{t}-1} *\left(1+\Delta \% \mathrm{up}_{\mathrm{t}}\right)}\right]$ & $\mathrm{PDOL}_{\mathrm{t}} *\left[\frac{\mathrm{CM}_{\mathrm{t}-1}+\mathrm{S}_{\mathrm{t}-1} * \Delta \% \mathrm{up}_{\mathrm{t}}-\mathrm{VC}_{\mathrm{t}-1} * \Delta \% \mathrm{uvc}_{\mathrm{t}}}{\mathrm{CM}_{\mathrm{t}-1} *\left(1+\Delta \% \mathrm{up}_{\mathrm{t}}\right)}\right]$ \\
\hline$\Delta \% \mathrm{up}_{\mathrm{t}}$ & $\begin{array}{l}\text { Unit Price } \\
\text { percentage growth }\end{array}$ & $\mathrm{PDOL}_{\mathrm{t}} * \frac{\mathrm{S}_{\mathrm{t}-1}}{\mathrm{CM}_{\mathrm{t}-1}}$ & $\mathrm{PDOL}_{\mathrm{t}} * \frac{\mathrm{S}_{\mathrm{t}-1}}{\mathrm{CM}_{\mathrm{t}-1}}$ \\
\hline$\Delta \% \mathrm{uvc}_{\mathrm{t}}$ & $\begin{array}{l}\text { Unit Variable Cost } \\
\text { percentage growth }\end{array}$ & - & $\begin{array}{c}\mathrm{PDOL}_{\mathrm{t}} *\left(\frac{\mathrm{S}_{\mathrm{t}-1}}{\mathrm{CM}_{\mathrm{t}-1}}-\frac{\mathrm{VC}_{\mathrm{t}-1} * \Delta \% \mathrm{qms}_{\mathrm{t}}+\mathrm{FC}_{\mathrm{t}-1} * \Delta \% \mathrm{~F}_{\mathrm{t}}}{\mathrm{CM}_{\mathrm{t}-1} * \Delta \% \mathrm{~S}_{\mathrm{t}}}\right) \\
-\frac{\mathrm{VC}_{\mathrm{t}-1}}{\mathrm{EBIT}_{\mathrm{t}-1}} * \frac{1+\Delta \% \mathrm{qms}_{\mathrm{t}}}{\Delta \% \mathrm{~S}_{\mathrm{t}}} * \Delta \% \mathrm{uvc}_{\mathrm{t}}\end{array}$ \\
\hline$\Delta \% \mathrm{~F}_{\mathrm{t}}$ & $\begin{array}{c}\text { Fixed Costs } \\
\text { percentage growth }\end{array}$ & - & $\begin{array}{c}\mathrm{PDOL}_{\mathrm{t}} *\left(\frac{\mathrm{S}_{\mathrm{t}-1}}{\mathrm{CM}_{\mathrm{t}-1}}-\frac{\mathrm{VC}_{\mathrm{t}-1} * \Delta \% \mathrm{VC}_{\mathrm{t}}}{\mathrm{CM}_{\mathrm{t}-1} * \Delta \% \mathrm{~S}_{\mathrm{t}}}\right)+ \\
-\frac{\mathrm{FC}_{\mathrm{t}-1}}{\mathrm{EBIT}_{\mathrm{t}-1}} * \frac{1}{\Delta \% \mathrm{~S}_{\mathrm{t}}} * \Delta \% \mathrm{~F}_{\mathrm{t}}\end{array}$ \\
\hline
\end{tabular}

Table 4. Analytical reports of the effect on the DFL volatility and its asymptotes for values tending to $\pm \infty$ by the four primary variables, remembering that $\mathrm{K}_{\mathrm{t}}$ becomes zero when $\Delta \% \mathrm{~S}_{\mathrm{t}}<0$

\begin{tabular}{|c|c|c|c|}
\hline$V_{t}$ & Variable name & $\zeta\left(\mathbf{D F L}_{t} \mid \mathbf{V}_{t}\right)$ & $\mathrm{DFL}_{\mathrm{t}}^{\mathrm{a}} \mid \mathbf{V}_{\mathrm{t}}$ \\
\hline$\Delta \% \mathrm{qms}_{\mathrm{t}}$ & $\begin{array}{c}\text { Quantity/Mix } \\
\text { percentage growth }\end{array}$ & $\frac{\sigma\left(\mathrm{N}_{\mathrm{t}} * \Delta \% \mathrm{qms}_{\mathrm{t}}-\mathrm{VV1}_{\mathrm{t}} * \mathrm{H}_{\mathrm{t}} \mid \Delta \% \mathrm{qms}_{\mathrm{t}}\right)}{\sigma\left(\Delta \% \mathrm{qms}_{\mathrm{t}}\right)}$ & $\mathrm{N}_{\mathrm{t}}-\frac{\mathrm{Z}_{\mathrm{t}}}{\mathrm{DFL}_{\mathrm{t}-1}^{*}} *\left[\frac{\mathrm{K}_{\mathrm{t}-1} *\left(\mathrm{~K}_{\mathrm{t}}+\mathrm{K}_{\mathrm{t}}\right)}{\mathrm{DOL}_{\mathrm{t}}^{\mathrm{a}} \mid \Delta \% \mathrm{qms}_{\mathrm{t}}}-\mathrm{ROI}_{\mathrm{t}-1} *\left(1-\alpha_{\mathrm{t}}\right)\right]$ \\
\hline$\Delta \% \mathrm{up}_{\mathrm{t}}$ & $\begin{array}{c}\text { Unit Price } \\
\text { percentage growth }\end{array}$ & $\frac{\sigma\left(\mathrm{N}_{\mathrm{t}} * \Delta \% \mathrm{up}_{\mathrm{t}}-\mathrm{VV}_{\mathrm{t}} * \mathrm{H}_{\mathrm{t}} \mid \Delta \% \mathrm{up}_{\mathrm{t}}\right)}{\sigma\left(\Delta \% \mathrm{up}_{\mathrm{t}}\right)}$ & $\mathrm{N}_{\mathrm{t}}-\frac{\mathrm{Z}_{\mathrm{t}}}{\mathrm{DFL}_{\mathrm{t}-1}^{*}} *\left[\frac{\mathrm{K} 1_{\mathrm{t}-1} *\left(\mathrm{~K}_{\mathrm{t}}+\mathrm{K}_{\mathrm{t}}\right)}{\mathrm{DOL}_{\mathrm{t}}^{\mathrm{a}} \mid \Delta \% \mathrm{up}_{\mathrm{t}}}-\mathrm{ROI}_{\mathrm{t}-1} *\left(1-\alpha_{\mathrm{t}}\right)\right]$ \\
\hline$\Delta \% \mathrm{uvc}_{\mathrm{t}}$ & $\begin{array}{l}\text { Unit Variable Cost } \\
\text { percentage growth }\end{array}$ & $\frac{\sigma\left(\mathrm{N}_{\mathrm{t}} * \Delta \% \mathrm{uvc}_{\mathrm{t}}+\mathrm{VV}_{\mathrm{t}} * \mathrm{H}_{\mathrm{t}} \mid \Delta \% \mathrm{uvc}_{\mathrm{t}}\right)}{\sigma\left(\Delta \% \mathrm{uvc}_{\mathrm{t}}\right)}$ & $\mathrm{N}_{\mathrm{t}}-\left[-\frac{\mathrm{Z}_{\mathrm{t}}}{\mathrm{DFL}_{\mathrm{t}-1}^{*}} * \mathrm{ROI}_{\mathrm{t}-1} *\left(1-\alpha_{\mathrm{t}}\right)\right]$ \\
\hline$\Delta \% \mathrm{~F}_{\mathrm{t}}$ & $\begin{array}{c}\text { Fixed Costs } \\
\text { percentage growth }\end{array}$ & $\frac{\sigma\left(\mathrm{N}_{\mathrm{t}} * \Delta \% \mathrm{~F}_{\mathrm{t}}+\mathrm{VV}_{\mathrm{t}} * \mathrm{H}_{\mathrm{t}} \mid \Delta \% \mathrm{~F}_{\mathrm{t}}\right)}{\sigma\left(\Delta \% \mathrm{~F}_{\mathrm{t}}\right)}$ & $\mathrm{N}_{\mathrm{t}}-\left[-\frac{\mathrm{Z}_{\mathrm{t}}}{\mathrm{DFL}_{\mathrm{t}-1}^{*}} * \mathrm{ROI}_{\mathrm{t}-1} *\left(1-\alpha_{\mathrm{t}}\right)\right]$ \\
\hline
\end{tabular}

In Tables 3 and 4, we have summarised the equations determining $\zeta\left(D L_{t} \mid V_{t}\right)$ and $\zeta\left(D F L_{t} \mid V_{t}\right)$ as a function of the four primary variables and compared them to the equation of their asymptote. In Table 3 , we can examine the analytical comparison between the risk $\zeta\left(\mathrm{DOL}_{\mathrm{t}} \mid \mathrm{V}_{\mathrm{t}}\right)$ and the asymptote relating to $\mathrm{V}_{\mathrm{t}}$ for $\Delta \% \mathrm{qms}_{\mathrm{t}}$ and $\Delta \% \mathrm{up}_{\mathrm{t}}$ that are identical. $\Delta \% \mathrm{uvc}_{\mathrm{t}}$ and $\Delta \% \mathrm{~F}_{\mathrm{t}}$ do not generate any impact on $\zeta\left(\mathrm{DOL}_{\mathrm{t}} \mid \mathrm{V}_{\mathrm{t}}\right)$ even if there is a DOL oblique asymptote related to their uncertainty.

Table 4 reported the analytical comparison between $\zeta\left(D F L_{t} \mid V_{t}\right)$ and the corresponding asymptote $D_{F} L_{t}^{a} \mid V_{t}$ of the four primary variables. We remind that the secondary variables, the Cost of Debt and Tax Rate, do not cause any impact on the DFL volatility, only on Net Profit growth one. When $\mathrm{H}_{t}$ is not a random variable, the left expression converges on the right one. While this condition always happens in the case of $\Delta \% \mathrm{uvc}_{\mathrm{t}}$ and $\Delta \% \mathrm{~F}_{\mathrm{t}}$, in the case of $\Delta \% \mathrm{qms}_{\mathrm{t}}$ and $\Delta \% \mathrm{up}_{\mathrm{t}}$, this occurs only when the volatility range of Revenue growth $\Delta \% \mathrm{~S}_{\mathrm{t}}$ is limited to the positive or negative domain. If this does not happen, $\Delta \% \mathrm{~S}_{\mathrm{t}}$ determines the $\mathrm{H}_{\mathrm{t}}$ volatility, which 
implies the swing of DFL in a sufficiently narrow range between its negative and positive asymptote due to its imperfect axial symmetry. Below we report the DFL fluctuation range:

$$
\frac{\mathrm{Z}_{\mathrm{t}}}{\mathrm{DFL}_{\mathrm{t}-1}^{*}} * \frac{\mathrm{K}_{\mathrm{t}-1}{ }^{*} \mathrm{~K}_{\mathrm{t}}}{\mathrm{DOL}_{\mathrm{t}}^{\mathrm{a}} \mid \mathrm{V}_{\mathrm{t}}}
$$

The last very particular aspect concerns the EBIT growth volatility compared to the $\mathrm{V}_{\mathrm{t}}$ uncertainty, which means $\sigma\left(\Delta \% \mathrm{EBIT}_{\mathrm{t}} \mid \mathrm{V}_{\mathrm{t}}\right) / \sigma\left(\mathrm{V}_{\mathrm{t}}\right)$. This ratio does not coincide with $\zeta\left(\mathrm{DOL}_{\mathrm{t}} \mid \mathrm{V}_{\mathrm{t}}\right)$ but informs about the degree of risk deriving from the uncertainty of a primary variable.

Such a ratio corresponds to the partial derivative of $\Delta \% \mathrm{EBIT}_{\mathrm{t}}$ to $\mathrm{V}_{\mathrm{t}}$ :

$$
\frac{\sigma\left(\Delta \% \mathrm{EBIT}_{\mathrm{t}} \mid \mathrm{V}_{\mathrm{t}}\right)}{\sigma\left(\mathrm{V}_{\mathrm{t}}\right)}=\frac{\partial \Delta \% \mathrm{EBIT}_{\mathrm{t}}}{\partial \mathrm{V}_{\mathrm{t}}}
$$

Table 5. Analytical reports of the impact produced by the four primary variables on the $\Delta \% \mathrm{EBIT}_{\mathrm{t}}$ volatility and

\begin{tabular}{|c|c|c|c|}
\hline$v_{t}$ & Variable name & $\sigma\left(\Delta \% \mathbf{E B I T}_{\mathbf{t}} \mid \mathbf{V}_{\mathbf{t}}\right) / \sigma\left(\mathbf{V}_{\mathbf{t}}\right)$ & $\partial \Delta \% \mathbf{E B I T}_{\mathrm{t}} / \partial \mathbf{V}_{\mathrm{t}}$ \\
\hline$\Delta \% \mathrm{qms}_{\mathrm{t}}$ & $\begin{array}{l}\text { Quantity/Mix } \\
\text { percentage } \\
\text { growth }\end{array}$ & $\begin{array}{c}\mathrm{PDOL}_{\mathrm{t}} *\left[\frac{\mathrm{CM}_{\mathrm{t}-1}+\mathrm{S}_{\mathrm{t}-1} * \Delta \% \mathrm{up}_{\mathrm{t}}-\mathrm{VC}_{\mathrm{t}-1} * \Delta \% \mathrm{uvc}_{\mathrm{t}}}{\mathrm{CM}_{\mathrm{t}-1}}\right] \\
=\left(1+\Delta \% \mathrm{up}_{\mathrm{t}}\right) * \zeta\left(\mathrm{DOL}_{\mathrm{t}} \mid \Delta \% \mathrm{qms}_{\mathrm{t}}\right)\end{array}$ & $\mathrm{PDOL}_{\mathrm{t}} *\left[\frac{\mathrm{CM}_{\mathrm{t}-1}+\mathrm{S}_{\mathrm{t}-1} * \Delta \% \mathrm{up}_{\mathrm{t}}-\mathrm{VC}_{\mathrm{t}-1} * \Delta \% \mathrm{uvc}_{\mathrm{t}}}{\mathrm{CM}_{\mathrm{t}-1}}\right]$ \\
\hline$\Delta \% \mathrm{up}_{\mathrm{t}}$ & $\begin{array}{l}\text { Unit Price } \\
\text { percentage } \\
\text { growth }\end{array}$ & $\begin{array}{c}\operatorname{PDOL}_{\mathrm{t}} * \frac{\mathrm{S}_{\mathrm{t}-1}}{\mathrm{CM}_{\mathrm{t}-1}} *\left(1+\Delta \% \mathrm{qms}_{\mathrm{t}}\right)= \\
=\left(1+\Delta \% \mathrm{qms}_{\mathrm{t}}\right) * \zeta\left(\mathrm{DOL}_{\mathrm{t}} \mid \Delta \% \mathrm{up}_{\mathrm{t}}\right)\end{array}$ & $\mathrm{PDOL}_{\mathrm{t}} * \frac{\mathrm{S}_{\mathrm{t}-1}}{\mathrm{CM}_{\mathrm{t}-1}} *\left(1+\Delta \% \mathrm{qms}_{\mathrm{t}}\right)$ \\
\hline$\Delta \% \mathrm{uvc}_{\mathrm{t}}$ & $\begin{array}{l}\text { Unit Variable } \\
\text { Cost percentage } \\
\text { growth }\end{array}$ & $-\frac{\mathrm{VC}_{\mathrm{t}-1}}{\mathrm{EBIT}_{\mathrm{t}-1}} *\left(1+\Delta \% \mathrm{qms}_{\mathrm{t}}\right)$ & $-\frac{\mathrm{VC}_{\mathrm{t}-1}}{\mathrm{EBIT}_{\mathrm{t}-1}} *\left(1+\Delta \% \mathrm{qms}_{\mathrm{t}}\right)$ \\
\hline$\Delta \% \mathrm{~F}_{\mathrm{t}}$ & $\begin{array}{l}\text { Fixed Costs } \\
\text { percentage } \\
\text { growth }\end{array}$ & $-\frac{\mathrm{FC}_{\mathrm{t}-1}}{\mathrm{EBIT}_{\mathrm{t}-1}}$ & $-\frac{F_{t-1}}{\mathrm{EBIT}_{\mathrm{t}-1}}$ \\
\hline
\end{tabular}
comparison with the corresponding partial derivative

Table 5 shows the relative analytical values. While $\partial \Delta \% \mathrm{EBIT}_{\mathrm{t}} / \partial \mathrm{V}_{\mathrm{t}}$ is the slope of the $\Delta \% \mathrm{EBIT}_{\mathrm{t}}$ function at any $\mathrm{V}_{\mathrm{t}}$ point, $\sigma\left(\Delta \% \mathrm{EBIT}_{\mathrm{t}} \mid \mathrm{V}_{\mathrm{t}}\right) / \sigma\left(\mathrm{V}_{\mathrm{t}}\right)$ represents the ratio between the volatility of the former in respect of the uncertainty of the latter. From equation (80), we can see that $\Delta \% \mathrm{EBIT}_{\mathrm{t}}$ is a linear function of the other four primary $V_{t}$ variables from which it depends; therefore, its slope for the chosen variable $V_{t}$ is constant throughout its domain and, consequently, the choice of its uncertainty range has no consequences in the volatility range of the codomain.

$$
\Delta \% \mathrm{EBIT}_{\mathrm{t}}=\frac{\mathrm{S}_{\mathrm{t}-1} *\left[\left(1+\Delta \% \mathrm{up}_{\mathrm{t}}\right) *\left(1+\Delta \% \mathrm{qms}_{\mathrm{t}}\right)-1\right]-\mathrm{vC}_{\mathrm{t}-1} *\left[\left(1+\Delta \% \mathrm{uvc}_{\mathrm{t}}\right) *\left(1+\Delta \% \mathrm{qmvc}_{\mathrm{t}}\right)-1\right]-\mathrm{FC}_{\mathrm{t}-1} * \Delta \% \mathrm{~F}_{\mathrm{t}}}{\operatorname{EBIT}_{\mathrm{t}-1}}
$$

It is logical that through equation (80), the condition (79) holds.

Such linearity still keeps for $\Delta \% \pi_{\mathrm{t}}$ and its relationship with the four primary variables but not for the Cost of Debt and the Tax Rate, which give rise to non-linear relations: consequently, their volatility ranges depend on the uncertainty ranges chosen for the secondary variables. 
Table 6. Analytical reports of the impact produced by six fundamental variables on the volatility of $\Delta \% \pi_{\mathrm{t}}$ and comparison with the corresponding partial derivative

\begin{tabular}{|c|c|c|c|c|}
\hline$V_{t}$ & Variable name & $\boldsymbol{\sigma}\left(\Delta \% \boldsymbol{\pi}_{\mathbf{t}} \mid \mathbf{V}_{\mathbf{t}}\right) / \boldsymbol{\sigma}\left(\mathbf{V}_{\mathbf{t}}\right)$ & $\partial \Delta \% \pi_{t} / \partial V_{t}$ & Status \\
\hline$\Delta \% \mathrm{qms}_{\mathrm{t}}$ & $\begin{array}{l}\text { Quantity/Mix } \\
\text { percentage } \\
\text { growth }\end{array}$ & $\frac{\sigma\left(\Delta \% \mathrm{EBIT}_{\mathrm{t}} \mid \Delta \% \mathrm{qms}_{\mathrm{t}}\right)}{\sigma\left(\Delta \% \mathrm{qms}_{\mathrm{t}}\right)} * \zeta\left(\mathrm{DFL}_{\mathrm{t}} \mid \Delta \% \mathrm{qms}_{\mathrm{t}}\right)$ & $\begin{array}{c}\frac{\partial \Delta \% E B I T_{t}}{\partial \Delta \% \mathrm{qms}_{t}} * \mathrm{DFL}_{\mathrm{t}}^{\mathrm{a}} \mid \Delta \% \mathrm{qms}_{t}= \\
=\left(1+\Delta \% \mathrm{up}_{\mathrm{t}}\right) * \zeta\left(\mathrm{DOL}_{\mathrm{t}} \mid \Delta \% \mathrm{qms}_{\mathrm{t}}\right) * \zeta\left(\mathrm{DFL}_{\mathrm{t}} \mid \Delta \% \mathrm{qms}_{\mathrm{t}}\right)\end{array}$ & \multirow{4}{*}{ 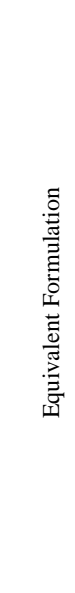 } \\
\hline$\Delta \% \mathrm{up}_{\mathrm{t}}$ & $\begin{array}{l}\text { Unit Price } \\
\text { percentage } \\
\text { growth }\end{array}$ & $\frac{\sigma\left(\Delta \% \mathrm{EBIT}_{\mathrm{t}} \mid \Delta \% \mathrm{up}_{\mathrm{t}}\right)}{\sigma\left(\Delta \mathrm{up}_{\mathrm{t}}\right)} * \zeta\left(\mathrm{DFL}_{\mathrm{t}} \mid \Delta \% \mathrm{up}_{\mathrm{t}}\right)$ & $\begin{array}{c}\frac{\partial \Delta \% E_{\text {EII }}}{\partial \Delta \% \mathrm{up}_{t}} * \mathrm{DFL}_{\mathrm{t}}^{\mathrm{a}} \mid \Delta \% \mathrm{up}_{t}= \\
=\left(1+\Delta \% \mathrm{qms}_{\mathrm{t}}\right) * \zeta\left(\mathrm{DOL}_{\mathrm{t}} \mid \Delta \% \mathrm{up}_{\mathrm{t}}\right) * \zeta\left(\mathrm{DFL}_{\mathrm{t}} \mid \Delta \% \mathrm{up}_{\mathrm{t}}\right)\end{array}$ & \\
\hline$\Delta \% \mathrm{uvc}_{\mathrm{t}}$ & $\begin{array}{l}\text { Unit Variable } \\
\text { Cost percentage } \\
\text { growth }\end{array}$ & $\frac{\sigma\left(\Delta \% \mathrm{EBIT}_{\mathrm{t}} \mid \Delta \% \mathrm{uvc}_{\mathrm{t}}\right)}{\sigma\left(\Delta \% \mathrm{uvc}_{\mathrm{t}}\right)} * \zeta\left(\mathrm{DFL}_{\mathrm{t}} \mid \Delta \% \mathrm{uvc}_{\mathrm{t}}\right)$ & $\begin{array}{c}\frac{\partial \Delta \% \mathrm{EBIT}_{\mathrm{t}}}{\partial \Delta \% \mathrm{uvc}_{\mathrm{t}}} * \mathrm{DFL}_{\mathrm{t}}^{\mathrm{a}} \mid \Delta \% \mathrm{uvc}_{\mathrm{t}}= \\
=-\frac{\mathrm{VC}_{\mathrm{t}-1}}{\mathrm{EBIT}_{\mathrm{t}-1}} *\left(1+\Delta \% \mathrm{qms}_{\mathrm{t}}\right) * \zeta\left(\mathrm{DFL}_{\mathrm{t}} \mid \Delta \% \mathrm{uvc}_{\mathrm{t}}\right)\end{array}$ & \\
\hline$\Delta \% \mathrm{~F}_{\mathrm{t}}$ & $\begin{array}{l}\text { Fixed Costs } \\
\text { percentage } \\
\text { growth }\end{array}$ & $\frac{\sigma\left(\Delta \% \mathrm{EBIT}_{\mathrm{t}} \mid \Delta \% \mathrm{~F}_{\mathrm{t}}\right)}{\sigma\left(\Delta \% \mathrm{~F}_{\mathrm{t}}\right)} * \zeta\left(\mathrm{DFL}_{\mathrm{t}} \mid \Delta \% \mathrm{~F}_{\mathrm{t}}\right)$ & $\frac{\partial \Delta \% \mathrm{EBIT}_{\mathrm{t}}}{\partial \Delta \% \mathrm{~F}_{\mathrm{t}}} * \mathrm{DFL}_{\mathrm{t}}^{\mathrm{a}} \mid \Delta \% \mathrm{~F}_{\mathrm{t}}=-\frac{\mathrm{FC}_{\mathrm{t}-1}}{\mathrm{EBIT}_{\mathrm{t}-1}} * \zeta\left(\mathrm{DFL}_{\mathrm{t}} \mid \Delta \% \mathrm{~F}_{\mathrm{t}}\right)$ & \\
\hline $\mathrm{i}_{\mathrm{t}}$ & Cost of Debt & $\frac{\mathrm{W}_{\mathrm{t}}}{\mathrm{i}_{\mathrm{t}-1}} * \frac{\sigma\left[\frac{1}{\left.\frac{1}{i_{\mathrm{t}}-\left(1-\alpha_{\mathrm{t}}\right.}\right]}\right.}{\sigma\left(\mathrm{i}_{\mathrm{t}}\right)}$ & $-\frac{\mathrm{W}_{\mathrm{t}}}{\mathrm{i}_{\mathrm{t}-1}} * \frac{1}{\left[1-\mathrm{i}_{\mathrm{t}} *\left(1-\alpha_{\mathrm{t}}\right)\right]^{2}}$ & \multirow{2}{*}{ 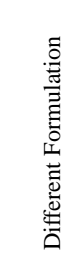 } \\
\hline$\alpha_{t}$ & Tax Rate & $\frac{1}{1-\alpha_{t-1}} * \frac{\sigma\left[\mathrm{EE}_{\mathrm{t}} * \alpha_{\mathrm{t}}+\mathrm{J}_{\mathrm{t}} * \frac{\mathrm{H}_{\mathrm{t}} \mid \alpha_{\mathrm{t}}}{\left(1-a_{\mathrm{t}}\right)} \mathrm{i}_{\mathrm{t}}\right]}{\sigma\left(\alpha_{\mathrm{t}}\right)}$ & $\begin{array}{c}\frac{\mathrm{Z}_{\mathrm{t}}}{\mathrm{DFL}_{\mathrm{t}-1}^{*}} *\left[\frac{\mathrm{H}_{\mathrm{t}}}{\left(1-\alpha_{\mathrm{t}}\right) *\left[1-\mathrm{i}_{\mathrm{t}} *\left(1-\alpha_{\mathrm{t}}\right)\right]}-\mathrm{ROI}_{\mathrm{t}-1} *\left(1+\Delta \% \mathrm{EBIT}_{\mathrm{t}}\right)\right]+ \\
-\left(1+\Delta \% \mathrm{EBIT}_{\mathrm{t}}\right) * \frac{\left(1+\mathrm{A}_{\mathrm{t}-1}\right)}{\left(1-\alpha_{\mathrm{t}-1}\right)}\end{array}$ & \\
\hline
\end{tabular}

Table 6 shows $\sigma\left(\Delta \% \pi_{t} \mid \mathrm{V}_{t}\right) / \sigma\left(\mathrm{V}_{\mathrm{t}}\right)$ volatility as a function of $\mathrm{V}_{\mathrm{t}}$. It corresponds to the partial derivative $\partial \Delta \% \pi_{\mathrm{t}} / \partial \mathrm{V}_{\mathrm{t}}$ of the four primary variables. In particular, the relationship established using partial derivatives is the following:

$$
\frac{\sigma\left(\Delta \% \pi_{\mathrm{t}} \mathrm{V}_{\mathrm{t}}\right)}{\sigma\left(\mathrm{V}_{\mathrm{t}}\right)}=\frac{\partial \Delta \% \pi_{\mathrm{t}}}{\partial \mathrm{V}_{\mathrm{t}}}=\frac{\partial \Delta \% \mathrm{EBIT}_{\mathrm{t}}}{\partial \mathrm{V}_{\mathrm{t}}} * \zeta\left(\mathrm{DFL}_{\mathrm{t}} \mid \mathrm{V}_{\mathrm{t}}\right)
$$

The uncertainty that assumes paramount importance is the unit price percentage growth $\Delta \% \mathrm{up}_{\mathrm{t}}$ that takes the following analytical form:

$$
\frac{\sigma\left(\Delta \% \pi_{\mathrm{t}} \mid \Delta \% \mathrm{up}_{\mathrm{t}}\right)}{\sigma\left(\Delta \% \mathrm{up}_{\mathrm{t}}\right)}=\frac{\partial \Delta \% \pi_{\mathrm{t}}}{\partial \Delta \% \mathrm{up}_{\mathrm{t}}}=\left(1+\Delta \% \mathrm{qms}_{\mathrm{t}}\right) * \zeta\left(\mathrm{DOL}_{\mathrm{t}} \mid \Delta \% \mathrm{up}_{\mathrm{t}}\right) * \zeta\left(\mathrm{DFL}_{\mathrm{t}} \mid \Delta \% \mathrm{up}_{\mathrm{t}}\right)
$$

In essence, the Net Profit growth volatility caused by the uncertainty arising from the unit price growth depends on the combined DOL and DFL risk increased by a multiplier due to the Revenue quantity/mix growth.

The firm's risk will be greater the lower the profitability and the higher the Revenue growth rate.

In a complex planning model, where we can simultaneously vary the four primary variables as a function of the Revenue quantity/mix growth and the Cost of Debt as a function of the Debt Ratio, the results could significantly deviate from what so far illustrated. Now here, we are opening wide in respect of the OAT approach.

The reasons are as follows:

1) negative changes offset others of opposite sign, owing to interactions among input variables. In particular, the Fixed Costs change stabilises the negative impact of other variables.

2) The uncertainty ranges are not necessarily linear; they can proceed by jumps, making the EBIT and Net Profit growth discontinuous; in turn, these variables cause DOL and DFL discontinuity that make their trends smoother in respect to the one induced by a single variable fluctuation.

3) DOL could show an abatement by reducing the level of business risk $\zeta\left(\mathrm{DOL}_{t} \mid \mathrm{V}_{\mathrm{t}}\right)$.

4) Conversely, DFL could generate an increase in the level of business risk $\zeta\left(D L_{t} \mid V_{t}\right)$ due to the simultaneous volatility of both the Cost of Debt and the other four primary variables.

5) Eventually, an overall risk reduction, measured by the product $\zeta\left(\mathrm{DOL}_{\mathrm{t}} \mid \Delta \% \mathrm{up}_{\mathrm{t}}\right) * \zeta\left(\mathrm{DFL}_{\mathrm{t}} \mid \Delta \% \mathrm{up}_{\mathrm{t}}\right)$, would be obtained. 
Nevertheless, the potential risk of volatility deriving from a single fundamental variable highlights its effects if not offset by suitable management decisions and actions. The worst view is the best to understand the underlying risk and induce managerial behaviour appropriate to its containment.

The perspective in which we set ourselves to analyse firm's risk is not the fund manager one who is most interested in the systematic risk of the investment portfolio, but that of the firm's manager and owner who cannot adequately diversify such a risk and must manage it through consistent business decisions.

\section{Conclusions}

In paragraph 2, we have dealt with some minor issues related to DOL and DFL. In particular, we showed the DOL oversimplifications adopted in the economic literature that prevented its operational use in business practice. Secondly, the analogy between operating leverage and mechanical lever rests on margins rather than costs, just the opposite of the prevailing economic literature theorises. Thirdly, the concept of Potential DOL can link all the Income Statements in an ex-ante time series. Eventually, an investment decision impacts both DOL and DFL, while the financial one impacts only DFL, even when related to the former.

In paragraph 3, we have analysed the possibility of using the DOL function to highlight the sensitivity of the factor and product markets to replace the concepts of supply and demand elasticity. Such a perspective can explain or predict which business policy is preferable according to the growth of the quantity/mix and the unit values of Revenue, Variable and Fixed Costs, with or without economies of scale, given the characteristics of the factor and product markets. Based on these peculiarities and sensitivities, it is possible to establish whether a market penetration is more appropriate than a market skimming or a profit-maximising policy.

In paragraph 4, we have analysed through an OAT approach the impact that the uncertainty of six fundamental economic variables induces on the EBIT and Net Profit growth volatility and indirectly on the DOL-DFL nexus one. Not all the six variables can influence DOL and DFL volatility, but when such a possibility exists, the firm's risk rate is not the operating point of the DOL and DFL curves in which the firm operates, but their asymptote. Under normal business conditions, DOL underestimates the business risk rate while DFL performs a risk containment function. Besides, such variables determine a risk rate not related to the chosen uncertainty range. The higher the uncertainty, the higher is the resulting volatility, but its rate of change is constant inside a single financial period. For such a reason, we can call it risk rate.

The uncertainty arising from every fundamental variable emphasises the perceived risk compared to the simultaneous unfurling of a broader set of them since some operate to offset each other by reducing it. Nevertheless, we have seen that the uncertainty of the unit price growth (or decrease) appears by far the higher risk that management must face. The quantity/mix growth rate boosts such a risk: even a modest market price cut, coupled with an impetuous sales growth, could have a significant impact on Net Profit and its volatility, raising the firm's risk rate. Such a combination of events, if not adequately addressed by management, could have negative consequences for the managed business. Just think of the dynamics of falling prices and the significant increase in quantity sold in the market of personal computers, laser and inkjet printers and mobile phones.

The analytical tools made available by the DOL-DFL nexus can explain and predict both profitability and business risk, ex-post and above all ex-ante, allowing better business planning.

\section{References}

Brigham, E., \& Ehrhardt, M. (2011). Financial Management: Theory and Practice (13th ed.). South-Western Cengage Learning, Mason.

Chen, Z., Harford, J., \& Kamara, A. (2019). Operating Leverage, Profitability, and Capital Structure. Journal of Financial and Quantitative Analysis, 54(1), 369-392. https://doi.org/10.1017/S0022109018000595

Chiladze, I. (2017). Factor Analysis of the Enterprise's Operating Leverage. Applied Finance and Accounting, 3(1), 75-82. https://doi.org/10.11114/afa.v3i1.2050

Czitrom, V. (1999). One-Factor-at-a-Time versus Designed Experiments. The American Statistician, 53(2), 126-131. https://doi.org/10.1080/00031305.1999.10474445

Dudycz, T. (2020). The Mystery of Operating Leverage. SSRN Electronic Journal. https://doi.org/10.2139/ssrn.3578189

Li, M., Nissim, D., \& Penman, S. H. (2014). Profitability Decomposition and Operating Risk. SSRN Electronic Journal. https://doi.org/10.2139/ssrn.3778720

Paganini, M. A. (2019). Potential and Real Operating Leverage. International Journal of Economics and Finance, 
11(8), 138-164. https://doi.org/10.5539/ijef.v11n8p138

Paganini, M. A. (2021). The DOL-DFL Nexus: The Relationship between the Degree of Operating Leverage (DOL) and the Degree of Financial Leverage (DFL). International Journal of Economics and Finance, 13(6), 71. https://doi.org/10.5539/ijef.v13n6p71

Prezas, A. P. (1987). Effects of Debt on the Degrees of Operating and Financial Leverage. Financial Management, 16(2), 39. https://doi.org/10.2307/3666002

Royston, P. (1992). Approximating the Shapiro-Wilk W-test for non-normality. Statistics and Computing, 2(3), 117-119. https://doi.org/10.1007/bf01891203

Sarkar, S. (2020), The relationship between operating leverage and financial leverage. Account Finance, 60, 805-826. https://doi.org/10.1111/acfi.12374

Shapiro, S. S., \& Wilk, M. B. (1965). An Analysis of Variance Test for Normality (Complete Samples). Biometrika, 52(3/4), 591. https://doi.org/10.2307/2333709

Sinha, S. (2012). Operating Leverage Analysis - A Conceptual Framework. SSRN Electronic Journal. https://doi.org/10.2139/ssrn.1988443

\section{Appendix A}

The following Tables show the data of the Income Statements, Balance Sheets, parameters and variables used for processing Figures 3 to 8 and Table 2. For more information, refer to the paper by Paganini (2021).

Table A1. Income statements of the two financial periods used in the analysis

\begin{tabular}{|c|c|c|c|c|}
\hline Income Statement & Period t-1 & Period $\mathbf{t}$ & Growth & Symbol \\
\hline Revenue & $€ 525,000,000$ & $€ 551,250,000$ & $5.000 \%$ & $\Delta \% \mathrm{~S}_{\mathrm{t}}$ \\
\hline Variable Costs & $-€ 315,000,000$ & $-€ 330,750,000$ & $5.000 \%$ & $\Delta \% \mathrm{VC}_{\mathrm{t}}$ \\
\hline Contribution Margin & $€ 210,000,000$ & $€ 220,500,000$ & $5.000 \%$ & - \\
\hline Fixed Costs & $-€ 176,800,000$ & $-€ 183,872,000$ & $4.000 \%$ & $\Delta \% \mathrm{~F}_{\mathrm{t}}$ \\
\hline EBIT & $€ 33,200,000$ & $€ \mathbf{3 6 , 6 2 8 , 0 0 0}$ & $10.325 \%$ & $\Delta \% \mathrm{EBIT}_{\mathrm{t}}$ \\
\hline Interest Expenses & $-€ 1,987,614$ & $-€ 2,172,594$ & - & - \\
\hline Taxes & $-€ 7,803,096$ & $-€ 8,613,852$ & - & - \\
\hline Net Profit & $€ 23,409,289$ & $€ 25,841,555$ & $10.390 \%$ & $\Delta \% \pi_{\mathrm{t}}$ \\
\hline Dividends & $€ 23,409,289$ & $€ 25,841,555$ & - & - \\
\hline
\end{tabular}

Table A2. Balance sheets of the two financial periods used in the analysis

\begin{tabular}{ccc}
\hline Balance Sheet & Period t-1 & Period t \\
\hline Cash & $€ 21,000,000$ & $€ 22,050,000$ \\
Net Working Capital & $€ 131,250,000$ & $€ 137,812,500$ \\
Assets & $€ 149,375,000$ & $€ 153,443,750$ \\
Capital Invested & $€ \mathbf{3 0 1 , 6 2 5 , 0 0 0}$ & $€ \mathbf{3 1 3 , 3 0 6 , 2 5 0}$ \\
Equity & $-€ 202,244,289$ & $-€ 204,676,555$ \\
Debt & $-€ 99,380,711$ & $-€ 108,629,695$ \\
\hline
\end{tabular}


Table A3. Parameters and variables used in the analysis

\begin{tabular}{ccc}
\hline Parameters and Variables & Period t-1 & Period t \\
\hline$\Delta \%$ up & - & $0.000 \%$ \\
$\Delta \%$ qms & - & $5.000 \%$ \\
$\Delta \%$ uvc & - & $0.000 \%$ \\
$\Delta \%$ qmvc & - & $5.000 \%$ \\
PDOL & - & $632.530 \%$ \\
DOL & - & $206.506 \%$ \\
$\mathrm{i}$ & $2.000 \%$ & $2.000 \%$ \\
$\alpha$ & $25.000 \%$ & $25.000 \%$ \\
$\mathrm{~T}$ & - & $100.000 \%$ \\
$\mathrm{~A}$ & $6.368 \%$ & - \\
$\mathrm{N}=\mathrm{T} *(1+\mathrm{A})$ & - & $106.368 \%$ \\
$\mathrm{M}$ & - & $100.000 \%$ \\
$\mathrm{P}$ & - & $104.102 \%$ \\
$\mathrm{Q}=\mathrm{A} * \mathrm{M} * \mathrm{P} * \mathrm{~T}$ & - & $6.629 \%$ \\
$\mathrm{~K} 1$ & $174.057 \%$ & - \\
$\mathrm{K} 2$ & - & $29.000 \%$ \\
$\mathrm{~K} 3$ & - & $85.500 \%$ \\
$\mathrm{~K} 4$ & - & $43.431 \%$ \\
$\psi$ & - & $98.926 \%$ \\
$\mathrm{DFL} *$ & $32.948 \%$ & $34.672 \%$ \\
$\mathrm{DFL}$ & - & $100.628 \%$ \\
& &
\end{tabular}

\section{Copyrights}

Copyright for this article is retained by the author(s), with first publication rights granted to the journal.

This is an open-access article distributed under the terms and conditions of the Creative Commons Attribution license (http://creativecommons.org/licenses/by/4.0/). 